\title{
Special Issue Race Ethnicity and Education: Initial teacher education: developments, dilemmas and challenges
}

\section{Introduction}

\section{Vini Lander University of Chichester v.lander@chi.ac.uk}

The education of new teachers is a fundamental aspect of education provision within any country in the world. The education of pre-service teachers is known to have a direct impact on the outcomes for children in our schools. In England, teacher education within universities has been subject to erosion with the introduction of more school-based training and greater scrutiny by the government inspection agency, the Office for Standards in Education (Ofsted) (DfE 2011). The education of teachers in England continues to be an arena within which greater and greater government control is being exercised (DfE 2011). The preparation of teachers in England within the higher education sector has recently had to demonstrate greater flexibility as market forces have been brought to bear with the forthcoming introduction of School Direct in September 2013 (DfE 2011). This new training route reinforces the conception amongst some of the teacher as a technicist rather than an intellectual (Down and Smyth 2012). Under this new School Direct training regime new entrants will be trained to become teachers in one year, in one school, in one locality with minimum input from a higher education institution. The outcomes of such parochial preparation to teach will no doubt be documented in future years.

In England, as in most countries, such as Australia and Norway, the pupil population is becoming increasingly diverse whilst simultaneously neo-liberal ideology plays out (Ball 2012) through government policies to limit the content of the teacher education curriculum to a list of classroom related competencies which include little or no reference to diversity, 'race', ethnicity or culture. The significance of these factors on the lives of children within a diverse society are absent within the official Teachers' Standards 2012 (DfE 2012). This mismatch between the content of the teacher education curriculum, the ethnicity of the candidates who enter pre-service courses [in 2011, $12 \%$ of primary trainee teachers in England were from Black and minority ethnic groups (NCTL) and in the US approximately $21 \%$ of teachers are from African American or Hispanic groups (Nolet 2013)] and the demographics of the pupil population (in $201126.5 \%$ of primary/elementary pupils were from Black and minority ethnic groups) seem to be a concern for only a minority of teacher educators across the UK, US, Europe and Australia. In England, we continue to struggle to 
maintain a foothold (at times this feels like a fingernail hold) to introduce new teachers to issues related to 'race', ethnicity and the education for the benefit of all children in our schools. This special issue is intended to highlight the factors that student teachers, especially new candidates of colour, face in their pursuit to become teachers in what appear to be, at times, hostile or indifferent attitudes to ethnic diversity and the pursuit for social justice. As a teacher educator who has worked in the sector for 20 years I have observed the demise of multicultural education in schools and in initial teacher education (ITE). The current developments that further reduce teachers' preparation to teach in a diverse society may not be a surprise and some may argue that in fact nothing has changed. The government in England conducts an annual survey of all newly qualified teachers (NQTs) to ascertain their perceptions about the effectiveness of their initial teacher preparation programmes. One of the questions on the NQT Survey asks, 'How good was training to teach learners from minority ethnic backgrounds?' In the last 10 years NQTs in primary schools rating their training as good or better increased from 29\% in 2003 to $54 \%$ in 2012. Whilst this may seem to be a cause for celebration it has to be asked why this percentage is not nearer to $100 \%$ and why over the last 10 years it has been one of the lowest rated elements of the survey and other elements have a much higher rating.

The hostility and indifferent attitudes to 'race', ethnicity and racism could be theorised as the products of whiteness-at-work which Yoon $(2012,590)$ defines as the 'paradoxes, contradictions and hypocrisies' contribute to the construction of whiteness and that permeate people's actions, inactions and statements. In the face of policies which erode the contribution of universities within the education of teachers the burning questions are: Who will educate or train new entrants to the profession to understand the complex factors affecting pupils from Black and minority ethnic (BME) backgrounds and to ensure that the school curriculum does not perpetuate whiteness through perhaps in one way its failure to acknowledge the contribution of BME people? And who will take responsibility for this important aspect of teacher preparation?

This special issue of Race, Ethnicity and Education was conceived to highlight the challenges facing teacher educators who, in the absence of statutory requirements, labour to include the subject of 'race' and ethnicity within the teacher education curriculum they teach and to support all student teachers to understand their racialised positions within the school environment. The special issue is designed to not only acknowledge and document the work of dedicated teacher educators who work to provide alternative perspectives, but to show how 
racism is present and persistent within ITE. The articles within this special issue range from a literature review to examining the experiences of BME student teachers in schools within the US. They show how majority White and BME student teachers have little appreciation of how their identities may influence their interactions in classrooms; how the practices within teacher education serve to maintain the dominant discourse of whiteness; fail to help all student teachers to deal with racist incidents and reinforce the notion of the 'Other'.

Bhopal and Rhamie's article illustrates how student teachers understand the concepts of 'race', diversity and inclusion on postgraduate initial teacher education programmes at two English universities. The article shows how these students feel confused and unprepared to deal with issues of 'race' and racism within the classroom and that in order to meet the requirements of equality legislation much more needs to be done within teachers' initial preparation to help them feel secure to tackle racist incidents and how to actively educate against racism.

The contradictory nature of whiteness within one aspect of teacher education in the UK and the US is illustrated in the call to recruit and retain teachers from BME backgrounds. Keffrelyn Brown outlines teacher education literature from the US and using critical race theory she illustrates how the pervading dominant discourse and culture of whiteness and white hegemony can be a real barrier and challenge to teachers of colour on teacher education programmes. Indeed Brown's paper sets the scene for the later articles by Flintoff, Kohli and Pearce.

Flintoff's article employs a story-telling technique to create a narrative about BME teachers persevering on their teacher education programmes despite the racism they encounter as part of their school placements be it from pupils, colleagues or racist thugs on the street. The article highlights the dilemmas faced by BME students attempting to pursue training to be Physical Education (PE) teachers, one of whom is acting against her parents' wishes. Flintoff notes that PE is a subject area not known for its diverse intake of student teachers and she notes that racist attitudes prevail within the field where it may be much harder for BME candidates to succeed and therefore specific support may be required for students and educators alike.

Rita Kohli uses critical race theory to examine how teachers of colour have learnt to internalise early experiences of racism in such a way as to deny their own identity and currently as teachers how they were able to analyse these processes and begin to apply their 
self-knowledge in such a way as to change their own practice. Kohli argues that there are insufficient opportunities for pre-service teachers to explore and discuss aspects related to inequality especially racial inequality.

In fact, in her article, Sarah Pearce illustrates how students who are now teachers in school feel unprepared to deal with the racism they encounter in classrooms but additionally they feel disappointed by existing practitioners' inability to tackle institutional racism choosing instead to 'play it down' and to deal with racism as purely an individual act rather than tackle the institutional structures that maintain it. She argues that the teachers' handling of racist incidents leaves children feeling confused and unsure and new teachers feeling unsupported. Pearce notes that as the landscape of teacher education in England shifts towards more school-based provision then opportunities to discuss and reflect on 'race' inequality and racism will diminish and in order to address this support needs to be given to schools and teachers.

Charlotte Chadderton's article explores and analyses the migration of the Troops to Teachers campaign from the US to England. She deftly argues that this strategy is one which seeks to privilege and control. Indeed she regards it is an instrument of oppression targeted to be used in some schools which have pupils already subordinated along race and class lines. The article notes that the Troops to Teachers initiative will lead to the further devaluing of initial teacher education. As you read this article, those of you within the English context will recognise how the Troops to Teachers initiative, alongside the introduction of School Direct, will not only further diversify initial teacher education, but also contribute to the hierarchy of school provision within England with the introduction of academies and free schools alongside private education and current state funded comprehensive schools.

Ninetta Santoro illustrates how efforts of one ITE institution in Australia to broaden student teachers' understandings of diversity through placements abroad in countries such as India serve to reinforce stereotypes. Santoro notes how ill-prepared the students were for such placements and how the placements provided a one-sided experience for the students reinforcing their notions of poverty and the exotic 'Other'. Santoro uses a neo-colonial framework to analyse the student teachers' experiences and she notes how the opportunity to experience another culture resulted in affirming notions for the White students of the benevolent-self and how such experiences serve to underscore the nature of whiteness. 
Wilkins examines the culture and process of Ofsted inspections of ITE in England. His article 'inspects the inspectors' showing how there is a significant gap between rhetoric on equality policy and practices within ITE especially in the inspection of ITE with respect to equality legislation. Indeed Wilkins notes how the inspection process focuses on compliance and compounds the failure to tackle structural inequality within ITE and therefore fails to improve practice within this area and maintain the inertia within it.

The omissions related to race, ethnicity and culture in the Teachers' Standards in England and wider teacher education curricula have left teachers and student teachers unsure and lacking in confidence about how to talk about race and ethnicity never mind how to understand their position as teachers to tackle the inequalities that schools as public instituions may perpetuate. This is evidence of the neo-liberal project in action. The institutional inertia and professional impotence related to race and racism, as evidenced in this Special Issue can be seen as an outcome of national and local policies which Gillborn (2005) would argue is a means of maintaining White dominance and supremacy. However, as educators, researchers and teacher educators our role is to improve teacher preparation for all student teachers as well as those from diverse ethnic groups, and within each article there are suggestions for how practice can be improved (nationally and internationally), and importantly, how student teachers themselves can be advocates for change in their higher education institutions, schools and classrooms.

\section{References}

Ball, S. J. (2012) Global Inc.: New Policy Networks and the Neoliberal Imaginary London, Routledge.

Department for Education (2011) Training our next generation of outstanding teachers available at www.education.gov.uk/publications.

Department for Education (2012) Annual Survey of Newly Qualified Teachers 2012 London DfE.

Down, B. and Smyth, J. (2012) Critical Voices in Teacher Education: Teaching for Social Justice in Conservative Times London, Springer.

Gillborn, D. (2005) 'Education Policy as an act of White Supremacy: Whiteness, Critical Race Theory and education reform'. Journal of Education Policy, 20, no.4:485-505.

National College for Teaching and Leadership (2011) ITT Statistics available at http://dataprovision.education.gov.uk [Accessed 20 ${ }^{\text {th }}$ May 2013] 
Nolet, V. (2013) Teacher Education and ESD in the United States: The Vision, Challenges and Implementation. In Schooling for Sustainable Development in Canada and the United States pp53-67. Netherlands Springer.

Yoon, I. H (2012) The paradoxical nature of whiteness-at-work in the daily life of schools and teacher communities Race, Ethnicity and Education 15, no.5: 587-613.

\title{
2. Initial teacher training: understanding 'race', diversity and inclusion
}

Kalwant Bhopal, University of Southampton, UK (corresponding author) and Jasmine Rhamie University of Roehampton, UK. K.Bhopal@soton.ac.uk Jasmine.Rhamie@roehampton.ac.uk

\begin{abstract}
There is little research which has explored how students on Initial Teacher Training (ITT) courses understand and conceptualise discourses of 'race', diversity and inclusion. This article will focus on student understandings of racialised identities; it will explore the discourses by which students understand what it means to be White and what it means to be Black, within the context of ITT. The article will examine the different facets and themes of identity within the context of belonging and exclusion which exist within higher education in the cultural and social contexts of English universities. The data for this article is based on interviews conducted with a total of thirty students who were training to become teachers on primary and secondary PGCE (Postgraduate Certificate of Education) courses at two universities in the South of England. The majority of students who agreed to be interviewed were from White backgrounds and only a small minority were from BME (Black and minority ethnic backgrounds). The findings indicate that students' understandings of 'race', diversity and inclusion on ITT courses are complex and multifaceted. Many of the students were aware of the importance of these issues, but were unsure about how to approach these subjects in the classroom, particularly in relation to how they would be taught. Many also felt unequipped when thinking about how they would deal with racist incidents in the classroom. The article argues that greater training is needed in relation to the practical assistance that student teachers require in terms of increasing their understanding of diversity and dealing with racism in the classroom. There is also a need to examine the impact of the Equality Act (2010) on ITT courses and the teaching of 'race', diversity and inclusion.
\end{abstract}

\section{1 words}

Keywords: 'race', diversity, inclusion, initial teacher training, trainee teachers

Initial teacher training: understanding 'race', diversity and inclusion

\section{Introduction}

There have been some significant changes in policy making in relation to educational equality and inclusion in England in the last few years. The most significant policy change has been the introduction of the Equality Act in 2010. The Equality Act replaced all previous 
equality legislation such as the Race Relations Act (1976), Race Relations (Amendment) Act (2000), Disability Discrimination Act (2005) and Sex Discrimination Act (1975). The

significance of the Act is that it provides one single, consolidated source of discrimination law, covering all the types of discrimination that are unlawful. It simplifies the law by removing anomalies and inconsistencies that have developed over time in the existing legislation, and it extends protection from discrimination in certain areas.

In terms of education, particularly schools, the effect of the new law is the same as it has been in the past - schools cannot unlawfully discriminate against pupils because of their sex, 'race', disability, religion or belief and sexual orientation. Protection is now extended to pupils who are pregnant or undergoing gender reassignment. The exceptions to the discrimination provisions for schools that existed under previous legislation - such as the content of the curriculum, collective worship and admissions to single-sex schools and schools of a religious character, are all replicated in the new Act. However, there are some changes that will have an impact on schools. Under the new duties, schools will be expected to publish their equality information and objectives, which will also be required to be regularly updated. Positive action provision will allow schools to target measures that are designed to alleviate disadvantages experienced by pupils with particular protected characteristics (for example providing special catch-up classes for Roma children or a project to engage specifically with alienated Asian boys) (EHRC no date).

In 2002, Citizenship was introduced as a statutory subject in the English National Curriculum, following the recommendations of the Crick Report in 1998. Citizenship is taught as part of the school curriculum to all pupils aged 11-16 years old in maintained schools in England. The Ajegbo Report was published in 2007 and emphasised the complexity of understanding diversity and inclusion. The report recognised the different understandings of the term 'British' and acknowledged that people construct identities in multiple and plural ways. Ajegbo also noted that respondents shared concerns that the term 'Britishness' has the potential to be divisive and can be used as a means of excluding particular groups. Moreover, defining the term is problematic (Ajegbo 2007). Some academics have called for the vague term 'Britishness' to be replaced with citizenship and equal rights (Parekh, 2007; Khan, 2007). Furthermore, in relation to teacher training the report states, 'The Training and Development Agency for Schools (TDA) should evaluate the effectiveness of education for diversity across initial teacher training (ITT) providers. Local 
authorities should be encouraged to develop lead Advanced Skills Teachers (ASTs) ${ }^{1}$ with a specific brief for education for diversity. This should be disseminated across the authority as part of outreach. Schools should be encouraged to use the flexibilities in the teaching and learning responsibility points of the teachers' pay structure to promote excellence in education for diversity within the school' (p22). However, some authors have recognised problems with issues of diversity and citizenship in schools, for example Osler states that the 'identity and diversity' strand in the citizenship curriculum may become a new placebo. 'If schools promote a depoliticised multiculturalism which does not encourage political literacy or critical analysis, there is a real danger that this will leave unchallenged (and possibly disguise) the considerable inequalities within schools, while allowing individual institutions to assert that they are fulfilling their duty to promote community cohesion' (Osler, 2009: 14).

Currently in the National Curriculum in England, citizenship is taught at Key Stage 3 (age 11-14) and Key Stage 4 (age 14-16) as foundation subjects in schools. However, the recent review of the National Curriculum reports little support for the retention of citizenship in the National Curriculum (DfES, 2011). 'Despite their importance in balanced educational provision, we are not entirely persuaded of claims that design and technology, information and communication technology and citizenship have sufficient disciplinary coherence to be stated as discrete and separate National Curriculum subjects' (DfES, 2011:24). Instead the report recommends, 'citizenship is of enormous importance in a contemporary and futureoriented education. However, we are not persuaded that study of the issues and topics included in citizenship education constitutes a distinct 'subject' as such. We therefore recommend that it be reclassified as part of the Basic Curriculum' (DfES, 2011,24). The report whilst acknowledging the importance of citizenship recommends its reclassification without considering the need to address the training issue highlighted in the Ajegbo Report. The curriculum review on diversity and citizenship found that teachers lack confidence and knowledge about these issues and often side step them (DCSF, 2007). Indeed, many teachers may not have had adequate training to deal confidently with such complex issues in class. Where diversity and citizenship were taught, lessons were found to be 'unsatisfactory or lacking in conceptual depth' (ibid, p.96). Some schools which attempt to include diversity within the curriculum lack the understanding to address its implications sensitively and correctly. This can lead to pupils viewing and experiencing diversity negatively implying that

\footnotetext{
${ }^{1}$ Under the new Coalition Government the TDA and AST were scrapped and no longer exist.
} 
'only minority groups have 'diversity'...' (Maylor, 2010 p. 248). A number of reports highlight the need for enhanced ITT and an expansion of ITT places in citizenship and the need for ITT to be informed by a developing research evidence base (Kerr, et al., 2007). This may be threatened if the coalition government's plans to downgrade citizenship to the basic curriculum are realised.

This article will focus on trainee teachers understandings of racialised identities; it will explore the discourses by which trainee teachers understand what it means to be White and what it means to be Black ${ }^{2}$, within the context of ITT. The article will examine the different facets and themes of identity within the context of belonging and exclusion which exist within higher education in the cultural and social contexts of English universities.

\section{Context and Background}

There is growing body of research that examines the ability and willingness of trainee teachers to understand and engage in issues associated with 'race', diversity, inclusion and identity in the classroom (Ambe, 2006; Santoro \& Allard, 2005). These studies (mainly drawn from areas such as North America, Europe and Australasia) show a mismatch between the ethnic identity of the teaching population (which is predominantly White and in some cases it has been pointed out female and middle class) and that of the student intake which is increasingly becoming ethnically mixed.

There have been some attempts to address concerns about the teaching of 'race' and inclusion on ITT courses. This has included a focus on teacher training and the development of programmes to encourage trainee teachers to understand issues associated with 'race', diversity and educational inclusion (see Causey, Thomas and Armento, 2000; Mills, 2008, 2009). These programmes consisted of university teaching sessions, school placements in very diverse settings and a period for reflection and discussion post school placement. They have resulted in varied success. Positive short term outcomes have been reported but these changes have not been sustained in the early years of professional practice (Causey, Thomas and Armento, 2000). Much of the research has focused on identifying misconceptions and preconceptions around 'race' and diversity (see Garcia \& Lopez, 2005). Korthagen et al (2001) argue that it is possible to work with trainee teachers only after they themselves know

\footnotetext{
2 We use the term 'Black' as a political term to refer to those from non-white minority ethnic groups who are positioned as 'other' due to their racial identity (see Bhopal and Danaher, forthcoming 2013).
} 
that their own stereotypes have to be challenged. However, other researchers have shown that the impact of such interventions is not as effective, and can be quite limiting (Hollins and Guzman; Sleeter, 2001). Furthermore, research into these areas has raised methodological concerns regarding the sample size and lack of details on the context and the overuse of selfreporting methods. (Hollins and Guzman, 2005; Sleeter, 2001). The reasons for this remain complex, but part of the problem may be that the lecturers and tutors themselves may not be particularly knowledgeable about such issues and so may lack the confidence to support trainee teachers effectively (Hick et al, 2011).

Research has also found that few courses on teacher training in the USA facilitate teachers' understandings of race, diversity and culture (Ladson-Billings, 1990). By contrast, through engagement in diversity focused teacher education courses, pre-service teachers can gain greater critical insight into the effects of diversity upon teaching and learning (LadsonBillings, 1995; 2001). Research in Australia suggests that teachers have a responsibility to teach in a way that is anti-discriminatory and inclusive of all students irrespective of students' backgrounds (Aveling, 2002; Bhopal and Danaher, 2013). Other research suggests that teacher education programs must take a multicultural perspective in order to contribute to principles of social justice (Levine Rasky, 2001; Solomon et al, 2005). Equally, Picower's (2009) study explores how White pre-service teachers' life-experiences shape their understanding of race which in fact maintains their dominant and stereotypical understandings of the meaning of race in the classroom.

The identity of teachers and its relationship to the educational achievement of some minority ethnic groups has been highlighted in England. For example, Maylor's research (2009) has shown that some teachers exhibit unintentional racism towards students, whereas Rhamie (2007) highlights how many African Caribbean pupils have negative experiences at school in which they receive little support and encouragement from teachers and in which they perceive a sense of being treated differently from their White peers. Recent research suggests that there are several reasons associated with which institutions students from BME backgrounds decide to attend when thinking about teacher training. Smith (2007) examines how these decisions are sometimes complex and based on a diverse range of factors such as ethnicity, class and gender as well as a desire to study locally and, 'how living and learning in a predominantly 'White' environment leads to different preferences in terms of the ethnicity of university populations' (p.433). Bhopal (2010) has also found that when choosing a degree course many students from Asian backgrounds are more likely to want to study at 
their local universities due to the presence of a 'critical mass' which will ensure a sense of belonging and provide support - rather than choosing to study far away from their homes. Lander's research (2011) has found that the language used by trainee teachers when examining issues associated with BME pupils is seen in relation to 'otherness' and many feel unequipped to deal with issues to do with 'race', particularly if students are in predominantly White areas where there is little or no perceived ethnic diversity. This has further implications for inclusive policy making and ITT as well as questioning Whiteness as being, 'neutral, colour-blind and liberal' (Lander, 2011, 362). Smith and Lander (2011) further examine how Whiteness operates to reinforce inequitable power relations in teaching in ITT, particularly when students' racist assumptions of teacher ability are often based on perceptions of 'race'. Wilkins and Lall (2011) in their recent research report how on the one hand BME trainee teachers report positive experiences on ITT courses, but on the other hand, they also report being isolated and experiencing stereotypical attitudes towards them from their White peers as well as examples of overt racism in school placements. Bhopal, Harris, and Rhamie (2009) in their research found that the majority of trainee teachers had an understanding of the key issues associated with 'race', diversity and inclusion they all felt these issues should be central to all ITT programmes. Furthermore, the majority of respondents in the research wanted specific sessions on 'how to deal with racist incidents'. The research (like others) points out that future educational policy making should include a compulsory course for ITT students on issues to do with 'race', diversity and inclusion as well as continuous professional development for all students and teachers on for example the legal updates around equality and equal opportunities.

Research carried out by Davies and Crozier (2006) has examined the extent of training provision in England regarding issues to do with diversity, 'race' and inclusion. The findings suggest that the majority of providers had policies relating to equality and diversity but policies for tackling racism in schools were not consistent across the board. Furthermore, 'race' and diversity were addressed in relation to students with English as an Additional Language (EAL), and there was little coverage of these issues when students were in predominantly White higher education institutions.

The majority of respondents in this study felt that there was a need for further development in this area. Many of the ITT providers employed generic lectures, key readings and the use of visiting speakers to address issues of diversity. Some said that diversity permeated the curriculum, while others said that it needed further development. Many of the programmes 
did not address racism, underachievement or teacher expectations, although some providers did refer to the Race Relations (Amendment) Act (RRAA, 2000) but did not require the trainees to consider the implications of the RRAA for their own practice. The recent introduction of the Equalities Act 2010 has brought all individual equality legislation under the same Act. While there is clearly justification for harmonising legislation for various aspects of equality such as disability, gender, sex and race, under a single equality act there are risks in doing so. The new Act has contributed to a growing trend for race and matters relating to racism becoming invisible (Tomlinson, 2011; ROTA, 2012). The new OFSTED framework for inspecting schools and providers of teacher education has removed the requirement to inspect for race equality (OFSTED 2012). This has the potential to negatively impact the importance and value given to matters relating to race and addressing racism on teacher training courses given the emphasis on the national priorities of Early maths, Phonics, behaviour management English as an additional language EAL and Special Educational Needs SEN. Furthermore, schools are no longer required to record data by race and ethnicity neither do they have to address race directly but can focus on poverty, disability or gender. As a result of this there is less likely to be a focus on matters relating to race, ethnicity, diversity and inclusion in ITT programmes (Tomlinson, 2011).

Davies and Crozier (2006) suggest that 'race' and anti-racism need to be addressed overtly on ITT programmes and discussing issues to do with 'race' cannot be an 'add on' or a tokenistic response or measure. The recruitment and retention of BME trainees onto courses was also a cause for concern. On the one hand this was seen as an advantage but on the other hand the targets set by institutions were seen as being unrealistic. There was insufficient advice and guidance in this area and there was a crucial need for continuing professional development on 'race' and diversity for all trainees as well as consistency across the programmes.

Gurin et al (2002) have argued that different types of diversity have to be addressed in order for it to be effective in teaching: structural diversity, informal interactional diversity and classroom diversity. Moreover, 'We contend that students educated in diverse institutions will be more motivated and better able to participate in an increasingly heterogeneous and complex society' (p. 339). Similarly, Orfield (2001) has found that there are a variety of individual, institutions and societal benefits that are linked to the teaching of diversity.

Research has shown that teachers are not well prepared to teach diverse students whose cultural values are different from their own (Santoro, 2009), and that many White teachers 
hold negative stereotypical views about minority ethnic children and have little knowledge of cultural diversity (Sleeter, 2008). Such trainees then attribute those children's academic failure to home and cultural backgrounds, rather than questioning their own pedagogies (Chubbuck, 2010; Sleeter, 2008). Many programmes that try to deal with diversity are simply 'add ons' that do not deal directly with issues of diversity and inclusion (McDonald, 2005). As society is becoming more and more diverse, the teacher population must reflect this diversity if it is to take seriously the notion of social justice and multiculturalism. The qualities that teachers should have include 'a sense of mission, solidarity with, and empathy for their students, the courage to challenge mainstream knowledge, improvisation and a passion for social justice' (Nieto, 2006, 463).

In view of the issues identified in the literature and the importance of these matters in ensuring that teachers are prepared and equipped to teach in diverse schools this paper aims to report on research undertaken to explore trainee teachers' understandings of 'race', diversity and inclusion. The research aims were:

1. What are the views of trainee teachers' on the teaching of 'race', diversity and inclusion on ITT courses?

2. To what extent do trainee teachers' understandings of these issues above affect their teaching practice in the classroom?

3. How well are trainee teachers equipped to deal with issues of diversity in the classroom?

\section{Methodology}

The data for this article is based on interviews conducted with a total of thirty students who were training to become teachers on primary and secondary PGCE (Postgraduate Certificate of Secondary Education) courses at two universities in the South of England. The majority of respondents who agreed to be interviewed were from White backgrounds (18) and almost half were from minority ethnic backgrounds. Five were from Black Caribbean backgrounds, five were Asian and two were mixed race (Black/White). Only 3 respondents were male. A total of ten interviews were conducted in University A and twenty interviews with students in University B. The research took place over a period of three years from 2009-2011. Both of the universities which participated in the research are traditional 'red brick' (research intensive) universities and located in the South of England. The research conducted in 
University A also consisted of a questionnaire completed by a total of 59 trainee teachers on PGCE courses. This paper will present findings from the in-depth interviews from both universities. The research conducted in University A was part of a funded project (see Bhopal, Harris and Rhamie, 2009 for further details of the research).

The interviews addressed such issues as how respondents understood the concepts of 'race', diversity and inclusion (before they joined the course and their present understanding whilst on the course); whether trainee teachers felt equipped to deal with issues of diversity and 'race' in the classroom; how respondents understood their own identity (as being Black, Asian or White) and whether they felt their own identity would affect interactions and dynamics in the classroom.

All of the interviews were tape-recorded and the data transcribed. The interviews lasted on average for one hour. The data was analysed by using methods of grounded theory as developed by Charmaz (2006). Particular themes associated with identity and the complexities of student identities in relation to their roles as future teachers were examined. The data was analysed to explore how the different themes were interrelated and the discourses participants used to describe their accounts and their experiences of being on a teacher training course. The data was analysed by using codes for particular themes and developing these codes into categories which would form the basis of our understanding of the discourses respondents used to discuss their experiences. Grounded theory was developed by comparing responses and making sense of the meanings attached to them. Consequently we were able to develop our notion of grounded theory which was an emerging process in the data. Critical Race theory underpinned the theoretical approach to the data analysis. Critical Race theory acknowledges and foregrounds race suggesting that Whiteness is normalised in society and others are positioned in relation to this norm. This recognition of race and racisms provides a useful means of legitimising investigations into these issues while valuing the experiences and stories of participants. It also seeks to work against the marginalisation of race in current discourse (Ladson-Billings, 2004).

\section{The Findings}

\section{The complexity of identity}

When trainee teachers were asked about their experiences of being White, they translated this as something which was seen in terms of privilege. Many of them were reflective about 
their own identities and saw this in terms of being in a position of advantage. Yet at the same time, they did not think that their identity would have a significant effect on their pupils regardless of the pupils' backgrounds. Julian who described himself from a middle class background said,

As a White student I know that I am privileged, but I also think that if I am a good teacher I don't think that my identity should affect my pupils because I am a teacher first. It doesn't matter where my pupils come from; as long as I am a good teacher then I should be able to get the best out of them.

$\mathrm{John}^{3}$ was White and had thought somewhat about his own identity and the affect it had on his choice of career as a teacher.

It doesn't mean a huge amount to me, being White it's just a label. I think we all make a great play of backgrounds, but ultimately we're all humans aren't we? But I suppose it doesn't work like that in practice, does it? I hate to say so, but being European, or White is seen as being advantaged. You still get some people who think with old ideas and so treat you in a certain way because of their racial views. I think I have a great place to offer in the classroom as a role model because I don't think we have enough diversity in education and because of that it's up to White people to influence that in how they teach and what they say about people who are not in a privileged position like us because they are Black.

John was from a privileged background, yet he felt disadvantaged because of this privilege.

I kind of can feel, but not really know what it's like to be treated differently because of you're not White but know what it's like for people to treat you in a certain way because of the way you are. I went to an independent school and so I speak in a posh way and sometimes people will treat me in a certain way. I don't tell people I went to an independent school because it would mean they would judge me because of that.

Meena on the other hand was adamant that her identity - her 'race' and gender (which she could not disguise) made a significant difference to how she was treated in the classroom.

There are issues on how you are treated in schools, both by the teachers and the pupils. If they see you as an Asian female then they will treat you in a certain way - usually

\footnotetext{
${ }^{3}$ All names are pseudonyms.
} 
based on stereotypes and if you are a White male you will be treated in a different way. Sometimes, these things are not intentional, they are not thought about and other times they are very intentional and they are meant to make you feel in a certain way.

Meena felt her identity as an Asian female who was also from a working class background with a strong Midlands accent made her conscious of her identity. This also demonstrated the complexity of identities within the classroom and how the intersectionality of identity - based on 'race', gender and class - were all contributory factors in how trainee teachers were perceived by others, but also how they perceived themselves. Both Meena and John were aware of their intersecting identities and the effects of this on their own presence in the classroom. Julie on the other hand was quite open about her Black identity and the negative effects it had on her life and her educational experience.

I know that Black women are seen in a certain sort of way and because I am a big woman as well, I am seen as someone with attitude. But that can be a good thing; it depends on how you use that attitude! I am convinced that I am judged because of what I look like and that can be negative. Some of the pupils in the school have treated me differently and I don't think they would treat a White female in that way. There is racism in schools and we are aware of it, but it's how you deal with it. You could be negative about it, or you could turn it into a positive - by showing that you are a professional and that you are good at what you do.

Although Julie was aware and open about racism (some of which she herself had experienced), she was equally pragmatic and philosophical about her approach in how she dealt with it in the classroom.

It [experiencing racism] would have to be dealt with properly, but being a Black person, we are told by our family that we should always be professional in what we do. That is the best way because then there is always that notion that you were as professional as you could be - rather than starting to argue, swear or be aggressive which is in a way what people want you to do and think you will do.

These respondents noted the challenges presented by their individual racialised identities. For the Asian and Black females it was clear that they had to manage not just the differential treatment they received but had to consciously behave in ways to challenge the stereotypical expectations placed upon them. 


\section{Understanding diversity, 'race' and inclusion}

Many of the trainee teachers' understanding of issues to do with diversity, 'race' and inclusion were related to their own experiences of not just schooling but also the way they themselves were brought up. Both of Sally's parents were teachers and she had a complex understanding of these issues. Sally described herself from a 'liberal White middle class background'.

For me, those things are about variety. A variety and difference of culture, religion and your background. As a teacher you're faced with diverse teachers and diverse schools so your pupils are not all going to be the same. There will be diversity of race and diversity of religion and social background. Family background is very important and you have to learn to deal with that kind of background in the classroom where you are expected to create a sense of community for the pupils and in the school.

Sally went on to explain that understanding diversity was difficult as the concept of identity was a 'slippery issue'.

There is so much diversity that it is very difficult to define what we mean by diversity. For example if you say someone is White, they could be White but they could also be mixed race - White and something else - or they could be Polish or White European and that means something different again. I think it's too general to say that 'this is how Whiteness or Blackness is perceived in society' and it could be perceived in a negative way as well.

In a similar respect, Jeanette who was from a Black Caribbean background understood the complexity of these issues.

I think being a teacher your identity is very important but to look at these things diversity and inclusion in the classroom is really about integration to me. For example if you are an Asian person - obviously you don't look White - but you are British, you are integrated because of the way you speak and have the same culture as White British - but you still look different and you may be treated differently because of this. So I just don't think it's that simple. As a Black person, I would say I am treated differently because I am not White, I am Black but I am integrated and I am British but I am still seen as being different. 
Carl one of the few male Black trainee teachers on the course emphasised,

Becoming a teacher, I never considered the impact my colour or background would have on it. I mean honestly and this may be naïve, the only things I thought would have an impact on my perceptions of becoming a teacher were things like the education I have had and whether that's going to impact on the kinds of schools that will want me. But it isn't like that in reality, because all schools have their prejudices and they may not want me - a Black male - to teach in their school, for whatever reason that may be.

The acknowledgement of the complexity of their own experiences of diversity, 'race' and inclusion supports the need for further opportunities for student teachers to address these issues in depth rather than relying on the often superficial and simplistic approach adopted in their training.

\section{The practicalities of dealing with 'race'/racism in the classroom}

The majority of trainee teachers did not feel equipped to deal with racist incidents in the classroom. Many stressed the importance of knowing how to deal with such incidents, particularly in relation to 'race', but also 'otherness'. Jane a White student said,

I don't know how I would deal with these incidents and we're not really told how we should do it on a practical basis. We do have some input about equality issues but it seems to be separate from the rest of the course. More on these aspects, not just about 'race', but about kids who are having other problems and who are different should be included in the course.

Jeanette also indicated the importance of this.

I think as a teacher you have to know how to deal with these issues because you have to make sure you do it properly. But as a Black person I think it would make me cross, because I am Black and it would be hurtful to think that children can behave like that [be racist]. The other issue is also the fear that you may experience racism from their teachers and their pupils and I know people who have had those experiences and that must be hard to deal with.

Farah, an Asian Muslim had similar experiences. 
I think people do judge me because I wear a headscarf and they have assumptions about my identity. I have had pupils say things to me, but to be honest I am not so sure if they have been dealt with in the appropriate way. I think that being different in schools can be a good thing but it can also have its disadvantages because you stand out and you risk being called names and discriminated against.

Maria, a White student had witnessed one of her pupils call another pupil a racist name and was clear that the school could have dealt with it differently.

To be honest when it happened I was very upset and couldn't believe that kids still behave like that - just using bad names - and it made me think about why it happens. The schools just don't know how to deal with these things and so tend to go overboard and tell everyone off. But they just focus on that person and think about why he did it - it's not everyone else's fault that you have one bad apple. And we are not taught on our course how to deal with it, we are just taught about the theories of difference.

Maria felt it was more about how children learnt about other cultures in the classroom which affected how they treated Black and Minority Ethnic (BME) groups.

I think one of the big things is that kids learn about racism and how to be racist. I don't think we teach enough about the history of our nation to kids and why we are so diverse and why we have a rich mix of cultures. And I think if kids know about the history, they won't harbour resentment towards BME groups, because there seems to be a lot of resentment about BME groups and immigration and some people feel animosity towards them. They say they can't speak English, shouldn't be here, blah blah blah - and they don't know about the history.

The lack of knowledge and confidence in how to deal with racist incidents is clear in these accounts which highlight the importance of adequate ITT provision in this respect. But they also point to the failure of ITT to adequately prepare trainee teachers to effectively and confidently deal with racist incidents despite 40 years of race policy and legislation.

\section{Dealing with 'otherness' in the classroom}

Many of the respondents when they spoke about their experiences in the classroom, quite often referred to the notion of 'difference' and what can be termed as the 'other'. There was 
an indication that there were many differences which existed in the classroom and in some sense they could not all be tackled, but in another sense it was important to make every effort to ensure that they were in fact recognised - if they could not be tackled. These differences were related to issues of social class background. These differences included language, accent, their approach to education, the kind of support they received at home and religion. Some of the trainees were teaching in diverse schools (though not all) and those who were, referred to aspects of religious difference and identity, which they felt made a big difference to notions of the 'other'. For some, this was in relation to Muslim identity and for others, (in schools with high numbers of Polish pupils ) Catholicism. However, it was the physical markers of 'race' which were identified as being the most prominent markers of difference which continued to have the biggest impact on aspects of how trainee teachers were seen. Several spoke about this. Mary, a White student spoke about this 'otherness' in detail.

There are lots of things you have to think about as a teacher when you are in the classroom. One of the issues is - are you treating everyone the same - are you treating them by taking into consideration that they are different? There are many things that we need to think about, these days the issue of religion is very important. With all the changes going on in society, you have to be sensitive to that difference. You have to think about what you teach - and what other students say - and the impact this has on the students.

Mary also spoke about difference in relation to some of her White pupils .

My school has lots of different children from many diverse backgrounds. I think there are about 23 different languages spoken in our school. So we have to be mindful of what we are saying and what we are teaching. Many of the Polish students here can't speak much English and many of them are very religious, they are Catholics. We have to try and cater for them, just like we have to cater for the Muslim students and the other Somali students who are unable to speak English. It should not be about the colour of the person's skin, it should be about learning and creating an environment where the children can all learn together and learn from each other [original emphasis].

Brian (who was from a White, middle class background), explicitly referred to the issue of class. 
There are some children in my class who are very different to me and to the other children. They come from backgrounds which are not so advantaged and some of them struggle. We have to think about the impact that - say for example - divorce or even unemployment has had on them. Because it does affect them in lots of different ways and when they have a setback like that, it can affect everything they do at school. That's one of the reasons it is important to know what is going on with a student. Some of the kids are from backgrounds that don't value education and so don't make an effort and that can affect their life chances.

Brian went on to discuss how it was important for teachers to be able to get a sense of the whole situation for their pupils, rather than just an individual sense from their pupils.

It is our job to make sure that we try and get children to learn and as teachers we have to do what we can. If some children do come from those backgrounds [which don't value education] we have to make sure we enable parents to see the value of education for their children and I can imagine that would be tough.

Here, Brian was referring to some White children at his school placement who revealed to him that their own parents had left school at 16 and did not see the value of their children staying on at school beyond this age.

However, it was Natalie, a Black British student who outlined the significant physical markers of difference.

I know that we have to be aware of difference and how that is perceived, but I have to go back to what I have always thought and that is that what you look like cannot be disguised. My appearance as a Black woman will always affect how people see me and the judgements they make about me. I have had experiences in my life where I know I have been treated in a negative way compared to a White person in the same situation. People are quick to make judgements about you - and because you are a Black female that happens a lot. And I don't like to say this, but yes it does happen in schools and it happens with other teachers, but more so with the pupils who make these judgements about us.

Natalie went on to explain how she dealt with this notion of being an 'outsider', in an environment where she should have been an insider. 
As a trainee teacher, I should be seen as the teachers - with respect and be treated like that. I know I haven't qualified yet and they have more experience than me - but I am on my way to be qualified. But it just seems that these judgements are made about you - and I think it is because I am a Black female. So I do what I have always done and I am very professional, I speak clearly and articulately and do my job the best I can - then I cannot be criticised. It's a bit like the old saying, you have to be more than $100 \%$ because you are not White...I think sometimes being professional does make a difference - in the school it does - but in the real world I'm not so sure. There is always the notion that you are not quite seen as other people - you are always the second class citizen.

None of the White students referred to being treated differently based on their skin colour, several however did mention being treated differently due to their social class background. Gemma described herself from a White working class background.

I come from a family of manual labourers and I was brought up on a council estate and I notice that I don't speak like a lot of the other students or teachers. I would say a lot of them come from backgrounds that are more middle class, some of them have said that their parents are teachers - and so they are used to this kind of environment. I am not, so I do feel different to them sometimes.

For many of the trainee teachers, it was the type and mix of the school where they were located which affected their attitudes towards 'race', gender, class, religion and the 'other'. If they were in a school which was ethnically and culturally diverse, they were forced to think about diversity, multiculturalism and how their teaching would affect students who may be different to the 'norm'. Becca, who described herself as a White, middle class student emphasised this.

If you are in a school that is ethnically mixed with all cultures and religions, you have no choice as a school but to address these issues. If you were in a school that was all White the assumption would be and has been that you don't have to deal with these issues - because it doesn't affect your school - and that is wrong, because these kind of things ['race', diversity and inclusion] affect all schools no matter who is in them or where they are located (original emphasis). 


\section{Discussion}

The respondents demonstrated a complexity of responses with regard to their identities. Contrary to previous research, our research suggests that respondents were fully aware of issues to do with race, diversity and inclusion and were clearly engaged in how these issues affected them as trainee and future teachers (Causey et al 2000; Lander, 2011) On the one hand they were fully aware that their own identities would have an impact in the classroom when teaching, yet on the other hand they felt this should not be the case in reality. When asked about how they would define themselves and about their own identities, the majority of trainee teachers defined themselves in terms of their ethnic identity rather than their visual identity, based on colour. Yet at the same time, many respondents recognised that the physical markers of difference (such as their 'race') played a significant part in how they were perceived by others - both inside and outside the school gates. In fact, many of the respondents felt that such notions of identity (White and Black) were crude and did not represent their culture, history or background. Many of them felt that such definitions of being White or Black did not mean or say anything about their identities when used on their own, rather the terms only had meaning if they were associated with their ethnic and cultural background. When trainee teachers spoke about White identities, they spoke about them in relation to being privileged, advantaged and in a position of power compared to those who were Black. Whiteness was considered the 'norm', it was an identity from which all other non-White identities were judged or based from. It was seen as the starting point of how other identities were defined; it was the one identity which was considered acceptable and the norm not just in British society, but worldwide. Whiteness carried a universal connotation of acceptance and privilege.

Whilst White trainee teachers acknowledged the power and privilege associated with their Whiteness what was not clear was the extent to which these trainee teachers knew or understood their own role in addressing the impact of their Whiteness on Black pupils in their classes. There was an absence of discussions that showed that they had moved on from being aware of the racism and the power afforded as a result of their own White privilege and the lack of power experienced in Blackness to recognising their own role as social justice or antiracist educators (Marx, 2004) or indeed being able to then disrupt White privilege (Hytten and Warren, 2003). 
In comparison, respondents understood that the category or identity of being Black was seen in opposition to being White, as being disadvantageous, as an identity that would immediately exclude individuals based on what they looked like (though not all of the respondents themselves had these views, but recognised that most of society felt and thought this way). Smith and Lander (2012) highlight the importance of what is the norm for students and indeed society. They note that the majority of teachers are White and school pupils' own experiences of teachers are White therefore where Black teachers are encountered they are considered different falling outside -what is considered the norm. As a result as suggested by Goffman (1969) (cited in Smith and Lander, 2012) this difference is then interpreted as deficient or deviant. This exclusion of individuals based on their physical characteristics such as skin colour becomes a dominant feature rendering the Black teacher as illegitimate and therefore not a 'good' teacher (Smith and Lander, 2012). It also brings to the fore the plethora of negative images and perceptions ascribed to Blackness through various media in society. This goes some way towards explaining the 'otherness' and positioning of Black teachers as outsiders resulting in their being treated differently. One of the challenges for teacher education is how to ensure that trainee teachers engage critically with these issues in order to challenge and address them within the classroom.

Other intersectionalities associated with identity were also apparent. Many of the respondents spoke about class and how this was related to 'race' and locality, for example some respondents indicated that where people came from made a difference to how they were treated. Many of the respondents spoke about class in terms of how they and others were treated. Locality in relation to class background was also an issue that many of the students spoke about, particularly in relation to accent. What was interesting in relation to this issue was John's experience of being treated differently because of his 'posh' accent. This experience, he suggests affords some insight, though he admits not fully, into understanding how Black students experience being treated differently. However, what he fails to recognise is that his differential treatment is not founded upon him being seen to be different in a deficient way, as has been shown for Black students (Smith and Lander, 2012).

Many of the trainee teachers spoke about the training they received on their courses as being insufficient to deal with issues of 'race' and racism in the classroom. Although many did state that they were taught about theories and policies of inclusion, 'race' appeared as a side issue to this. Attempts to develop student teachers' understandings of White privilege and, Whiteness and its relationship to racism have been met with limited success. A number of 
researchers have found that students resist discussions of White privilege (Sleeter, 2001). Furthermore, Smith and Lander (2012) highlighted the challenges faced when teacher educators attempt to engage students in discussions of these issues turning the spotlight onto Whiteness results in hostility and rejection when led by a Black tutor and compliance and engagement in 'White talk' when led by a White tutor. Many of the respondents related identity to visible markers of difference, for example some were aware that they could hide their working class roots, but Whiteness was far more difficult to hide, just as a Black person was unable to hide their non-White identity. There has been a growing body of knowledge around multiple identities, (Brah and Phoenix, 2004), constellations of identity categories, (Youdell, 2006), and the idea of multiple belongings (Knowles, 2011). While trainee teachers were able to articulate their own understandings of their identity and the identity of others it was evident that there is a need for a greater engagement in the issue of identity and its multiple forms as well as a better integration of these issues within the ITE curriculum.

\section{Conclusions}

This research has demonstrated that identity plays a crucial role in the experiences of ITT students. The student responses show the complexities and different facets student teachers bring to their teacher training experiences. Their understandings of identity are woven within their understandings of a diverse range of differences such as their 'race', gender, class and also their own experiences of learning in the classroom. What is clear is the different facets of identity and how they translate into the classroom and how they are related to the' different roles of trainee teachers as teacher and educator. They bring their own identities into the classroom and are aware of the impact these identities may have on pupils' learning. What is more important though is that they are all aware of how identity impacts on the learning experience. They all felt that inclusion and diversity were important goals to be aimed for, but not all of them believed they could be achieved. However, part of being a teacher for many of the respondents was the need to make a significant difference to the lives of pupils, even if this was in small steps, they felt it would lead to greater differences which could impact on the school and local communities. Whilst racism was recognised as something that continued to exist in society, the school was an environment in which racist views and prejudiced could be challenged, it was seen as a 'safe environment' in which these challenges could take place, for some this was an uncomfortable experience, but for others it was about 'making a difference'. While the trainee teachers received some training on diversity, inclusion and 'race' (albeit) in a theoretical fashion, all agreed that their institutions could and 
should be doing more to equip students with greater skills to deal with incidents of racism and prejudice as well as with a focused understanding of these issues. This was particularly the case for those who not only grew up in predominantly White areas, but also those who taught in predominantly White schools. For these trainee teachers, issues of 'race' and diversity were more important as the teaching of these issues helped to combat the stereotypes pupils had of Black and ethnic minorities when they attended all White schools. What is clear from the data is the recognition that trainee teachers were very reflexive about their teaching practice and all of the trainee teachers wanted to make a difference in their teaching, some by being inclusive in their curriculum, others by using engaging and innovative methods of teaching which would encourage their own students to question racism and prejudice. The respondents were also aware of the impact of their own identities on their teaching and how they could use these identities in the classroom to engage and motivate students in their own learning experience. Identities were also seen as shifting, changing and dynamic. Some of the trainee teachers were reflexive about where they had grown up and how their changing identities (such as their class position) had shifted once they had entered the teaching profession. What was clear however was that some identities were unable to be changed, those visible markers of difference, of being White and being Black remained firmly part of their role as teachers and educators. These identities were those which would continue to have a greater impact (in one way or another) on their teaching and learning experience.

The fact that issues of identity and diversity continue to be marginalised within ITE and taught as an 'add-on' is one that needs addressing. It may be that the decision making around what, when and where in the timetable these matters are addressed falls to White academics who themselves may not fully understand the implications and importance of providing sufficient time within the curriculum to truly embed these issues. It may be that Johnson, Lachuk and Mosely (2012) are correct in suggesting that ITE tutors also need to critically engage with their own understandings and historical narratives of how such discourses have developed in order to inform their pedagogic interactions with students on these matters.

The external pressures on ITE providers to respond to numerous and far reaching changes in education in recent decades may have contributed to issues of identity and diversity being progressively squeezed out of ITE. Providers are required to be responsive to developments within schools and to changes in government policy. Changes to the curriculum with a greater emphasis on the teaching of phonics, early maths, behaviour and Special and 
Inclusive education have moved the focus away from issues relating to race, ethnicity and identity. The QTS Teacher Standards that were introduced in 2007 specifically related to the need to take account of diversity and promote equality and inclusion in teaching (TDA, 2007). The new Teachers' Standards introduced in September 2012 omit specific references to race equality, diversity and inclusion (DfE 2011). It is likely that changes in Teachers' Standards is seen by providers as an indicator of government priorities and could be seen as the gauge for what should and should not be emphasised or included in teacher education. With less of a focus on these issues ITE providers may deem it necessary to further reduce time spent on these matters to focus on new government priorities. It is also important to mention that the current government's drive to remove teacher education from universities and into schools through initiatives such as School Direct may have a direct impact on how these issues are addressed and potentially lead to schools addressing issues in training that are only relevant to their locality which may or may not include an emphasis on race equality, diversity or inclusion in its widest sense. is a valid consideration and is raised as a question/possibility therefore I don't think it needs a reference.

There are a number of recommendations that arise out of this research.

- ITE providers should provide explicit teaching on how to manage racism in schools with specific strategies and information on policy guidance.

- Opportunities should be provided for students to engage in discussions of their identities and how these may impact on their teaching.

- Issues of identity should be embedded across the whole of ITE provision ensuring that tutors themselves critically engage with their own identities drawing on this to support interactions with students.

- Further research in this area is needed, particularly the impact of the Equalities Act 2010 and how it affects the training of student teachers.

Whilst these issues are clearly important in providing an inclusive experience for future teachers, at the time of writing (February 2013) there is little evidence however to suggest that future government policy will take such issues on board. Consequently, this will raise further questions about how we address issues of race, diversity and inclusion in providing trainee teachers with the means by which they can deal with diversity and difference in the classroom. 


\section{References}

Ambe, E. (2006) 'Fostering multicultural appreciation in pre-service teachers through multicultural curricular transformation' Teaching and Teacher Education 22, 690-699.

Ajegbo Report, The (2007) Diversity and Citizenship Curriculum Review. London: DfES.

Aveling, N (2002) Student Teachers' Resistance to Exploring Racism: reflections on 'doing border pedagogy', Asian-Pacific Journal of Teacher Education, 30: 119-30. Bhopal, K. (2010) Asian Women in Higher Education: Shared Communities. Stoke on Trent: Trentham.

Bhopal, K and Danaher, PA (2013) Identity and Pedagogy in Higher Education: International Comparisons. London: Continuum.

Bhopal, K., Harris, R., and Rhamie, J. (2009) The teaching of 'race' diversity and inclusion on PGCE courses. A case study analysis. Multiverse: TDA (posted 19.06.09)

Brah, A. and Phoenix, A. (2004) 'Ain't I a woman: Revisiting intersectionality'. Journal of International Women's Studies 5,30, 75-86

Causey, V., Thomas, C., and Armento, B. (2000) 'Cultural diversity is basically a foreign term to me: the challenges of diversity for preservice teacher education' Teaching and Teacher Education 16, 33-45.

Charmaz, K (2006) Constructing grounded theory. London: Sage.

Chubbuck, S.M. (2010) Imperatives for Social Justice in Teacher Education: Realization in Theory and Practice. Teacher Education \& Practice, 23(4), 462-465.

The Crick Report (1998) Education for citizenship and the teaching of democracy in schools. London: DfES.

Davies, J and Crozier, G (2006) Diversity and Teacher Education: Research into Training Provision in England. London: Multiverse website.

Department for Education (DfE) (2011) The Framework for the National Curriculum. A report by the Expert Panel for the National Curriculum review. London: Department for Education.

Department for Education (DfE) (2011) Teachers' Standards London:DfE.

The Equality Act (2010) London: Home Office.

Equalities and Human Rights Commission (EHRC) no date Education provider's School Guidance, Available at : http://www.equalityhumanrights.com/advice-andguidanceleducation-providers-schools-guidance/introduction. (Date accessed 24/05/13)

Garcia, O. and Lopez, R. (2005) 'Teachers' initial training in cultural diversity in Spain: attitudes and pedagogical strategies' Intercultural Education 16 (5), 433-442. 
Gurin, P., Dey E.L., Hurtado, S., and Gurin, G. (2002) 'Diversity and Higher Education: Theory and Impact on Educational Outcomes.' Harvard Educational Review, 72 (3) pp 330366.

Hick, P., Arshad, R., Mitchell, L., Watt, D. \& Roberts, L. (2011) Promoting Cohesion, Challenging Expectations - Educating the teachers of tomorrow for race equality and diversity in 21 st century schools.

Hollins, E. R. and Guzman, M. T. (2005) 'Research on Preparing Teachers for Diverse Populations' in M. Cochran-Smith and K. M. Zeichner (eds) Studying Teacher Education: The Report of the AERA Panel on Research and Teacher Education. Mahwah, NJ: AERA/Lawrence Erlbaum Associates.

Hytten, K. and Warren, J. (2003) Engaging whiteness: how racial power gets reified in education. Qualitative studies in education, 16(1) 65-89

Johnson Lachuk, A.S. and Mosley, M. (2012) Us and them? Entering a three-dimensional narrative inquiry space with white pre-service teachers to explore race, racism, and antiracism. Race Ethnicity and Education, 15, 3, 311-330

Kerr, D., Lopes, J., Nelson, J., White, K., Cleaver, E. And Benton, T. (2007) Vision versus pragmatism: Citizenship in the secondary school curriculum in England. Citizenship Longitudinal study fifth annual report. RR845: NFER

Khan, O. (2007) Policy, Identity and Community cohesion: How race equality fits. In M. Wetherell, M, Lafleche and R Berkeley (Eds) Identity, Ethnic Diversity and Community Cohesion. London: Sage Publications Ltd.

Knowles, G. (2007) 'Identity'. In G. Knowles and V.Lander Diversity, Equality and Achievement in Education. London: Sage Publications Ltd. Korthagen, F. A. J., Kessels, J.,

Koster, B., Lagerwerf, B. and Wubbels, T. (2001) Linking Theory and Practice: the pedagogy of realistic teacher education. Mahwah, New Jersey: Lawrence Erlbaum Associates.

Ladson-Billings, G. (2004) 'Just what is Critical Race Theory and what is it doing in a nice field like education?' in G. Ladson-Billings and D. Gillborn (eds) The Routledge-Falmer Reader in Multicultural Education. London: RoutledgeFalmer

Lander, V (2011) 'Race, culture and all that: an exploration of the perspectives of White secondary student teachers about race equality issues in their initial teacher education'. Race, Ethnicity and Education 14, 3, 351-364.

Lafleche and R, Berkeley (Eds) Identity, Ethnic Diversity and Community Cohesion. (London: Sage Publications Ltd).

Levine-Rasky, C (2001) Identifying the Prospective Multicultural Educator: Three Signposts, Three Portrait. The Urban Review 33, 4: 291-319.

Maylor, U. (2009) 'They do not relate to people like us': Black teachers as role models for Black pupils, Journal of Education Policy, 24 (1): 1-21. 
Mills, C. (2008). Making a difference: Moving beyond the superficial treatment of diversity. Asia-Pacific Journal of Teacher Education, 36(4), 261-275.

Mills, C. (2009). Making sense of pre-service teachers' dispositions towards social justice: Can teacher education make a difference? Critical Studies in Education, 50(3), 277-288.

Milner, H (2010) Teacher education for inclusion. Brussels: European Development Agency.

Nieto, S. (2004) 'Critical Multicultural Education and Students' Perspectives' in G. LadsonBillings and D. Gillborn (eds) The RoutledgeFalmer Reader in Multicultural Education. Abingdon: RoutledgeFalmer.

Office for Standards in Education (OFSTED) (2012) Initial Teacher Education Inspection Handbook. Manchester: OFSTED.

Orfield, G (2001) Schools more separate: consequences of a decade of resegregation. Cambridge, MA: Harvard University Press.

Osler, A (2009) 'Citizenship, democracy and racial justice: 10 years on'. Race Equality Teaching 27(3), 21-27.

Parekh, B. (2007) Reasoned Identities: A committed relationship. In M. Wetherell, M,

Picower, B. (2009). The unexamined Whiteness of teaching: How White teachers maintain and enact dominant racial ideologies. Race, Ethnicity \& Education, 12(2), 197-215.

Race on The Agenda (ROTA) (2012), Racism in the Classroom: An alternative inquiry into education in London. Race on the Agenda.

Rhamie, J. (2007) Eagles who Soar: How Black learners find paths to success. Stoke onTrent: Trentham Books. Santoro, N. and Allard, A. (2005) '(Re) examining identities: Working with diversity in the pre-service teaching experience Teaching and Teacher Education 21, 863-873

Sleeter, C.E. (2001) 'Preparing Teachers for Culturally Diverse Schools: Research and the overwhelming presence of whiteness' Journal of Teacher Education 52 (2), 94-106

Smith, H and Lander, V (2012) 'Collusion or Collision: teacher ethnicity in teaching critical whiteness.' Race, Ethnicity and Education, 15, 3: 331-351.

Solomon, R. P., et al. (2005). The discourse of denial: how white teacher candidates construct race, racism and „white privilege". Race Ethnicity and Education, 8 (2), 147-169.

Teacher Development Agency (TDA) (2007) Professional Standards for Qualified Teacher Status. London:TDA.

Tomlinson, S. (2011) More radical reform (but don't mention race) gaps and silences in the government's discourse. Race Equality Teaching 29; 25-29

Wilkins and Lall (2011) 'You've got to be tough and I'm trying': Black and minority ethnic student teachers' experiences of initial teacher education'. Race, Ethnicity and Education 14, 3: 365-386. 
Youdell, D. (2006) Impossible Bodies Impossible Selves: Exclusions and Student

Subjectivities. Dortrecht: Springer.

3. Teaching in Color: A Critical Race Theory in Education Analysis of the Literature on Preservice Teachers of Color and Teacher Education in the U.S.

Keffrelyn D. Brown, Ph.D.

Associate Professor

The University of Texas at Austin

Department of Curriculum and Instruction

1912 Speedway Stop D5700

Austin, Texas 78712-1293

keffrelyn@austin.utexas.edu

512.232.4257 (home)

608.239 .6280 (cell)

512.471 .8460 (fax) 


\title{
Teaching in Color: A Critical Race Theory in Education Analysis of the Literature on Preservice Teachers of Color and Teacher Education in the U.S.
}

\begin{abstract}
$\underline{\text { Abstract }}$
In this paper I take seriously the call for recruiting and retaining more preservice teachers of color by critically considering some of the pressing challenges they might encounter in teacher preparation programs. I draw from critical race theory in education to review the extant literature on preservice teachers of color and teacher education in the U.S. I excavate how the dominant, (dis)embodied and normalized culture of Whiteness, White privilege and White hegemony pervades contemporary teacher education, and presents a formidable challenge to the goal of preparing teachers (of color) to teach in a manner that is relevant, critical and humanizing while also socially and individually transformative. I conclude by envisioning how teacher education programs might address these challenges in such a way that more effectively meets the needs of preservice teachers.
\end{abstract}

Key words: critical race theory, preservice teachers of color, teacher education, critical race theory in education, Whiteness, interest convergence, counter-storytelling 


\section{Teaching in Color: A Critical Race Theory in Education Analysis of the Literature on Preservice Teachers of Color and Teacher Education in the U.S.}

\section{$\underline{\text { Introduction }}$}

Teacher education programs and school districts across the U.S. face tremendous challenges in helping teachers gain the skills needed to teach all students effectively (Banks, CochranSmith, Moll, Richert, Zeichner, LePage, Darling-Hammond \& Duffy, 2005). While these challenges have always existed, they take on renewed impetus in the contemporary education context. This context is defined by high stakes accountability, deeply entrenched educational gaps in opportunity and achievement between students of differing racial, cultural, linguistic, learning and economic backgrounds (or what Ladson-Billings (2006) metaphorically recognizes as an education debt), and a sustained and growing mismatch between the background and experiences of aspiring and preparing teachers and the larger K-12 student population in which these teachers will serve.

While clearly not unique to this particular time period (Dilworth \& Brown, 2008), one solution offered for tackling this dilemma in the contemporary context, is to recruit and retain more people of color in the teaching field (Achinstein, Ogawa, Sexton \& Freitas, 2010). The argument here is that K-12 students of color have increased levels of achievement when their teachers share a similar racial, cultural and/or linguistic background as their students (Villegas \& Davis, 2008). Most recently, in 2010, Arne Duncan, the education secretary for the Obama Administration, expressed concerns about the low numbers of teachers of color, particularly among Black American men and the administration's intention to improve these numbers in K-12 schools (Duncan, 2010, November 16).

In this paper I take seriously the call for recruiting and retaining more preservice teachers of color. I critically consider some of the pressing challenges these teachers might encounter in teacher preparation programs to acquire a sociocultural knowledge for teaching that is relevant, critical and humanizing while also socially and personally transformative (Brown, 2012). To do this, I begin by framing my examination in the context of critical race theory in education (CRT), the theoretical lens that shaped how I read and made sense of the extant literature on teacher preparation and teachers of color. 
Following this discussion I consider some of the key themes that shape the broad scholarship on teachers of color and teacher preparation in the U.S. that include: the call to recruit and retain more preservice teachers of color in teacher preparation programs, the perspectives and voices of preservice teachers of color about teaching and the experiences teacher candidates of color encounter in teacher preparation programs. In this discussion I highlight the subtle and nuanced discourses that comprise this body of work and illuminate how the dominant, (dis)embodied and normalized culture of Whiteness that pervades contemporary teacher education, challenges the goal of preparing teachers (of color) to teach in a way that is relevant, critical and humanizing, while also socially and individually transformative. I conclude by considering how teacher education programs might address these challenges in such a way that more effectively meets the needs of preservice teachers.

\section{Theoretical Considerations}

In framing this project I drew from CRT in education, a framework that scholars have previously used to examine broad concerns with teacher education (Chapman, 2011; LadsonBillings, 1999). I argue from the perspective that this frame acknowledges the complex social terrain in which any attempt to prepare teachers, both those of color and those who are not, is likely to occur. This frame also acknowledges how Whiteness, as a cultural, sociopolitical and economic hegemonic force, has and continues to operate both nationally and globally. Drawing from Frankenberg (1993), I recognize Whiteness as operating across a "set of linked dimensions" in which

[f]irst, whiteness is a location of structural advantage, or race privilege. Second, it is a 'standpoint,' a place from which white people look at ourselves, at others and at society. Third, 'whiteness' refers to a set of cultural practices that are usually unmarked and unnamed. (p. 1)

Pushing beyond the notion of Whiteness as a privilege and a hegemonic force as well, Leonardo (2004) recognized that "in order for white racial hegemony to saturate everyday life, it has to be secured by a process of domination, or those acts, decisions and policies that white subjects perpetrate on people of color" (p. 137). Whiteness as hegemony, then, is evident in the knowledge, values, experiences and ways of being valorized in society and in educational settings, including (but not limited to) schools and teacher education programs. In the specific case of the U.S., the sociocultural factor of race has played a primary role in 
organizing and maintaining inequitable societal relationships. It is necessary, then, to place race at the center of social analysis (Brown, K.D. 2011; Brown \& Brown, 2010; Brown, A. L. 2012; Vasquez Heilig, Brown, \& Brown, 2012). This takes on particular importance when approaching teacher preparation because this area, also, operates in a racialized space that exists within and helps to reinscribe norms of Whiteness and privilege (Ladson-Billings, 1999; Montecinos, 2004; Sleeter, 2001). In the discussion that follows I provide an overview of CRT in education that informs how I approached the problematic of teacher preparation and its relationship to preparing teachers of color in the U.S.

Critical Race Theory in Education. Recognizing the enduring and primary role that race has occupied in patterning societal arrangements since the founding of the U.S., CRT (Crenshaw, Gotanda, Peller \& Thomas, 1995) provides a lens to understand the endemic nature of racism. CRT emerged as a response to criticisms of critical legal studies, a theoretical approach that while concerned about how law itself helped to maintain societal inequity, failed to address how the construct of race and the practice of racism operated in these processes. Dixson $\&$ Rousseau (2006) note several key tenets associated with CRT. Along with the pervasive role that race plays in society due to the historically linked relationship between property rights and human/civil rights in the U.S., CRT also contests dominant claims of objectivity, neutrality, color-blindness, and merit. CRT also challenges ahistorical, decontextualized analysis of how the law operates, while simultaneously valuing the experiential knowledge of people of color in analyzing law and society. Finally, CRT recognizes the project of eliminating racial oppression as interdisciplinary and part of a broader goal of ending all forms of oppression (Dixson and Rousseau, 2006).

Scholars have adopted CRT in various disciplinary areas, including education, to explore the nature of race and racism (Ladson-Billings \& Tate, 1995; Solórzano, 1997). The goal of CRT in education is to excavate how race operates in society and in education, at both the structural and local, everyday levels. This is accomplished through various strategies that include (1) counter-storytelling, an approach that calls attention to the voices of marginalized people of color by listening to how their own experiences, and the knowledge that emerges from them, illuminate and disrupt dominant narratives about race, racism and racial progress in society and schools (Solórzano \& Yosso, 2001); (2) recognizing Whiteness as a form of property that offers to White persons and their interests various rights and privileges that include the right to disposition, the right to use and to enjoy, and the right to exclude (Buras, 2011; Harris, 1993; Ladson-Billings \& Tate, 1995; Vaught \& Castagno, 2008); and (3) the nature, paradox and limitations of interest-convergence (Bell, 1995a; Donnor, 2005), or the 
strategy of addressing racial inequities in the context of remedies that serve and maintain dominant White interests. With its focus on centering race in the examination of societal relations, CRT in education offers a lens to understand the obvious, and more insidiously subtle ways that race operates in the context of teacher education. Yet while CRT moves from a place of pessimism about the ability to ever extinguish racism from the U.S. social landscape (Bell, 1995b), it is understood that this condition should not diminish the sincere passionate effort devoted to both uncovering and seeking to dismantle racism (Yamamoto, Serrano \& Rodriguez, 2003).

$\underline{\text { Reviewing the Literature on Preservice Teachers of Color in the U.S.: Methods and Findings }}$ To consider how preservice teachers of color are discussed in the U.S. context, I searched the Web of Knowledge and Education Full Text databases using the terms "preservice teachers of color" and "teacher candidates of color" to locate relevant literature. i I selected these databases because they capture a wide range of peer-reviewed scholarship and in the case of the Web of Knowledge, identifies scholarship that is published in highly cited scholarly journals. In addition to my primary search terms, I used different configurations of terms that are typically used to identify specific racial/ethnic groups including "Black and African American preservice teacher(s)/teacher candidate(s)", "Latino, Hispanic, and Mexican American preservice teacher(s)/teacher candidate(s), Native American/indigenous preservice teacher(s)/teacher candidate(s) and Asian American preservice teacher(s)/teacher candidate(s). With regards to the latter category I recognized and remained vigilant to capture the many different ethnic groups that linked with and collapsed under the pan-Asian racial designation, including Pacific Islander and East Indian; Chinese, Vietnamese, Japanese, Filipino and Cambodian. I should point out that in constructing the search in this way, my literature did not necessarily capture research that included teachers of color that might be subsumed with the larger category of "bilingual teacher" or within "bilingual teacher education". Taking into consideration these constraints, my search yielded about 80 articles, of which those devoted to empirical research were mostly qualitative in nature.

In addition to scholarly articles, I also drew from scholarship in recently published handbooks and book length treatments devoted to the study of teacher education including, Studying Teacher Education (Cochran-Smith \& Zeichner, 2005), the Handbook on Teacher Education, third edition (Cochran-Smith, Feiman-Nemser, McIntyre \& Demers, 2008), Preparing Teachers for a Changing World: What Teachers Should Learn and be Able to Do (DarlingHammond \& Bransford, 2011) and Studying Diversity in Teacher Education (Ball \& Tyson, 2011). These texts were selected because they are highly visible and associated with the 
American Educational Research Association (AERA), the largest organization associated with education research. Reading through these materials I took note of the key themes that emerged from the texts. Across much of this work I encountered both single research studies and reviews of existing research on the topic of preservice teachers of color in the U.S. I found considerable consistency across this body of work in terms of the key themes and findings presented. Additionally, much of the peer-reviewed published scholarship that I located was published during the late 1990s and early 2000s.

The goal of my targeted review of the extant scholarship on preservice teachers of color was to identify and call attention to the big themes that resonated across this body of work and to consider what these themes mean in the context of race and teacher preparation. It was not my intention to conduct a comprehensive review of all the extant literature ever published on the topic. My search yielded three predominant themes related to: the recruitment and retention of more preservice teachers of color in teacher preparation programs and in K-12 teaching; the perspectives and voices of preservice teachers of color about teaching, and the experiences teacher candidates of color encounter in teacher preparation programs. In the discussion that follows I explore each of these areas, paying particular attention to how each illuminates the perspectives about and the experiences encountered by preservice teachers of color in teacher education in the U.S.

Recruitment and Retention. The scholarship on preservice teachers of color is replete with calls to recruit and retain more K-12 teachers of color (Achinstein, Ogawa, Sexton \& Freitas, 2010; Guyton, Saxton \& Wesche, 1996; King, 1993; Quiocho \& Rios, 2000; Sleeter \& Milner, 2011). These calls occur both in the context of the ubiquitous "preservice teacher of color" and in the context of a more specified racial/ethnic group classification (e.g., African American, Latino/a, Asian American/Pacific Islander). These arguments move from at least two different perspectives. The first perspective is related to epistemic and ontological concerns that students of color need to see and interact with teachers that come from a similar background. Drawing from a review of literature on African American teachers, King (1993) made the argument for recruiting more African American teachers because of the philosophy they hold about teaching (African American students) that includes: holding high expectations for students learning, expecting that students will develop social responsibility, moral preparedness and an understanding of and ability to deal with racism when it occurs in their lives. Achinstein, et. al (2010) also argued that teachers of color that work in schools with high numbers of students of color from low income backgrounds, make these professional decisions in order to improve the educational opportunities provided to these 
students. Guyton, Saxton and Wesche (1996) acknowledged that across the diverse set of preservice early childhood teachers of color, a strong emphasis was placed on serving as a role model to the children they would eventually teach. All of the African American female preservice teachers of color in the study, along with the only Asian Indian female participant in the study recognized themselves as potential role models for their future students. Yet, for the African American participants, they also viewed themselves as teachers that would act as transformative change agents in the classroom. This was also the case in a study of Mexican American preservice teachers where Téllez (1999) noted that participants viewed themselves as "committed teachers" concerned about "giving something back to their community" (p. 564). Au and Blake (2003) found similar sentiments about serving as a role model to students with two preservice teachers of Hawaiian ancestry in their research. Drawing from a longitudinal case study that examined the professional trajectory of an African American preservice teacher from her preservice training to her first three years of teaching, Agee (2004) reported that teachers went into teaching to serve as a change agent and a role model for African American students. Frank (2003) also found in a study on African American preservice teachers that participants overwhelmingly wanted to teach "to make sure that black kids get a good education" (p. 712). Finally, in their review of teacher education programs that have had success in diversifying their student population, Sleeter and Milner (2011) note that while preservice teachers of color often possess vital cultural knowledge that can be used to bridge connections between teacher and student, this process includes helping candidates acquire the skills and knowledge needed to become effective teachers as well. Drawing from Ball's (2009) notion of generativity, these authors highlight the need for more teachers of color to enter the teaching profession and through their teacher education programs, build upon the knowledge they bring with them to their training. These authors provide powerful examples of how teacher education programs can successfully diversify their student body.

However, recruitment and retention issues are not only approached in the literature from this perspective. The second perspective on recruitment and retention discussed in the literature focuses less on (but is not necessary disconnected from) issues of common culture and compatibility between teachers of color and students of color. Here attention is placed on the reality that in "hard-to-staff, urban schools" (Achinstein, et al., 2010, p. 71) that have high numbers of students from low income and non-dominant racial and cultural communities, higher proportions of teachers of color teach in and persist as teachers at these schools. This reality makes it a strategic necessity to recruit more teachers of color into teacher education 
because they embody "a promising solution to solving the problem of hard-to-staff schools" (Achinstein, et. al, 2010, p. 81).

In light of the existing literature on preservice teachers of color, there is strong consensus that these individuals come into their programs with an awareness of both societal and school inequalities. As a consequence these teacher candidates often express a commitment to improve, through their teaching, both the educational and life opportunities of their future students. In the section that follows I extend from this discussion by outlining what I found in my review of the literature about the perspectives teacher candidates of color have about teaching and the commitments they hold for their future teaching.

Perspectives and Voices. The literature I reviewed also highlighted the positive perspectives and optimism that preservice teachers of color hold about teaching as a profession. While recognizing and sometimes even grappling with the negative status given to K-12 teaching in the larger society, these candidates generally held high regard for teaching (Quiocho \& Rios, 2000; Su, 1997), often discussing how their positive perspectives about teaching were bolstered by valued family and community members. The literature suggested that in the case of African American preservice teachers, they received encouragement from both family members and school-based professionals to "make a substantial difference in their communities" (Quiocho \& Rios, 2000, p. 498) by choosing to teach. Some scholars noted the complex and contradictory relationship some groups of Asian American/Pacific Islander preservice teachers hold towards teaching. For instance, Au and Blake (2003) found that two preservice teachers of Hawaiian ancestry recognized teaching as a way to serve as a role model to the Hawaiian students. Gordon (2000), however, found that while teachers and teaching were revered within these teachers' larger cultural communities, it was also recognized that teaching held a low status position in the U.S. context. As a result, teacher candidates across various Asian groups - including those of Vietnamese, Chinese, Japanese and Korean heritage - received pressure from members in their family and community to not go into teaching (Gordon, 2000; Nguyen, 2008).

It is not surprising that these conditions, coupled with the pervasive assumption that teachers should possess an abnormally high character and intellect, lead to the ambivalent feelings that many Asian American participants in Gordon's (2000) study held about going into teaching. Interestingly, however, some researchers also noted the pervasive racism, isolation and marginalization that Asian American/Pacific Islander preservice teachers encounter in their preparation programs (Nguyen, 2008; Pailliotet, 1997; Sheets \& Chew, 
2002) and thus begs the question of whether teacher education programs even offer an inviting and supportive space for these teachers to learn.

In their review of research on minority teacher candidates, Quiocho and Rios (2000) noted that teachers' personal identities were related to their professional identities and perspectives on teaching. Additional research studies reviewed also supported the perspective that a strong relationship exists between cultural/racial identity and the perspectives teacher candidates hold about teaching (Au \& Blake, 2003; Gomez, Rodriguez \& Agosto, 2008; King, 1993; Nguyen, 2008; Salinas \& Castro, 2010; Téllez, 1999). For instance, Salinas and Castro (2010) reported that the Latino preservice teachers in their study "had personal experiences with discrimination or economic oppression" that informed both their teacher identities and approaches to curriculum decision-making. Frank (2003) similarly noted that while not all of the African American preservice teachers in her study expressed an interest in teaching in an urban school environment, most of the candidates did because they felt they could understood and relate to these students. Additionally, Su (1997) found in a study on minority teacher candidates that of the 58 participants, one-third "demonstrate[d] an awareness of the need for them to challenge the existing curriculum in schools and in the dominant culture in the society, and to develop critical thinking and social reconstruction skills in their students" (pp. 328-329). Interestingly, however, Su (1997) did not address what, if any intra-group differences existed across the racial groups with regards to this finding.

The question of whether diversity in perspectives about teaching exists either within and/or across the different racial groups that comprise "preservice teachers of color", seems particularly important to consider. For instance, across the literature researchers reported different perspectives among teachers of color from different racial groups on their beliefs about teaching and plans for future teaching. Much of the work reviewed recognized African American teacher candidates and Latino candidates as possessing a critical understanding of society and the inequitable conditions students of color face in schools. Much of this literature supported the idea that African Americans and Latino preservice teachers viewed their teaching role as one in which they would operate as an advocate, a role model and/or a change agent.

In the case of Asian American/Pacific Islander preservice teachers there was very little discussion in the literature about their perspectives or experiences on teaching. Of the less than ten articles that I found related specifically to this group (including some that focus on particular ethnic groups falling under the pan-Asian category), it was often noted that these 
preservice teachers recognized teaching as a moral enterprise that commanded high respect. Issues associated with teaching for social justice rarely emerged as either an issue directly explored in the study or as a key finding from the research conducted with preservice teachers from this group.

One of the interesting insights that emerged from the review was the fact that in many cases, teachers of color envisioned themselves (successfully) teaching students from their own racial, ethnic, linguistic or cultural background(s). This was sometimes stated outright or merely implied. For example Téllez (1999) reported that Mexican American teacher candidates felt that "they might, only might be more effective with Mexican-American children" (p. 564, emphasis in the original). Agee (2004) also noted that an African American female teacher that left her teacher preparation program holding a commitment to teach in a critical multicultural way, later felt trepidation when confronted with enacting this teaching with White students. This teacher's fears stemmed from her belief that the White students might view her teaching as biased and self-motivated. She also felt that her teacher education program failed to prepare her to do this work effectively with a diverse student population.

What these fears point to is the lack of preparation that preservice teachers of color feel they receive in their teacher preparation programs about teaching effectively, both students from diverse backgrounds and across multiple school contexts (Quiocho \& Rios, 2000). In the section that follows I probe more deeply into this issue by considering the experiences of preservice teachers of color in teacher education programs in the U.S.

Experiences in Teacher Preparation. The crux of the call for recruiting and retaining more teachers of color rests on the claim that these teachers possess experiences and perspectives that inform their commitment to effectively teach K-12 students of color. However, Téllez (1999) noted the irony that exists alongside this call: teacher preparation programs are not designed to, nor actively seek to engage with the knowledge these candidates possess and consequently fail to prepare them to teach (all students) in a socially just way.

The perspective that preservice teachers of color encounter teacher preparation programs that are marginalizing, isolating and not culturally affirming was strongly supported by the research I reviewed. This literature highlighted the alienating and unsupportive environments that preservice teachers of color across all different races encounter in teacher education. Whether targeted at program curricula, field placements, program faculty and staff, or other students in the program teacher candidates of color report high levels of 
alienation, a disconnection from the larger program community and a sense of not "seeing themselves" in their programs.

For example, Gomez, Rodriguez \& Agosto (2008) reported that a group of Latin@ preservice teachers that attended a predominantly White university and teacher education program experienced low expectations from and cultural mismatch with faculty, staff and their White preservice teacher counterparts. Meacham (2000) also found that two African American teacher candidates felt pressure in their teacher preparation program to disavow cultural aspects of their identities that provided them both support and affirmation.

As pointed out previously, Asian American/Pacific Islander preservice teachers discuss feelings of social isolation and cultural mismatch when reflecting on their teacher education experiences. Nguyen (2008) and Pailliotet (1997) presented research on Asian American preservice teachers - Vietnamese and Vietnamese/Chinese - in which the participants noted feeling alienated and inauthentic while in their preparation programs. In some instances these feelings were related to the cultural disconnect the teacher candidates felt with regards to the coursework and the social environment of their programs. They also felt that the students and parents in their teaching sites viewed them, relative to their White peers, as less authentic teachers. Scholars have noted the concerns with teacher authenticity experienced by practicing Asian immigrant teachers in the U.S. (Subedi, 2008). This work pointed to how specific sociocultural markers associated with the teachers informed if they were viewed as authentic in the larger school and societal contexts. Drawing from their research on Chinese American preservice teachers, Sheets and Chew (2002) expressed how their participants felt that their coursework was designed for White students and not on preparing teachers of color to teach for diversity.

The extent to which preservice teachers of color recognized and named racism as operating in their programs, varied across studies and across preservice teacher groups of color. Guyton et. al (1996) noted that nearly all of the teacher candidates in their study (of which most were people of color) noted instances that they described as either prejudiced or racist occurring during their preparation program. The authors also stated that while the preservice teachers of color in the study "perceived racism to some degree in their fellow students... [t]hey did not perceive racism among faculty but did not believe faculty challenged racist comments" (Guyton, et. al, 1996, p. 650).

The Vietnamese teacher candidates in the study reported by Nguyen (2008) discussed that they were rendered invisible in their programs. Interestingly, one participant did not acknowledge or even consider how racism may have played a role in this context but rather 
justified this treatment on the basis of her own personal physical attributes. The Latino teacher candidates that Gomez et. al (2008) worked with reported having prejudiced and discriminatory experiences. These experiences included having to negotiate between the broad stereotypical assumptions that White cooperating teachers and White preservice teachers expressed about Latinos and the Latino teacher candidates' own behavior in the program. In addition, the researchers noted that the Latino preservice teachers felt pressure to accommodate to White normative behaviors in order to succeed in their program. These behaviors included acting in ways that were culturally unfamiliar, and that felt inauthentic to the participants. These conditions ultimately led the Latino teacher candidates to develop feelings of distrust and alienation towards their teacher education program.

Finally Frank (2003) noted how African American preservice teachers that also attended a predominantly White university and teacher education program experienced racism in their program and courses. These candidates discussed how their fellow White classmates dismissed the continued existence of racism in U.S. society, while also expressing stereotypes about African Americans that the African American preservice teachers felt a responsibility to challenge.

Given the limited number of studies reviewed that specifically addressed the topic of racism, one must take caution in drawing definitive conclusions about how preservice teachers of color broach this subject. However, the existing literature suggests that it should not be presumed that all preservice teachers of color recognize or understand how racism exists, even in the context of their own experiences. Indeed, programs that wish to prepare teachers to teach in critical, socially just ways must take care to prepare all candidatesincluding those of color - to recognize and work actively against racism.

\section{Critical Race Theory in Education, Teacher Education and Teacher Candidates of Color}

What do these findings tell us about preservice teachers of color and teacher preparation? Using a CRT in education framework to examine the previously reviewed scholarship on preservice teachers of color illuminates at least three CRT constructs at work, including: counter-storytelling, Whiteness as property, and interest convergence.

Counter-storytelling. In contrast to images of teacher education as race neutral in their cultural orientation, the literature on preservice teachers of color in mainstream teacher education programs are defined by Whiteness. To this, the preservice teachers of color in the extant literature voice their own counter-stories about the marginalization and lack of 
connection they feel to their programs, including their relationship to faculty, students and curriculum. What makes these stories "counter" is the fact that they offer an image of teacher education as one that is often alienating and ineffective for preservice teachers of color, particularly with regards giving these teachers what they need to develop into socially just teachers. These counterstories also serve to disrupt the dominant and normative culture of Whiteness that is pervasive in teacher education. The counterstories of preservice teachers of color discuss not seeing people that looked like them or that had similar perspectives and experiences; as well as about the burden of having to deflect and defend against deficit, stereotypical beliefs held by many in their programs about people of color.

Whiteness as property. One of the most consistent findings across much of the literature reviewed was the overwhelming culture of Whiteness that pervades preservice teacher education programs. As discussed previously, this culture is most prominently recognized through the voices and counterstories of preservice teachers of color. Whiteness as property refers to the fact that Whiteness occupies a valued space within society and in this case, teacher education programs. Here, Whiteness operates as a form of property by which preservice teachers that possess the experiences, perspectives, knowledge and dispositions aligned with and valued by the dominant White society find reinforcement and success. Those with access to the experiences, knowledge and values aligned with Whiteness, however, not only reap considerable benefits but also define what counts as normal by organizing what counts as valid knowledge and experience, as well as how people and groups are positioned and ultimately addressed. For example teacher candidates of color discuss the marginalization they feel in their programs. They often cite both how their experiential knowledge is not valued in their programs and their struggle to fit in socially with their White peers whom often position them as outsiders. Here, Whiteness matters because it frames, limits and impacts the everyday conditions, practices, knowledge and outcomes of teacher education on preservice teachers.

One outcome of Whiteness as property is the power it has to frame how preservice teachers of color are recognized and ultimately treated in teacher education programs. The existing literature points to how these teacher candidates get essentialized as possessing a commitment to teach for social justice and change and thus need to have more representation in the K-12 teaching force. When enacted in practice, such thinking dangerously generalizes and frames all teachers of color within this discourse and potentially limits the extent to which teacher education programs can enact practices to help develop such commitments in 
all teacher candidates, including those whom are not of color. Indeed, there was some indication from the literature I reviewed that not all preservice teachers of color may enter their program with a desire to teach for these reasons. In some cases, some preservice teachers may not even recognize racism when it is targeted directly at them. Additionally, examples emerged in the literature that pointed to differences between individuals from the same racial background that did not hold the same perspectives about and future plans for teaching [e.g., see Frank (2003) and Au \& Blake (2003) for examples of how preservice teachers from the same racial group differed in where they wanted to teach and in how they viewed themselves as teachers, respectively]. In addition, there is also ample scholarship from the literature on preservice teachers and deficit thinking that some teacher candidates of color hold deficit-oriented perspectives about students and communities of color.

Essentialized assumptions that frame these teachers as already committed to socially just teaching potentially limit the effectiveness of teacher education programs in helping these teachers recognize and challenge these damaging perspectives (Brown, 2010; Cozart, 2010; Fitts, Winstead, Weisman, Flores \& Valenciana, 2008; Fránquiz, del Carmen Salazar \& DeNicolo, 2011). In this example, Whiteness can operate as a blinder by essentializing the identities of teachers of color rather than recognizing them, as individuals and learners who like their White counterparts also need targeted effective teacher training to become socially just teachers.

Another outcome of Whiteness as property in teacher education occurs when teachers of color get enclosed in a frame that defines them as necessary role models for K-12 students of color, but not as potentially effective pedagogues for all students. Scholars have long cautioned against making sweeping generalizations about teachers of color as the abject role model for students with whom the teacher shares race/cultural membership, rather than as thoughtful and critical teachers that take their commitment to becoming an effective teacher seriously and require effective teacher training (Brown 2011, 2009a, 2000b; Irvine, 1989; Sheets, 2004, 2001). In making this point I recognize that historically and in a contemporary context, teachers of color have played an invaluable role in the lives of children and youth of color that are schooled in a society that is punctuated by a system of White supremacy and privilege (Dilworth \& Brown, 2008; Foster, 1997; Perry, Steele \& Hillard, 2003; SiddleWalker, 2001). Yet it is this essentializing racial tokenism discourse (Kelly, 2007) of teachers of color as primarily role models for students of color in teacher education that both entraps these teachers to one specific role (Madsen \& Mabokela, 2000) and helps to mask the actual ways that they might make a pedagogic difference for both $\mathrm{K}-12$ students of color, as 
well for their White counterparts. Additionally, and in the vein of CRT this framing discourse of the teacher of color places the fundamental responsibility for closing the opportunity gap in schools that have high populations of students of color, those from lowincome backgrounds and those whose first language is not English back on these teachers.

The cyclical relationship between individual teachers of color as the savior and rescuer (Popkewitz, 1998) of underachieving K-12 students of color offers insight into the nature of Whiteness and White hegemonic privilege in teaching and teacher education discourses. Moving from the perspective that preservice teachers of color can resolve the pervasive opportunity gap of students of color by virtue of the teachers' shared racial/cultural background with their students, positions the problem as one that is solely local and individualized. It also creates a situation in which the underachievement of student of color in the U.S. is disassociated from the racist practices that have maintained the wholesale denial of social and educational opportunities to these very groups since the founding of this country. In the context of a system defined by Whiteness as property, this splitting relies on what CRT calls, a color-blind ideology that recognizes race (i.e., acknowledgement of the under-acheivement among groups of color), yet disavows its role in maintaining inequitable conditions (Bonilla-Silva, 2006).

Interest convergence. One of the most consistent discourses across the literature reviewed in this paper argues the need to train more teachers of color for K-12 teaching. Much of this literature points out that teachers of color often come to their programs possessing experiential knowledge about societal inequities, including the inequitable nature of K-12 schooling. Their desire to teach is not simply a personal choice, but one that is informed by larger sociocultural factors associated with societal conditions and shared community/familial knowledge about the value of teaching. This commitment, along with the notable disparity between the number of White teachers and those of color in K-12 schools, the ongoing opportunity gap that exists between White students and students of color in K-12 schools and the assumption that teachers of color can serve as effective role models for K-12 students of color, supports the argument that more teachers of color are needed. This translates into the popular rhetoric found in many teacher education programs around the need to recruit more teacher candidates of color.

However, taking a closer look at this argument illuminates a key concern that aligns with the CRT construct of interest convergence. As pointed out in the opening of this paper, interest convergence refers to the institutional practice of implementing strategies for 
addressing racial inequities that specifically serve and maintain dominant White interests. For example, regardless of the desire to recruit and retain more teachers of color into teacher education programs, these programs exist in a normative culture of Whiteness that the extant literature suggests is not responsive to the actual needs of these teacher candidates.

Diversifying programs serves as a goal but begs the question: Who actually benefits from having teachers color in preservice teacher education programs? Does this call for bringing in more preservice teachers of color simply provide more experiences for White preservice teachers to interact with peers that may come from different racial backgrounds and have diverse experiences than their own? Does the call also provide a way to place the responsibility for closing the opportunity gap found between many K-12 students of color and their White counterparts back on teachers of color?

Indeed, while the calls for recruiting more preservice teachers of color are wellfounded, they exist in and help to maintain a system of interest-convergence wherein teacher education programs can potentially boast about efforts to bring in more teacher candidates of color while simultaneously not transforming the kinds of normative culture, knowledge and experiences that are valued, maintained and offered to these individuals.

\section{Implications on Teacher Education}

This review highlights the racial landscape surrounding teacher education programs for preservice teachers of color. The literature presents the challenges these teacher candidates encounter when navigating their preservice teacher training programs. These challenges include encountering programs mired in a normalized, White culture that fails to align with, include or support the experiential knowledge teachers of color bring with them while also neglecting to provide the knowledge and experiences needed to challenge and adequately prepare teachers color to become effective teachers of social justice. Another shortcoming highlighted in the literature is the fact that teachers of color are often discussed as possessing a similar critical stance in their reason for becoming teachers in the first place. This type of essentializing masks the diversity that likely exists both within and across preservice teachers of color with regards to reasons for becoming a teacher and the perspectives held about teaching and students. This myopic reading limits how teacher educators might more effectively respond to the needs of these teacher candidates.

These concerns are particularly palpable when considering the emphasis contemporary extant literature places on the need to prepare all teachers, including those of color to teach in 
socially just and culturally responsive, relevant ways (Banks, et. al, 2005; Gay, 2000; Hollins \& Guzman, 2005; Ladson-Billings, 2001; 2009[1994]; Villegas \& Davis, 2008). In the most recently published second edition Handbook of Teaching and Teacher Education (CochranSmith, Feiman-Nemser, McIntyre \& Demers, 2008), Villegas \& Davis (2008) note that teachers of color do not come into teacher education program intuitively possessing the requisite knowledge to teach in culturally responsive ways. This is important, particularly in light of the findings from the literature review that suggest some teacher candidates of color also fail to understand and recognize the existence of racism. Developing teachers that both hold a pedagogic commitment and understand how to effectively enact such socially just and relevant teaching in the classroom takes deliberate, targeted training. In some cases, this training may require expanding how teacher education programs and faculty approaches this work, particularly if the goal is to diversify the K-12 teaching force by recruiting more teachers of color.

If teacher education programs want to take seriously the call for recruiting more teachers of color, this goal must be grounded in the fact that teachers of color need quality teacher education training that fully addresses the contextual needs of its participants. This requires first recognizing that teacher training does not occur in a race-neutral context. Race must be acknowledged and critically addressed if teachers of color are to truly operate in a space of equity within teacher education. Second, teachers of color must be recognized as both individuals and members of historic groups that likely possess knowledge and experiences that are different from but complementary to those found in the dominant society. And third, programs must take care not to essentialize preservice teachers of color but recognize that all teachers — regardless of their background or race-require appropriate and relevant teacher training if they are to acquire the skills, knowledge and dispositions needed to become teachers committed to relevant, responsive and socially just teaching.

\section{References}

Achinstein, B., Ogawa, R. T., Sexton, D. \& Freitas, C. (2010). Retaining teachers of color: A pressing problem and a potential strategy for "hard-to-staff" schools. Review of Educational Research, 80(1), 71-107.

Agee, J. (2004). Negotiating a teaching identity: An African American teacher's struggle to teach in test-driven contexts. Teachers College Record, 106(4), 747-774.

$\mathrm{Au}, \mathrm{K}$. H. \& Blake, K. M. (2003). Cultural identity and learning to teach in a diverse community:

Findings from a collective case study. Journal of Teacher Education, 54(3), 192-205. Ball, A. (2009). Toward a theory of generative change in culturally and linguistically complex 
classrooms. American Educational Research Association, 46(1), 45-72.

Ball, A. F. \& Tyson, C. A. (Eds.). (2011). Studying diversity in teacher education.

American

Educational Research Association/Rowman Littlefield: Washington DC/Lanham, MD.

Banks, J., Cochran-Smith, M., Moll, L., Richert, A., Zeichner, K., LePage, P., Darling-

Hammond, L., and Duffy, H. (2005). Teaching Diverse Learners. In L. Darling-Hammond and J. Bransford (Eds.), Preparing teachers for a changing world: What teachers should learn and be able to do. (pp. 232-274). San Francisco: Jossey-Bass.

Bell, D. A. (1995a). Brown V. Board of Education and the interest convergence dilemma. In $\mathrm{K}$.

Crenshaw, N. Gotanda, G. Peller \& K. Thomas (Eds.), Critical race theory: The key writings that formed the movement (pp. 20-29). New York: The New Press.

Bonilla-Silva, E. (2006). Racism without racists: Color-blind racism and the persistence of racial inequality in the U.S. Lanham, MD: Rowman and Littlefield.

Brown. A.L. (2009a). "Brothas gonna work it out:" Understanding the pedagogic

performance

of African American male teachers working with African American male students. The

Urban Review, 41 (5), 416-435.

Brown, A.L. (2009b). "O brotha where art thou?" Examining the ideological discourses of

African American Male teachers working with African American male students. Race

Ethnicity \& Education, 12 (4), 473-493.

Brown, A.L. (2011). Pedagogies of experience: A case of the African American male teacher. Teaching Education, 22 (4), 363-376.

Brown, A.L. (2012) On human kinds and role models: A critical discussion about the

African

American male teacher. Educational Studies, 48(3), 296-315.

Brown, A. L. \& Brown, K. D. (2010). Strange fruit indeed: Interrogating contemporary textbook

representations of racial violence towards African Americans. Teachers College Record, 112(1), 31-67.

Brown, K. D. (2010). Is this what we want them to say? Examining the tensions in what U.S.

preservice teachers say about risk and academic achievement. Teaching and Teacher Education, 26, 1077-1087.

Brown, K. D. (2011). Elevating the role of race in ethnographic research: Navigating race relations in the field. Ethnography and Education, 6(1), 97-111.

Brown, K. D. (2012). Trouble on my mind: Toward a framework of humanizing critical sociocultural knowledge for teaching and teacher education. Race Ethnicity and Education, $1-23$.

Buras, K. (2011). Race, charter schools, and conscious capitalism: On the spatial politics of whiteness as property (and the unconscionable assault on Black New Orleans). Harvard Educational Review, 81(2), 296-330.

Chapman, T. (2011). A critical race theory analysis of past and present institutional processes

and policies in teacher education. In A. S. Ball \& C. A. Tyson (Eds), Studying diversity in teacher education. (pp. 237-256). American Educational Research Association/Rowman Littlefield: Washington DC/Lanham, MD.

Cochran-Smith, M. (2010). Toward a theory of teacher education for social justice. In A. Hargreaves, A. Lieberman, M. Fullan, \& D. Hopkins, (Eds.), The International Handbook of Educational Change. (pp. 445-467). ( $2^{\text {nd }}$ edition). Dordrecht, England: Springer. 
Cochran-Smith, M. \& Zeichner, K. M. (Eds.). (2005). Studying teacher education: The report of

the AERA panel on research and teacher education. Washington DC: American Educational Research Association/Mahwah, NJ: Lawrence Erlbaum.

Cozart, S. C. (2010). Becoming whole: A letter to a young, miseducated Black teacher.

Urban

Review, 42, 22-38.

Crenshaw, K., Gotanda, N., Peller, G. \& Thomas, K. (Eds.). (1995). Critical race theory:

The key

writings that formed the movement. New York: The New Press.

Darling-Hammond, L. \& Bransford, J. (Eds.). Preparing teachers for a changing world: What

teachers should learn and be able to Do. San Francisco: Jossey Bass.

Dilworth, M. E. \& Brown, A. L. (2008). Teachers of color: Quality and effective teachers one way

or another. In M. Cochran-Smith, S. Feiman-Nemser, D. J. McIntyre \& Kelly E. Demers

(Eds.), Handbook of Research on teacher education. (Third Edition). (424-444). New York:

Routledge, Taylor \& Francis Group and the Association of Teacher Educators.

Dixson, A. D. \& Rousseau, C. (2006). Critical Race Theory in Education: All God's children got

a song. New York, NY: Routledge.

Donnor, J. (2005). African-American football student athletes in major college sports. Race Ethnicity and Education, 8(1), 45-67.

Duncan, A. (2010, November 16). Speech given to the National Council for Accreditation of Teacher Education.

Fitts, S., Winstead, L., Weisman, E. M., Flores, S. Y. \& Valenciana, C. (2008). Coming to voice:

Preparing bilingual-bicultural teachers for social justice. Equity \& Excellence in Education, 41(3), 357-371.

Foster, M. (1997). Black teachers on teaching. New York: New Press.

Frank, A. M. (2003). If they come, we should listen: African American education majors' perceptions of a predominantly white university experience. Teaching and Teacher

Education, 19(7), 697-717.

Fránquiz, M. E., del Carmen Salazar, M. \& DeNicolo, C. P. (2011). Challenging majoritarian tales:

Portraits of Bilingual teachers deconstructing deficit views of bilingual learners. Bilingual

Research Journal, 34(3), 279-300.

Frankenberg, R. (1993). The social construction of whiteness: White women, race matters.

Minneapolis, MN: University of Minnesota.

Gay, G. (2000). Culturally responsive teaching: Theory, research, \& practice. New York:

Teachers College Press.

Gomez, M. L., Rodriguez, T. L. \& Agosto, V. (2008). Who are Latino prospective teachers and

what do they bring to U.S. schools? Race Ethnicity and Education, 11(3), 267-283.

Gordon, J. A. (2000). Asian American resistance to selecting teaching as a career: The

Power of

community and tradition. Teachers College Record, 102(1), 173-196.

Guyton, E., Saxton, R. \& Wesche, M. (1996). Experiences of diverse students in teacher education. Teaching and Teacher Education, 12(6), 643-652.

Harris, C. I. (1993). Whiteness as property. Harvard Law Review, 106(8), 1710-1791. 
Hollins, E. \& Torres-Guzman, M. (2005). Research on preparing teachers for diverse populations. In M. Cochran-Smith \& K. M. Zeichner (Eds.), Studying teacher education: The report of the AERA panel on research and teacher education. (pp. 477-548).

Washington DC: American Educational Research Association/Mahwah, NJ: Lawrence Erlbaum.

Irvine, J. J. (1989). Beyond role models: An examination of cultural influences on the pedagogical perspectives of black teachers. Peabody Journal of Education, 66(4), 51-63. Irvine, J. J. (2003). Educating teachers for diversity: Seeing with a cultural eye. New York: Teachers College Press.

Kelly, H. (2007). Racial tokenism in the school workplace: An exploratory of black teachers in

overwhelmingly white schools. Educational Studies, 41(3), 230-254.

King, S. H. (1993). The limited presence of African-American teachers. Review of Educational

Research, 63(2), 115-149.

Ladson-Billings, G. J. (1999). Preparing teachers for diverse student populations: A critical race

theory perspective. Review of Research in Education, 24, 211-247.

Ladson-Billings, G. (2001). Crossing over to Canaan: The journey of new teachers in diverse

classrooms. New York: John Wiley.

Ladson-Billings, G. (2006). From the achievement gap to the education debt: Understanding achievement in U.S. schools. Educational Researcher, 35(7), 3-12.

Ladson-Billings, G. (2009[1994]). The dreamkeepers. (second edition). San Francisco:

Jossey

Bass.

Ladson-Billings, G. \& Tate, W. (1995). Toward a critical race theory of education. Teachers College Record, 97(1), 47-68.

Leonardo, Z. (2004). The color of supremacy: Beyond the discourse of "white privilege".

Educational Philosophy and Theory, 36(2), 137-152.

Madsen, J. \& Mabokela, R. O. (2000). Organizational culture and its impact on African

American teachers. American Educational Research Journal, 37(4), 849-876.

Meacham, S. J. (2000). Black self-love, language, and the teacher education dilemma: The cultural denial and cultural limbo of African American preservice teachers. Urban

Education, 34(5), 571-596.

Montecinos, C. (2004). Paradoxes in multicultural teacher education research: Students of color positioned as objects while ignored as subjects. International Journal of Qualitative Studies in Education, 17(2), 167-181.

Nguyen, H. T. (2008). Conceptions of teaching by five Vietnamese American preservice teachers. Journal of Language, Identity \& Education, 7(2), 113-136.

Pailliotet, A. W. (1997). "I'm really quiet": A case student of an Asian, language minority preservice teacher's experiences. Teaching and Teacher Education, 13(7), 675-690.

Perry, T., Steele, C. \& Hilliard, A. (2003). Young, gifted and black: Promoting high achievement

among African American students. Beacon: Boston.

Popkewitz, T. S. (1998). Struggling for the soul: The politics of schooling and the

Construction of

the Teacher. New York: Teachers College.

Quiocho, A. \& Rios, F. (2000). The power of their presence: Minority group teachers and schooling. Review of Educational Research, 70(4), 485-528. 
Salinas, C. \& Castro, A. J. (2011). Disrupting the official curriculum: Cultural biography and the

curriculum decision making of Latino preservice teachers. Theory and Research in Social Education, 38(3), 428-463.

Sheets, R. H. (2001). Trends in the scholarship on teachers of color for diverse populations: Implications for multicultural education, Equity and Excellence in Education, 34(1), 26-31. Sheets, R. H. (2004). Preparation and development of teachers of color. International Journal of Qualitative Studies in Education, 17(2), 163-166.

Sheets, R. H. \& Chew, L. (2002). Absent from the research, present in our classrooms: Preparing

culturally responsive Chinese American teachers. Journal of Teacher Education, 53(2), 127141.

Siddle Walker, V. (2001). African American teaching in the south: 1940-1960. American Educational Research Journal, 38(4), 751-779.

Sleeter, C. E. (2001). Preparing teachers for culturally diverse schools: The overwhelming presence of Whiteness. Journal of Teacher Education, 52(2), 94-106.

Sleeter, C. E. \& Milner, H. R. (2011). Researching successful efforts in teacher education to diversify teachers. In A. S. Ball \& C. A. Tyson (Eds), Studying diversity in teacher education. (pp. 81-104). American Educational Research Association/Rowman Littlefield: Washington DC/Lanham, MD.

Solórzano, D. G. (1997). Images and words that wound: Critical race theory, racial stereotyping and teacher education. Teacher Education Quarterly, 24, 5-19.

Solórzano, D. G. \& Yosso, T. J. (2001). Critical race and LatCrit theory and method: Counter-

storytelling. International Journal of Qualitative Studies in Education, 14, 471-495. $\mathrm{Su}, \mathrm{Z}$. (1997). Teaching as a profession and as a career: Minority candidates' perspectives. Teaching and Teacher Education, 13(3), 325-340.

Subedi, B. (2008). Contesting racialization: Asian immigrant teachers' critiques and claims of

teacher authenticity. Race Ethnicity and Education, 11(1), 57-70.

Téllez, K. (1999). Mexican-American preservice teachers and the intransigency of the elementary school curriculum. Teaching and Teacher Education, 15, 555-570.

Vasquez Heilig, J., Brown, K. D., \& Brown, A. L. (2012). The illusion of inclusion: A critical race

theory textual analysis of race and standards. Harvard Educational Review, 82(3), 403424.

Vaught, S. E. \& Castagno, A. E. (2008). “I don't think I'm a racist”: Critical race theory, teacher

attitudes, and structural racism. Race Ethnicity and Education, 11(2), 95-113.

Villegas, A. M. \& Davis, D. E. (2008). Preparing teachers of color to confront racial/ethnic disparities in educational outcomes. In M. Cochran-Smith, S. Feiman-Nemser, D. J. McIntyre \& Kelly E. Demers (Eds.), Handbook of Research on teacher education. (Third Edition). (583-605). New York: Routledge, Taylor \& Francis Group and the Association of Teacher Educators.

Villegas, A. M. \& Lucas, T. (2002). Educating culturally responsive teachers: A coherent approach. Albany, NY.

Yamamoto, E., Serrano, S. K. and Rodriguez, M. N. (2003). American racial justice on trial-again: African American reparations, human rights and the war on terror. Michigan Law Review, 101, 1269-1337. 


\footnotetext{
i Please note that throughout my review and discussion, I used the terms "preservice teacher" and "teacher candidate" interchangeably.
}

4. Tales from the Playing Field: Black and Minority Ethnic students' experiences of Physical Education Teacher Education

\author{
A. Flintoff \\ Diversity, Equity and Inclusion Research Centre, Carnegie Faculty, Leeds Metropolitan \\ University, Leeds, England
}

Resubmitted version: $15^{\text {th }}$ March 2013

\begin{abstract}
:
This paper presents findings from recent research exploring black and minority ethnic (BME) students' experiences of Physical Education teacher education (PETE) in England (Flintoff, 2008). Despite policy initiatives to increase the ethnic diversity of teacher education cohorts, BME students are under-represented in PETE, making up just $2.94 \%$ of the $2007 / 8$ national cohort, the year in which this research was conducted. Drawing on in-depth interviews and questionnaires with twenty five BME students in PETE, the study sought to contribute to our limited knowledge and understanding of racial and ethnic difference in PE, and to show how 'race', ethnicity and gender are interwoven in individuals' embodied, everyday experiences of learning how to teach. In the paper, two narratives in the form of fictional stories are used to present the findings. I suggest that narratives can be useful for engaging with the experiences of those previously silenced or ignored within PE; they are also designed to provoke an emotional as well as an intellectual response in the reader. Given that teacher education is a place where we should be engaging students, emotionally and politically, to think deeply about teaching, education and social justice and their place within these, I suggest that such stories of difference might have a useful place within a critical PETE pedagogy.
\end{abstract}

Keywords: 'race' gender, intersectionality, physical education teacher education, narrative, Corresponding author: $\underline{\text { a.flintoff@ leedsmet.ac.uk }}$ 


\section{Tales from the Playing Field:}

\section{Black and Minority Ethnic Students' experiences of Physical Education Teacher Education}

\section{Introduction}

This paper presents findings from recent research exploring black and minority ethnic (BME) students' experiences of Physical Education teacher education (PETE) in England (Flintoff, 2008). In doing so, it has two aims; firstly, to contribute to our limited knowledge and understanding of racial and ethnic difference in Physical Education (PE) (Harrison and Belcher, 2006). Drawing on in-depth interviews and questionnaires with twenty five BME students in PETE, the study sought to move beyond an additive model of difference and show how 'race', ethnicity and gender are interwoven in individuals' embodied, everyday experiences in learning how to teach. Taking an intersectional approach it explored the shifting and diverse nature of social identities and power relations in students' experiences of PETE.

Secondly, the paper explores the use of narrative inquiry to write and present research findings, and as one way in which physical educationalists might be engaged to critically reflect on their practice in relation to racial discrimination and inequality. Dominant 'storylines' of 'race' and ethnicity revolve around what Pheonix (2009) and others, has called the 'normalised absence/pathologised presence' couplet. The two fictional narratives included here aim to present a different storyline. This storyline foregrounds heterogeneity of experience, agency, and negotiation in relation to power relations, as central to the experiences of becoming a teacher of PE.

\section{The research and policy context}

The research was set within a wider policy agenda concerned with increasing the diversity of teacher education cohorts. It extends other studies that have addressed BME students' and teachers' experiences of schooling, and career progression, by taking a particular focus on the subject specific context of PETE (e.g. Basit and McNamara 2004; Basit, et al, 2006;

Carrington, et al, 2001; Wilkins and Lall, 2011). Whilst recognising the limitations of ethnic monitoring (not least how 'ethnicity' is categorised to produce 'groups' and 'labels' such as 'BME' - the term most commonly used in the UK, see Bonnett and Carrington, 2000), the 
statistics nevertheless do show a significant and enduring 'race' gap between the numbers of BME students opting into teaching across all subject areas (at 11\%), and those opting specifically for PETE, a much lower figure - just 2.94\% (Turner, 2007). PETE as a specific teacher education context in England is overwhelmingly white, a situation that has shifted little over the last decade or so, and that is mirrored elsewhere in Western countries (e.g. Douglas and Halas, 2011).

The Training and Development Agency (TDA) (the government body responsible for teacher education, now the National College for Teaching and Leadership) require institutions to monitor, report and use actual ethnic recruitment figures as a first step to changing and improving practice ${ }^{\mathrm{i}}$. The impetus for our research emerged from a professional development seminar for PETE lecturers in 2007 that focused on analyzing the ethnic monitoring data for PETE (Turner, 2007). By the end of the day, a strong rationale emerged to explore BME students' experiences of PETE, to build on and supplement the picture presented through the monitoring statistics. As Gilborn and Mirza (2000) noted, whilst statistical analyses of distribution are useful for describing and highlighting patterns of inequality and point to the need for action, they are not explanatory, and as such open up the possibility of specific groups becoming 'labeled' as under-achievers, or as 'problems' for their low participation, as measured as deficit against a so-called 'norm' or 'target'. Whilst patterns of differences between the groups can be highlighted (in this case between what the TDA called 'majority' (white) students and BME students), this is at the expense of suppressing those within groups. The danger is that BME students are considered (and indeed constructed) as a homogeneous group, and different from white students. Our research aimed to provide rich, in-depth, insights into the heterogeneous experiences of BME students in PETE, including how processes of racialisation and gendering impacted upon, and were negotiated within, their experiences of becoming a teacher.

The participants in the study were twenty five, self identified, BME students or recent graduates drawn from across five English universities offering PETE courses. Given that the national figures of BME students in PETE in 2007/8, the year of the study, was just 65, we were pleased with the response to our invitation to join the research. We used anonymous questionnaires, followed by individual, in-depth interviews conducted by a member of the research team at the participant's own university. Interviews lasted between one to two hours, and were taped with the participants' consent. Space prevents a full analysis here of some of 
the significant methodological issues raised by the study - not least the theoretical and methodological challenges of operationalising concepts of 'race' and ethnicity; the practical issues and dilemmas involved in recruiting participants for the study; the difficulties of 'talking race' personally and professionally, and challenges of representing the experiences of 'others'. These are explored in full elsewhere (Flintoff and Webb, 2011).

\section{Researching difference - 'race' as the missing 'lens'}

Flintoff, Fitzgerald and Scraton (2008) have recently mapped the ways in which difference has been explored and researched in PE. Difference and inequality, they argue, has never been a major concern of practitioners and scholars in PE, reflecting the dominance of biobehavioural theories of the body over the social sciences within school, university, and teacher preparation courses (Dowling, 2008; Flintoff, 1993a). In addition, because PE has been seen as marginal to the broader concerns of schooling, it has often been omitted from wider, critical debates of schooling and education. In assessing the developing contribution of this work, Flintoff et al (2008) argue that research in PE has an important contribution to make to wider debates in education around difference, embodiment, identity and power. For example, men and women teachers' bodies have been seen as gendered 'tools of their trade' (Webb and Macdonald, 2007). However it is only in the related area of sport that racial stereotyping based on embodied difference has been highlighted (e.g. Hylton, 2008; Long, et al, 2009). And as Scraton (2001) argues, all too often, accounts of gender have assumed all women to be white, and 'race', if it has been a focus at all in research in PE and sport, has largely been taken to be a black male issue.

Flintoff, et al (2008) also highlight that existing research in PE has largely ignored particular differences (such as 'race') (but see Azzarito, 2009; Benn, 2002; Benn and Dagkas, 2006; Oliver and Lalik, 2004; Macdondald, et al, 2009; Nelson, et al, 2010; Wright, et al, 2003), and tends to underplay the interrelations between forms of social difference such as class, gender and disability. In this way, PE could be characterised as being 'one step behind' the wider critical debates in education that have addressed the complexity of differences and individuals' multiple identities (e.g. Archer, Hutchings, \& Leathwood, 2001; Mac An Ghail, 1994), or centred black educational experiences (e.g. Mirza, 2009; Mac An Ghail, 1988;

Swain, 2003). 
A number of scholars have recently begun to respond to these limitations; the work of Benn and Dagkas (Benn, 2002; Dagkas and Benn, (2006), Macdonald, et al (2008) and Knez (2007), for example, has made important contributions. These authors adopt a theoretical lens that places 'race', ethnicity and religion at the centre of their studies and identify western and masculine definitions of sport, and racism and Islamophobia as major issues. In addition, a small number of studies have also sought to explore the intersections of 'race' and ethnicity in boys' experiences of PE (e.g. Bramham, 2007; Fleming, 2001), highlighting the complex nature of different masculinities and their reproduction and negotiation within PE settings. These studies aside, the marginalisation of issues of 'race' and ethnicity is particularly apparent in PE research (Harrison and Belcher, 2006), and specifically in relation to research on PETE (including my own earlier work). Whilst a developing body of work has highlighted the significance of gender and sexuality for PETE (e.g. Flintoff, 1993a; b; 1994; Brown and Rich, 2002; Dowling, 2006; 2008; Rich, 2001; Sparkes et al, 2007; Sirna, et al, 2010) these studies have tended to adopt what Penney (2002) has called a 'single issue' approach - where gender has been fore-grounded as the focus, but with little recognition or analysis of the intersection of gender with other relations of power, particularly 'race'. As Penney (2002) concludes, these limitations reflect the intellectual and personal biographies of white researchers in PE, who have the power to determine which differences are viewed as noteworthy and get researched, and which get ignored. Our research therefore addresses a number of gaps in our understandings around the racialised and gendered nature of experiences in PETE, as well as contributing to on-going debates around embodiment and identity.

\section{Theorising race, ethnicity and gender - an intersectional approach}

Although the impact of black ${ }^{\mathrm{ii}}$ feminism on PE research has been minimal, elsewhere it has a long history of challenging assumptions around both the homogeneity of women's experiences, and the universalizing of black women's experiences (e.g. Brah, 1996; Carby, 1982; Hill Collins, 1991; Mirza, 1997; 2009; Mirza and Joseph, 2012). The recent 'flurry' of accounts examining intersectionality from a range of positions (for example, as a concept, or 'buzzword', or analytical framework - see Davies, 2009; Pheonix, 2006; Yuval Davies, 2006), are, as Anthias (2012:4) rightly points out, based on ideas that are not new. Intersectionality is 'essentially a heuristic device for understanding boundaries and hierarchies of social life'. Dominant discourses of 'race' and ethnicity have served to 
reproduce such boundaries and hierarchies through the couplet of 'normalized absence/pathologised presence' (Pheonix, 2009). For example, in PE and sport, essentialising discourses of ethnic difference have been used to explain South Asian or girls' under-representation in participation figures in England. Their absence has been normalized as a result of the 'problem' of their culture or religion (e.g. Carroll and Hollinshead, 1993), or as the result of low self-esteem, or motivation (e.g. Shropshire and Carroll, 1997).

Conversely the over-representation of (usually male) black athletes has been explained away by reference to a racialised discourse what constructs their talent as 'natural' and biological (Long, et al, 1997; 2009; Massao and Fasting, 2010). It is through exploring the heterogeneous, embodied, experiences of BME girls and women that black feminists have challenged these essentialised and homogenized discourses, where racial and ethnic difference is constructed as 'deficit' or 'Other'. Such critical accounts move beyond additive models of difference and static conceptions of identity, and show how 'race', ethnicity and gender are interwoven in individuals' embodied, everyday experiences and lives (e.g. Bhopal and Preston, 2011). However, Mirza (2009) warns of the dangers of privileging experience when constructing a theoretical and methodological framework:

Appeals to experience risk obscuring regimes of power by naturalising some experiences as normative and others as not, leaving the processes that structure dominance intact....Experience, as revealed by black and ethnicised female narrative voices in school ethnographies, research interviews, oral histories .....demonstrates the way in which regulatory, discursive power and privilege are 'performed' or exercised in the everyday material world of the socially constructed 'black woman' (Mirza, 2009, p.3).

Individual experiences need to be mapped back onto, and illuminate, the workings of broader, social structures and relations. Studies such as Scraton, Caudwell and Holland (2005), Kay (2006) and Ratna (2008) for example, adopt such an approach, exploring shifting social identities and power relations in their analysis of women's experiences of sport. For example, Scraton, Caudwell and Holland's study revealed black women's experiences in football (soccer) to be diverse and nuanced, yet at times, reflected common experiences of racialised social relations. Whilst some of their experiences were similar to those of white women's in football, they also shared experiences of racism similar to those of black male footballers. The authors therefore argue that by centralising and exploring the differentiated and heterogeneous lived experiences of women, the complex and shifting, rather than stable 
and given, nature of identities can be identified. They conclude that ethnic identity is therefore best seen as a dynamic, embodied and relational process, only meaningful when contextualized alongside gender, sexuality, class, and age.

Research needs to explore identities as 'situated accomplishments' (Valentine, 2007) in relation to material and discursive structures of inequalities. Similarly, it is important to locate any research about race, ethnicity and religion with the broader social, political and historical contexts of (in this case) 'multicultural' Britain, as well as within global discourses of, for example, Islamophobia. The terrorist attacks of September 2001 in the USA, and the $7^{\text {th }}$ July 2005 bombings in London have resulted in an increase in Islamophobia (Cole, 2009). As a result, there has been increasing recognition of, and more sustained focus on, religion and how this is interwoven with culture, ethnicity, nationality and gender in the experiences and lives of Muslim pupils and teachers (e.g. Benn and Dakas, 2006; Knez, 2007; Kay 2006; Walseth, 2006).

Informed by theoretical insights from a range of perspectives such as these, from black feminism and elsewhere, I have found the analytical framework proposed by Anthias (2001; 2008; 2012) useful in exploring BME students' experiences of PETE (see Flintoff, 2012) ${ }^{\mathrm{iii}}$. Anthias argues that 'race' and ethnicity as social divisions are produced through the twin processes of differentiation (and identification) and positionality. In order to explore how these operate, she argues that analysis needs to focus on four different 'societal arenas', or foci: the experiential, inter-subjective, organizational and the representational, each of which are interlinked. The experiential level would be interested in the experiences of BME students, within specific locations, of being defined as 'different' (e.g. to what extent do BME students feel a sense of belonging or not in PETE and how this might differ across different spaces or times); the inter-subjective level would be interested in the actions and practices that take place in relation to others (e.g. how do white students and staff interact with BME students and vice versa?); the organizational level is interested in the institutions' frameworks for the organisation of ethnic groups and resource allocation (e.g. how is ethnic diversity visible (or not) in the everyday practices and policies of PETE); and the representational - the symbolic and representational means, the images and language/texts circulating in these spaces (e.g. what kinds of discourses circulate about BME pupils/groups in PE?). By focusing on the processes of differentiation and positionality, rather than static identity categories, she argues that the framework can account for difference at the level of 
the individual experience and patterns of inequalities. Such an analysis allows for a conception of agency on the part of individuals: identities and relations are not fixed and immutable, but shifting, fluid and specific in time and place. In relation to intersectionality, and specifically this research reported here, the challenge is to explore how it is that 'race' takes on gendered or classed inflections for specific people in specific places and times within the arenas of organisation, representation, inter-subjectivity and experience (Anthias, 2012).

\section{Writing to make a difference}

In presenting some of the study's findings here, I address Smart's (2009) call to consider innovative and engaging ways of doing, and particularly, writing sociological research. She calls for us to take more risks in our work in order to give more of a voice to the lives and experiences of our participants. And whilst she recognises that we are increasingly using different kinds of methods in order to try to do this, she is also concerned about how we write our research, and what difference it makes. For example, she argues that too much of our work has been 'tidied up' in the process of writing up, so that emotions and feelings - such an important part of participants' experiences - are written out. We have a responsibility to our participants, but also to our readers, to capture their imagination and sentiments, as well as to simply convey knowledge.

As a PETE educator, engaging readers - in this case, student teachers - is an everyday challenge. How do I engage students in critical reflection about issues of equity and social justice in ways that help them become better teachers when the sessions they really seem to value are those on the soccer field, or in the gym, rather than my sociological classroom? (Flintoff, 1993a; Dowling, 2011; Flintoff and Fitzgerald, 2012). I have lost count of the number of times when the response has been - 'too long', or 'not relevant to teaching PE'after asking students to share their initial responses to a seminar reading I have selected with care. Their reading often fails to engage them in any meaningful way. They constructs gaps between 'theoretical' work - done in a classroom and, in their minds, a long way from the 'realities' of teaching PE - and the 'real work' of becoming a PE teacher, the practical activity sessions, where they learn really useful 'knowledge' about how to teach hockey, or soccer and so on. How, then, can we help students make the link between their individual practices as teachers, and power relations and inequalities? 
Narrative analysis has been suggested as one means that writers might better engage, interest and really move readers, for example, through the use of stories (Richardson and Adams St Pierre, 2005) or counter-storytelling (Solorzano and Yosso, 2002). Although arguably still far from established in PE and sport studies, there is now a range of work that has employed narrative inquiry methods such as poetic representations; auto-ethnography and fictional ethnography to construct and write research differently (e.g. Dowling, 2001; Dowling, Fitzgerald and Flintoff, 2012; Douglas and Carless, 2009; Hickey and Fitzclarence, 1999: Sparkes, 1997; Smith and Sparkes, 2004). In choosing to write and present their research in these different ways, the authors seek a different kind of response from the reader to that created by the realist or scientific tale (Sparkes, 2002). Facts, events, identities, experiences are rearranged into stories that set out to evoke an emotional as well as an intellectual response, and are judged accordingly. In this way, narratives are presented as useful ways in which individuals can be 'touched by' the issues at stake. The use of narrative has also been suggested as being particularly beneficial for addressing sensitive and/or 'taboo' issues (Douglas and Carless, 2009; Carless, 2011), or those previously silenced or ignored in PE and sport. Given the challenge of engaging white teacher education candidates in critical reflection on 'race' and racism (e.g. see Gaine, 2001; Housee, 2012; Lander, 2011; Solomon, et al, 2005), narrative methods might have a place. However, whilst relatively new to scholars in PE and sport, it is important not to forget that such narrative inquiry has a long history in feminist research (Chase, 2005). Black women have long used stories to highlight the painful experiences of racism, colonialism and sexism (e.g. Mirza, 2009; Bhattacharyya, 1997; Phoenix, 2009) - even if white feminists have not always acknowledged or heard these. Counter storytelling has also been proposed as a tool to help with 'exposing, analyzing and challenging majoritarian stories of racial privilege' (Solorzano and Yosso, 2002; 32).

There are multiple definitions of narrative inquiry and what it means to analyze narrative accounts (see Dowling, 2012). Here I have adopted the role of the 'storyteller' (Polkinghorne, 1995), and use data drawn from across all of the 25 interviews with the insights from the theoretical framework outlined above, to construct two fictional stories. Their aim is to provide interesting and explanatory tales about the processes of racialisation and gendering in PETE. As Dowling (2012, drawing on Smith and Sparkes, 2008; 21) suggests, such explanatory stories 'do the work of analyzing and theorising... storytellers move away from abstract theorizing and explaining towards the goal of evocation, intimate involvement, 
engagement and embodied participation with stories'. In this sense, then, the stories (should) speak for themselves (Dowling, 2012). In the concluding section, however, I point to some of the ways in which the tales could be explored using the intersectional lens proposed by Anthias.

The first story, 'Miss Whitney', focuses on a mixed 'race' woman in the moments just prior to, and at the beginning of teaching a dance lesson on her first teaching practice in a predominantly white school. The second, entitled 'Miss, Are you a Terrorist?' is about an Asian Muslim woman negotiating a place within PE with her parents, after experiencing a racist attack on her way home from university ${ }^{\text {iv }}$.

\section{'Miss Whitney'}

The bell for next lesson rings loudly, followed by hundreds of pairs of feet hurtling down the corridor. The noise is deafening. "Walk slowly! Don't push, you'll not get there any quicker!" I shout, but there's no order, I've lost the battle. "All right Whitney?" shouts Tim, the head of department, rudely pushing two boys out of his way to reach my side. "Can you manage this lot do you think, being such a youngster? Dance? Well, you've got the advantage anyway, natural rhythm, and all that, eh, and especially with your body! His eyes sweep slowly down the top of my shirt, then he glances quickly up at me and grins. "You'll love it, won't you Darren?" elbowing one of the bigger, stockier, boys nearby. I recognise him as the captain from last night's winning cricket team. His shirt tail hangs out over one side of his trousers, mud colouring both knees, testimony to the morning break kick about. A large, loose, knot on his tie, offering up a defiant challenge to the school's dress regulations. The team's win had been announced in assembly. Darren had collected the cup from the Head to loud cheering and clapping. Cricket's the game here, apparently and it was the first time we'd won the league. A proud moment for the whole school.... "Do we have to Sir?" Darren complains loudly. "Dance is for poofs! Why can't I do athletics with you, Sir?" Tim smacks him playfully on the head, laughing as he responds. "You'll be OK. Miss Whitney knows how to dance, don't you Miss Whitney? She'll give you boys a good time I'm sure!"

A hot flush sweeps slowly up my face and I turn away struggling to hide my embarrassment, anger, try to regain composure, as Tim - all six foot of him - strides 
purposefully towards the equipment cupboard, swinging his whistle, clip board under one arm, oblivious to my discomfort. What's worse, the nickname, the throw-away line undermining me in front of the kids in one quick move, or that it's always dance he seems to have a problem with? I'm not sure. Well, all of them actually! I feel a hard knot of frustration gathering in my chest, like a bad bout of indigestion, only worse. I know I won't do anything, say anything to challenge him. I can't. First teaching practice and challenging the head of department - Get real! But all this stuff from uni about 'learning from experienced teachers' - bloody hell! I'm really learning such a lot from him! Jonathan seems to be getting on ok with him though. Seems like they're best mates, especially since Friday night's drinking session celebrating the cricket. I thought it would be good, having two of us going to the same school, we could support each other but I never see him, he's always off to football practice or rugby practice or something, with Tim, all matey, matey.

Coaxing the stragglers into the gym, I tell myself, again, just a few more weeks and then you'll be back in university, stick it out, laugh it off - just survive. Helen had to explain the Whitney stuff to me. I didn't get it at first. "You know", she said, laughing, "Whitney Houston, the black singer? Her song, I wanna Dance with Someone?” Right. Ok, great. So what if I am a bit different from the average PE teacher being mixed 'race' - I'm certainly the only one on my course anyway! And in this school, well, I do stand out. But get over it, I want to tell him, there's a multicultural world out there, you know. You ought to open your eyes a bit more! But of course I don't. I daren't - he's writing my report. He's the expert! Joanne's good, she tried to intervene once, but he laughed it off, saying she needed to chill out, that she was being an 'old woman' - and couldn't she see it was only a joke. There's obviously no love lost between those two. I'm so glad Joanne's my mentor and not Tim! She's really helpful, doesn't have a problem. Treats me the same. And the kids are ok. They were always asking at first, "Oh Miss you've got a good suntan, where's that from? "How do you do your hair like that?" But that's different. Kids are just like that, it's the way they are. That one kid saying, yesterday, that it was great to have a PE teacher like her, was fantastic. That's what really counts!

Just keep my head down and try and fit in. That's what Mum says I should do. Of course it's different for me, I can fit in more than she can. She doesn't say much but you can tell it was bad for her when she was training- there weren't many black people around 
there then at all. And especially when she met Dad and moved to Barnstock, which is totally white. In a way, college has been no different for me - my school was all white, my friends were all white, so university wasn't anything new really. I didn't expect there to be hundreds of us so it was ok. But then sometimes it all comes back, hits you slap bang in the face. When we talk about 'race' at uni, it's like they totally forget I'm black or that I'm even in the room! They say oh people aren't racists nowadays and then the stuff they come out with, I can't believe it! Asians don't want to do this because of their religion or culture or stuff. And when James said that his PE teacher had told him he wouldn't get a place at this uni because they would pick people from different races over him because of filling their quotas - that hurt. Hurt a lot. I just sat there, sat on my hands, waiting for the lecture to end; I couldn't say anything. Why should I say anything anyway? Tony did try to challenge him, but I didn't hear his comments- there was too much blood pounding around in my ears. I was just thinking, let me get out of here! It wouldn't have made a difference whatever Tony had said - James had said it, hadn't he?

"Miss, do we have to go in bare feet or can we wear trainers?" My attention snaps back to the lesson, and I move into the studio, encouraging them to choose bare feet, better for dance. Two girls sit huddled against the wall at the far end, near the CD player. As I turn on the music, I hear, "I'm so fat I have been to the gym three times this week!" "Well, look at this, ugg!" - Lucy, I think she is called - responds, pinching her midriff between thumb and forefinger. Worrying about body fat at twelve - but I can't deal with this right now... Turning back to the group I start the lesson. "Ok, remember the warm up we did last week. Let's try it again.... ok, find a space and follow me!” Peter gets to his feet. He'd been sitting patiently - he always does - waiting quietly for the lesson to begin, with his hands wrapped around his bony knees, his long legs folded into his body. No one is sitting with him, he seems a bit of a loner, but sometimes, I see him really come out of himself, like he connects with the music and really begins to move well. I think he's beginning to enjoy dance.... Too late, I see the elbow dig hard into his ribs followed by Peter's “ouch”, and see him turn to identify the culprit. Stuart, Darren's mate, is smirking "Hey spasso, watch it, that was my space! Go find your own!" I pretend to not see, turning to adjust the music instead. I cop out, all the while, thinking I shouldn't have ignored that. But I can't do everything. I remember my mentor's feedback from last week - "Concentrate on getting a good start - get them active quickly, with a brisk opener that 
will set the scene." Easy for him to say....Anyway, what I'm learning is that becoming a teacher means a hell of a lot more than just teaching kids how to dance.

\section{Miss, are you a terrorist?}

I've reached the door, but stand outside, uncertain whether to go in. I shiver, suddenly cold, clammy skin, though the evening's warm. Minutes pass. Pull yourself together, come on now, breathe, it's fine, I tell myself. It's not that bad. My hand shakes as I reach up to explore my swollen cheek. The now-useless, sodden tissue leaks blood which runs slowly down my arm onto my coat sleeve. A dull, throbbing headache begins behind my temples. Why? Why me? I begin to cry again, I can't stop myself. I know I have to go and face them, but I know what they will say, well what Mum will say. But I'm already late and they'll be expecting me. I need to go in.

I struggle with the key in the lock, push open the door and move into the warmth of the kitchen. Cooking smells linger. I had hoped they'll be out for the evening. But they're sitting at the table finishing their meal, talking over their day. Their quiet conversation halts abruptly as they turn to greet me and see that's something wrong. Dad rushes over, and his arm around my back feels comforting; I collapse heavily onto the nearest chair, my college bag dropping to the floor. I can't look at Mum's face, but know she is beginning to cry. She asks me over and over again, "What's happened love, oh Nadia, what's happened". Dad rushes to get the first aid box, and wets cotton wool at the sink. "Here use this, gently now" he says, handing it to me to replace the tissue.

I try to explain but it's hard. I don't really know. One minute, I'm walking home from uni having said saying goodbye to Lucy, next I'm sprawled on the floor, dizzy and disorientated. A half brick lying next to me on the ground. The weapon, I guess. "I didn't see what they looked like. They were on the other side of the road, we're talking, we didn't take much notice". "Let's take a look at that now" Dad interjects as he slowly peels away the cotton wool and inspects the wound. "I don't think it'll need a stitch, but keep pressing to stop the blood for now. You were obviously just in the wrong place at the wrong time", he adds reassuringly, but I notice the concern showing in his eyes neverthe-less. "I'll be ok, I think they must've been drunk or something", I respond weakly, lying. I know full well it was my headscarf that had marked me out for their target 
practice. I'd heard their taunts. But whatever I say, it's still not what Mum wants to hear, and we slip into the conversation we've had so many times before.

"I just don't understand why you want to put yourself in that situation. How can you be a good Muslim and be a PE teacher? Your sister is fine, medicine's different, different people down there, nice people. Why choose to mix with non-Muslims all the time? Look what happens when you do". I try and suggest that what's happened this evening has nothing to do with my choice of career. That it could happen anywhere. She's not convinced. "Why don’t you stop?" she pleads quietly. "Won’t you stop now?"

Sighing, I glance at Dad for support. He was the same initially, didn't want me to teach, but after he saw I was getting good at sport, that I was serious about it, he's been really good. I've wanted to be a PE teacher since I was fourteen! I know he's had to put up with a lot of grief, particularly from his mum and dad and the cousins. Teaching was ok as a career, but teaching PE? Spending three or four years learning how to throw a ball? For what? No way could they get their heads around that! All they see is footballers on the telly, getting into fights, singing and drinking after the game. I'd daren't tell them that there's some of that at uni too. It's the most difficult thing for me, not the lectures, not the learning, that's great! I've enjoyed every minute of that. It's just difficult, the social side, if everything is about alcohol - I'm not seen as a team player because I can't join in. Even at school, teachers want to talk to you about your lesson down the pub. I haven't told Mum and Dad that, of course.

I respond firmly, "But Mum, it's important I'm there, I can educate kids, so things like this don't happen in the future to other people. Remember when I told you about my first few minutes at Brackenridge school, the all white school in Easingby where I did my first practice, when that kid called me a terrorist and asked whether I believed in killing people because I was Muslim? I made a difference there, just by being there, I know I did. Being a Muslim and a woman and teaching PE! But also, you know, I told you about those sessions I taught with Mr Brown's PSHE ${ }^{\mathrm{v}}$ group on stereotyping and Islam, remember that? Using us as the example?"

"I wasn't too pleased you'd used that photo of me, though" Dad joked, trying his best to lighten the atmosphere, "it was hardly me at my best". "Yeah Dad, but it got the message 
across!" I responded. "When I put up it up next to the picture of Bin Laden, they could see that you both looked the same, but that's all. I could show them that that was how stereotyping worked, through ignorance, and fear. It is important, Mum, it really is. I can educate them, and give them a different story to their Daily Mail front pages - 'Muslims and The War on Terror! They need people like me in teaching. I'm actually a real resource for schools if they choose to look at me that way. Mr Brown certainly saw me that way".

\section{Concluding comments}

Miss Whitney and Nadia's stories reveal the complex ways in which ethnic, racial and religious identities 'get done' in PETE - in this case, through glimpses into the everyday interactions between students, their teacher mentors, and the pupils (Sirna, et al, 2010). Their developing professional identities are inextricably linked to their different ethnic, religious, gendered and sexualized identities and family circumstances. Gendered and racialised power relations are experienced and negotiated on a moment by moment basis, through everyday interactions with the pupils and teachers, the 'micro-aggressions' (Kohli and Solorzano, 2012) of gendered and racialised jokes and 'banter', physical violence, and irrevocably linked to the 'colour blind' PETE curriculum, and the male, white, organizational culture of PE.

Individuals experience, negotiate and resist in different ways at different times across the varied spaces of PETE. For example, at the experiential and intersubjective levels, the interaction between 'Miss Whitney', and Tim, her male head of department, and one of the pupils, Darren, before her lesson illustrates the fluid and complex way in which power relations work and intersect. Tim's use of the nickname, 'Miss Whitney' to address her publically in front of the pupils, serves to racialise and 'Other' her through the use of crude stereotyping; if she is black then she must have 'natural' rhythm and be good at dance. However, this interaction is also sexualized and gendered: she is objectified by Tim's gaze, and his inaction in relation to Darren's homophobic comment about dance both reflects and reproduces the gendered and hetero-normative discourses underpinning the PE curriculum, and women's positioning within the subject area. As a woman PE teacher, her involvement in a 'feminine' activity such as dance, (in contrast to the 'high status' 'male' game of cricket), marks her as 'low value' in the gendered activity hierarchies within PE (Sparkes, et al, 2007) ${ }^{\text {vi }}$; her position as a student teacher compounds this still further. Yet her experiences are 
not determined totally by her ethnicity or gender; she is beginning to develop her professional identity and skills as a teacher, and recognise her role in the social relations played out in her own classroom, and in making a difference to boys' and girls' experiences. Nadia's experience of gender, sexuality and 'race' is different: her embodied faith (Benn, et al, 2011), signified by her hijab, results in a violent attack and shows the importance of attending to the different ways in which racism can be perpetuated and experienced. Religion, culture and family are social and discursive practices that impact on Nadia's gendered experiences of becoming a PE teacher, but not in straightforward determining ways. She has been able to negotiate a move into PE teaching, despite the concerns of her family, and draws on her religious and cultural identity, proactively, as a central part of her professional identity and pedagogy.

The women's experiences show the interconnectedness of their different personal and professional identities, but they also show their challenges of learning to work with difference, in their own practices, with pupils. In this sense, their stories show the significant disjuncture between the disembodied, 'objective' and technocratic discourses dominating their teacher training, and their own subjective, embodied experiences. Over the last twenty years or so, teacher education in England has seen significant shifts away from reflection and theoretical concerns of equality and social justice, towards practically based 'competencies' and skills enshrined in the qualified teacher status 'standards' (Mahony and Hexhall, 1997, 2000). Student teachers are graded first and foremost on their abilities to plan, structure and deliver lessons that show knowledge and understanding of subject content - including the importance of a good brisk warm up!

The government's most recent changes to teacher education seem set to 'harden' such technocratic approaches to teaching. For example, increased numbers of teachers will be trained through school-based routes, including the new School Direct (Department for Education, DfE, 2012a), where schools will select and train student teachers, liaising with a university for input into that training, as they see fit. In addition, the new 'Teachers' Standards' by which new entrants to the profession will be judged (DfE, 2012b) are worryingly silent on issues of equity and social justice, making no reference at all to the ways in which 'race', ethnicity or gender might impact on pupils' experiences, or that this might be useful knowledge for new teachers to acquire. As school intakes become increasingly ethnically diverse, the challenge of selecting and educating new teachers to reflect the wider 
population they will go on to serve becomes increasingly evident, and urgent. PETE has some way to go before it can claim the successes seen in other subject areas in widening the participation of BME candidates choosing teaching as a career. And yet, as these stories show, it is not simply a question of implementing widening access strategies, and recruiting more BME 'role models' (Carrington and Skelton, 2003). We need better knowledge and understanding of the ways in which 'race' relations are constituted through PE practices, and how individuals resist and negotiate these. These stories show the significance of adopting an intersectional lens to reveal the complex and shifting ways in which religion, gender, 'race' and embodiment intersect in experiences of PETE. Further research exploring the intersectionality of social relations in PETE must also take account more explicitly of social class, a difference not specifically addressed in these particular stories.

I also suggest that there may be a need for us to consider how we write research in order to make a difference. Fictional stories might be one way to engage the reader about racism and sexism, moving them in an emotional as well as in an intellectual sense. Teacher education is a place where we should be engaging students, emotionally but also politically, to think deeply about teaching, education and social justice, and their place within these (CochranSmith, 2004). 'Stories of difference' like these might therefore have a useful place in a critical PETE pedagogy.

\section{Acknowledgements}

Thanks are due to the students who shared their experiences so willingly with us, and to the full research team: Anne Chappell, Cathy Gower, Saul Keyworth, Julia Lawrence, Julie Money, Sarah Squires and Louisa Webb. This article is dedicated to Louisa Webb who died from cancer in January 2012.

\section{Notes}

${ }^{\mathrm{i}}$ Despite the fact that the 2000 amendment to the UK Race Relations Act (1976) has strengthened the requirement for all public authorities to promote 'race' equality and good 'race' relations (Commission for Racial Equality/now the Equality and Human Rights Commission, 2008), research such as Callender, et al, (2006), suggest there is little evidence that the gathering of statistics on ethnicity actually results in changed practices.

\footnotetext{
ii I use the term 'black feminism' here, and draw mainly on the work of black British feminists, whilst recognising the dangers that this might suggest, erroneously, a homogeneous black feminist 'voice'.

iii Elsewhere I have argued for a 'middle ground' approach between modernism and post modernism, to explore racialised and gendered experiences of PE and PETE (Flintoff, et al, 2008; Flintoff, 2012). Drawing on Archer, et al, 2001:42), research adopting such a position 'share a general treatment of 'race', class, gender sexuality and disability as fluid, shifting and non-discrete identities and hold a common awareness and commitment to
} 
addressing the associated, very 'real' inequalities'. Alternative frameworks, such as Hill Collins' Matrix of Domination, or Critical Race Theory have been used (e.g. Stride (2008) has used Hill Collins to explore Muslim girls' experiences of PE and sport; Hylton (2008), Critical Race theory for an examination of sport).

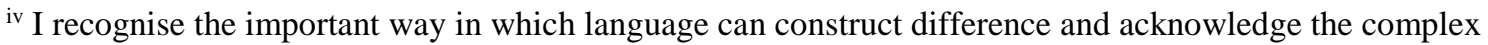
debates over the use of terms such as Asian, black, black and ethnic minority. I use the term Asian here because of its use by the (then) TDA in their monitoring. In the UK, the term Asian is commonly used to describe people of Pakistani, Indian, and Bangladeshi heritage. See Aspinall (2002) for a useful discussion.

vi The specific context of the research in England is important here, particularly in relation to the social and cultural organisation of PE. In many secondary schools (11-18 years) in England, boys and girls continue to be taught separately in single sex groups, with different curricular activities being offered, reflecting strong gendered ideas about physicality (Scraton, 1992). Whilst schools do offer dance to mixed groups, this is often to younger aged children (11/12 years), and delivered by women, not men teachers, and would rarely form a significant part of the curriculum (Waddington, et al, 1998; Evans, et al, 1996). Although figures are difficult to obtain, white, young men predominate in key decision making positions such as heads of department (Penney, et al, 2002).

\section{References}

Anthias, F. (2001) 'The Concept of 'Social Division' and Theorising Social Stratification: Looking at Ethnicity and Class', Sociology, 35(4): 835-854.

Anthias, F. (2008) 'Thinking through the lens of translocational positionality: an intersectional frame for understanding identity and belonging', Translocations, 4(1): $5-20$.

Anthias, F. (2012) 'Intersectional what? Social divisions, intersectionality and levels of analysis', Ethnicities, 13(1): 3-19.

Archer, L., Hutchings, M. and Leathwood, C. (2001) 'Engaging in Commonality and Difference: theoretical tensions in the analysis of working class women's educational discourses', International Journal of Sociology of Education, 11(1): 41-62.

Aspinall, P. J. (2002) 'Collective Terminology to Describe Minority Ethnic Population: the persistence of confusion and ambiguity in usage', Sociology, 36(4): 803-816.

Azzarito, L. (2009) 'The Panopticon of physical education: pretty, active and ideally white', Physical Education and Sport Pedagogy, 14(1): 19-40.

Basit, T. and Mcnamara, O. (2004) 'Equal Opportunities or Affirmative Action? The Induction of Minority Ethnic Teachers', Journal of Education for Teaching, 30(2): 97115.

Basit, T., Roberts, L., Mcnamara, O., Carrington, B., Maguire, M. and Woodrow D (2006) 'Did they jump or were they pushed? Reasons why minority ethnic trainees withdraw from initial teacher training courses', British Educational Research Journal, 32(3): 387-410.

Benn, T. (2002). 'Muslim women in teacher training: issues of gender, 'race' and religion', in Penney, D. (Eds) Gender and Physical Education: contemporary issues and future directions, London: Routledge, 57-79. 
Benn, T. and Dagkas, S. (2006) 'Incompatible? Compulsory mixed-sex Physical Education Initial Teacher Training and the inclusion of Muslim women: a case study on seeking solutions', European Physical Education Review, 12(2): 181-200.

Benn, T., Dagkas, S. and Jawad, H. (2011) 'Embodied faith: Islam, religious freedom and educational practices in education', Sport, Education and Society, 16(1): 17-34.

Bhattacharyya, G. (1997). 'The fabulous adventures of the mahony princesses', in Mirza, H. (Eds) Black British Feminism: A Reader, London: Routledge,

Bhopal, K. and Preston, J. (Eds) Intersectionality and "Race" in Education, London: Routledge

Bonnett, A. and Carrington, B. (2000) 'Fitting into Categories or Falling Between Them? Rethinking ethnic classification?' British Journal of Sociology of Education, 21(4): 487-500.

Brah, A. (1996) Cartographies of Diaspora: Contesting Identities, London: Routledge.

Bramham, P. (2003) 'Boys, masculinity and PE', Sport, Education and Society, 8(1): 57-71.

Brown, D. and Rich, E. (2002). 'Gender positioning as pedagogical practice in physical education', in Penney, D. (Eds) Gender and Physical Education: contemporary issues and future directions, London: Falmer, 80-100.

Callender, D., Robinson, Y. and Robertson, A. (2006) 'The impact of ethnic monitoring on the achievement of black and minority students in ITE [Internet]', Available from http://open.tean.ac.uk/handle/123456789/755 [Accessed March 13th].

Carby, H. (1982). 'White women listen! Black feminism and the Boundaries of Sisterhood', in Centre for Contemporary Cultural Studies (Eds) The Empire Strikes Back, CCCS: Hutchinson,

Carless, D. (2011 [iFirst]) 'Negotiating sexuality and masculinity in school sport:an autoethnography', Sport Education and Society

DOI:10.1080/13573322.2011.554536.

Carrington, B., Bonnett, A., Demaine J, Hall I, Anoop N, Short G, Skelton C, Smith F and Tomlin, R. (2001) Ethnicity and the Professional Socialisation of Teachers [Internet], London: Teacher Development Agency, Available from http://www.tda.gov.uk/partners/recruiting/consultationdata.aspx [accessed 28th Feb 2008].

Carrington, B. and Skelton, C. (2003) 'Re-thinking 'role models' : equal opportunities in teacher recruitment in England and Wales', Journal of Education Policy, 18(3): 253265.

Carroll, B. and Hollingshead, G. (1993). 'Equal opportunities: race and gender in physical education: a case study', in Evans, J. (Eds) Equality, Education and Physical Education, London: Falmer, 154-169.

Chase, S. E. (2005). 'Narrative Inquiry', in Denzin, N. andLincoln, Y., S. (Eds) The Sage Handbook of Qualitative Research: Third Editon, London: Sage, 
Cochran-Smith, M. (2004). Walking the Road: Race, Diversity, and Social Justice in Teacher Education: New York, N.Y.; London : Teachers College Press, c2004.

Cole, M. (2009) 'A plethora of 'suitable enemies': British racism at the dawn of the twentyfirst century', Ethnic and Racial Studies, 32(9): 1671-1685.

Davies, K. (2009) 'Intersectionality as buzzword. A sociology of science perspective on what makes a feminist theory successful', Feminist Theory, 9(1): 67-85.

Department for Education (2012a). School Direct: Quick Start Guide for Schools [Internet]: Available from:

https://www.education.gov.uk/publications/standard/AllPublicationsNoRsg/Page1/TA -00021-2013 [Accessed 14th March 2013].

Department for Education (2012b) Teachers' Standards [Internet], London: Department for Education [Available from;

https://www.education.gov.uk/publications/eOrderingDownload/teachers\%20standard s.pdf Accessed 14th March 2013\}.

Douglas, D. and Halas, J. (2011 (iFirst article)) 'The wages of whiteness: confronting the nature of the ivory tower racism and the implications for physical education', Sport Education and Society DOI: 10.1080/13573322.2011.602395: 1-22.

Douglas, K. and Carless, D. (2009) 'Exploring taboo issues in professional sport through a fictional approach', Reflective Practice, 10(3): 311-323.

Dowling, F. (2006) 'Physical education teacher educators' professional identities, continuing professional development and the issue of gender equality', Physical Education and Sport Pedagogy, 11(3): 247-263.

Dowling, F. (2008) 'Getting in touch with our feelings: the emotional geographies of gender relations in PETE', Sport, Education and Society, 13(3): 247-266.

Dowling, F. (2011) "Are PE teacher identities fit for postmodern schools or are they clinging to modernist notions of professionalism?' A case study of Norwegian PE teacher students' emerging professional identities', Sport Education and Society, 16(2): 201222.

Dowling, F. (2012). 'A narrative approach to research in physical education, youth sport and health', in Dowling, F.,Fitzgerald, H. andFlintoff, A. (Eds) Equity and Difference in Physical Education, Youth Sport and Health: A Narrative Approach, London: Routledge, 37-59.

Dowling, F., Fitzgerald, H. and Flintoff, A. (Eds) Equity and difference in physical education, youth sport and health: A narrative approach, London: Routledge

Evans, J., Davies, B. and Penney, D. (1996) 'Teachers, teaching and the social construction of gender relations', Sport, Education and Society, 1(2): 165-183.

Fleming, I. (1991). 'Sport, schooling and Asian male youth culture', in Jarvie, G. (Eds) Sport, Racism and Ethnicity, London: Falmer, 30-57.

Flintoff, A. (1993a). 'Gender, Physical Education and Teacher Education', in Evans, J. (Eds) Equality, Education and Physical Education, London: Falmer, 184-204. 
Flintoff, A. (1993b). 'One of the boys? Gender identities in Physical Education initial teacher education', in Siraj-Blatchford, I. (Eds) 'Race', Gender and the education of teachers., Buckingham: Open University Press, 74-93.

Flintoff, A. (1994) 'Sexism and Homophobia in Physical Education; the challenge for Teacher Educators.' Physical Education Review, 17(2): 95-105.

Flintoff, A. (2012 (iFirst)) 'Playing the 'Race' Card?: Black and minority ethnic students' experiences of physical education teacher education', Sport, Education and Society, DOI:10.1080/13573322.2012.745397(

Flintoff, A., Fitzgerald, H. and Scraton, S. (2008a) 'The Challenges of Intersectionality: Researching difference in Physical Education', International Studies in Sociology of Education, 18(2): 73-85.

Flintoff, A. and Webb, L. (2011) ' 'Just open your eyes a bit more': researching black and minority ethnic trainees' experiences of physical education teacher education.' Sport, Education and Society, 17(5): 571-599.

Flintoff, A., With, Chappell, A., Gower, C., Keyworth, S., Lawrence, J., Money, J., Squires, S. L. and Webb, L. (2008b). Black and Minority Ethnic Trainees' Experiences of Physical Education Initial Teacher Training: Report for the Training and Development Agency., Carnegie Research Institute: Leeds Metropolitan University.

Furlong, J., Whitty, G., Barton, L. and Barrett, E. (1996). 'From integration to partnership: changing structures in ITE', in McBride, R. (Eds) Teacher Education Policy: Some issues arising from Research and Practice., London: Falmer,

Gaine, C. (2001) 'If it's not hurting it's not working: teaching teachers about 'race", Research Papers in Education, 16(1): 93-113.

Gilborn, D. and Mirza, H. (2000) Education inequality: Mapping race, class and gender: a synthesis of research evidence, London: Office for Standards in Education.

Harrison, L., Jr and Belcher, D. (2006). 'Race and ethnicity in physical education', in Kirk, D.,Macdonald, D. andO'Sullivan, M. (Eds) The Handbook of Research in Physical Education, London: Sage, 740-751.

Hickey, C. and Fitzclarence, L. (1999) 'Educating Boys in Sport and Physical Education: Using Narrative Methods to Develop Pedagogies of Responsibility', Sport Education and Society, 4(1): 51-62.

Hill Collins, P. (1991) Black Feminist Thought: Knowledge, Consciousness and the Politics of Empowerment, London: Routledge.

Housee, S. (2008) 'Should ethnicity matter when teaching about 'race' and racism in the classroom?' Race Ethnicity and Education, 11(4): 415-428.

Hylton, K. (2008) 'Race'and Sport: Critical Race Theory, London: Routledge.

Kay, T. (2006) 'Daughters of Islam: Family influences on Muslim Young Women's participation in Sport', International Review for the Sociology of Sport, 41(3): 357373. 
Knez, K. (2007). The meaning and place of physical activity in the lives of young Muslim women. Unpublised PhD thesis. University of Queensland, Australia.

Kohli, R. and Solorzano, D. G. (2012) 'Teachers, please learn our names! Racial micro aggressions and the K-12 classroom', Race, Ethnicity \& Education, 15(4): 441-462.

Lander, V. (2011) 'Race, culture and all that: An exploration of the perspectives of White seconary student teachers about race equality issues in their initial teacher education', Race, Ethnicity \& Education, 14(3): 351-364.

Long, J., Carrington, B. and Spracklen, K. (1997) ' 'Asians Cannot Wear Turbans in the Scrum': Explanations of racist discourse within professional rugby league', Leisure Studies, 16(4): 249-259.

Long, J., Hylton, K., Sparklen, K., Ratna, A. and Bailey, S. (2009). Systematic Review of Literature on Black and Minority Ethnic Communities in sport and physical recreation, Leeds: Carnegie Research Institute, Leeds Metropolitan University, for The UK Sports Councils and Sporting Equals.

Mac an Ghaill, M. (1988) Young, Gifted and Black., Buckingham: Open University Press.

Mac an Ghaill, M. (1994) The Making of Men: masculinities, sexualities and schooling., Buckingham: Open University Press.

Macdonald, D., Abbott, R., Knez, K. and Nelson, K. (2009) 'Taking exercise: cultural diversity and physically active lifestyles', Sport, Education and Society, 14(1): 1-19.

Mahony, P. and Hexhall, I. (1997) 'Sounds of silence: The social justice agenda of the teacher training agency', International Studies in Sociology of Education, 7(2): 137156.

Mahony, P. and Hexhall, I. (2000) Reconstructing teaching: standards, performance and acccountablity, London: Routledge.

Massao, P. and Fasting, K. (2010) 'Race and Racism: Experiences of Black Norwegian athletes', International Review for the Sociology of Sport, 45(2): 147-162.

Mc Cullick, B., Lux, K., Belcher, D. and Davies, B. (2011) 'A portrait of the PETE major: re-touched for the early twenty-first century', Physical Education and Sport Pedagogy, DOI:10.1080/174089989.2011.565472(1-17).

Mirza, H. (Eds) Black British Feminism: A Reader, London: Routledge

Mirza, H. and Joseph, C. (Eds) Black and Postcolonial Feminisms in New Times

Researching Educational Inequalities., London: Routledge

Mirza, H. S. (2009) Race, Gender and Educational Desire: Why Black Women Succeed and Fail, London: Routledge.

Nelson, A., Macdonald, D. and Abbott, R. (2010). 'The cultural interface: theoretical and 'real' spaces for urban Indigenous young people and physical activity', in Wright, J. andMacdonald, D. (Eds) Young People, Physical Activity and the Everyday, London: Routledge, 75-92. 
Oliver, K. and Lalik, R. (2004). "The Beauty Walk': Interrogating whiteness as the norm for beauty within one school's hidden curriculum.' in Evans, J.,Davis, B. andWright, J. (Eds) Body Knowledge and Control: studies in the sociology of physical education and health, London: Routledge, 115-129.

Penney, D. (2002). 'Equality, equity and inclusion in Physical Education', in Laker, A. (Eds) The Sociology of Sport and Physical Education, London: Routledge, 110-128.

Penney, D., Houlihan, B. and Eley, D. (2002) Report of the first National Survey of Sports Colleges, Loughborough: Institute of Youth Sport, Loughborough University.

Pheonix, A. (2006) 'Intersectionality', European Journal of Women's Studies, 13(3): 187-192.

Pheonix, A. (2009) 'De-colonising practices: negotiating narratives from racialised and gendered experiences of education', Race Ethnicity and Education, 12(1): 101-114.

Polkinghorne, D. (1995). 'Narrative configuration in qualitative analysis', in Amos Hatch, J. andWisniewski, R. (Eds) Life History and Narrative, London: Falmer Press, 5-23.

Ratna, A. (2008). British Asian Females' Racialised and Gendered Experiences of Identity and Women's Football, unpublished PhD thesis. University of Brighton.

Rich, E. (2001) 'Gender positioning in teacher education in England: new rhetoric, old realities", International Studies in Sociology of Education, 11(2): 131- 154.

Richardson, L. and Adams St Pierre, E. (2005). 'Writing: A Method of Inquiry', in Denzin, N. andLincoln, Y., S. (Eds) The Sage Handbook of Qualitative Research: Third Edition, London: Sage,

Scraton, S. (1992) Shaping up to Womanhood: Gender and Girls' Physical Education, Buckingham: Open University Press.

Scraton, S. (2001). 'Re-conceptualising race, gender and sport: the contribution of black feminism',' in Carrington, B. andMcDonald, I. (Eds) Race, Sport and British Society, London: Routledge, 170-187.

Scraton, S., Caudwell, J. and Holland, S. (2005) 'Bend it like Patel: Centering 'Race', Ethnicity and Gender in Feminist analysis of women's football in England', International Review for the Sociology of Sport, 40(1): 71-88.

Shropshire, J. and Carroll, B. (1997) 'Family Variables and Children's Physical Activity: Influence of Parental Exercise and Socio-economic Status', Sport Education and Society, 2(1): 95-129.

Sirna, K., Tinning, R. and Rossi, T. (2010) 'Social processes of health and physical education teachers' identity formation: reproducing and changing culture', British Journal of Sociology of Education, 31(1): 71-84.

Smart, S. (2009) 'Shifting horizons: Reflections on qualitative methods', Feminist Theory, 10(3): 295-308.

Smith, B. and Sparkes, A. (2008) 'Narrative and its potential contribution to disability studies', Disability \& Society, 23(1): 17-28. 
Smith, B. and Sparkes, A. C. (2004) 'Men, sport and spinal cord injury: an analysis of metaphors and narrative types', Disability and Society, 19(6): 613-626.

Solomon, R. P., Portelli, J. P., Daniel, B.-J. and Campbell, A. (2005) 'The discourse of denial: how white teacher candidates construct race, racism and 'white privilege", Race Ethnicity and Education, 8(2): 147-169.

Solorzano, D. G. and Yosso, T. J. (2002) 'Critical Race Methodology: Counter-Storytelling as an Analytical Framework for Education Research', Qualitative Inquiry, 8(1): 23-44.

Sparkes, A. (1997) 'Ethnographic fiction and representing the absent other', Sport, Education and Society, 2(1): 25-40.

Sparkes, A. (2002) Telling Tales in Sport and Physical Activity: A Qualitative Journey, Leeds: Human Kinetics.

Sparkes, A. C., Partington, E. and Brown, D. H. (2007) 'Bodies as bearers of value: the transmission of jock culture via the 'Twelve Commandments", Sport Education and Society, 12(3): 295-316.

Stride, A. (2012). Telling Tales of Difference? Exploring South Asian, Muslim Girls' Experiences of Physical Education and Physical Activity. Unpublished PhD Thesis Leeds Metropolitan University.

Swain, F. (2003) The schooling and identity of Asian girls, Stoke on Trent: Trentham Books.

Turner, D. (2007) 'Ethnic Diversity in Physical Education Teaching', Physical Education Matters, 2(2): 14-16.

Valentine, G. (2007) 'Theorizing and researching Intersectionality: A challenge for feminist geography', The Professional Geographer, 59(1): 10-21.

Waddington, I., Malcolm, D. and Cobb, J. (1998) 'Gender stereotyping and physical education', European Physical Education Review, 4(1): 34-46.

Walseth, K. (2006) 'Young Muslim Women and Sport: the impact of identity work', Leisure Studies, 25(1): 75-94.

Webb, L. and Macdonald, D. (2007) 'Techniques of Power in Physical Education and the Under-representation of Women in Leadership', Journal of Teaching in Physical Education, 26(3): 279-297.

Wilkins, C. and Lall, R. (2011) "You've got to be tough and I'm trying': black and minority ethnic student teachers' experiences of initial teacher education', Race, Ethnicity \& Education, 14,(3): 365-386.

Wright, J., Macdonald, D. and Groom, L. (2003) 'Physical Activity and Young People: Beyond Participation', Sport Education and Society, 8(1): 17-34.

Yuval-Davis, N. (2006) 'Intersectionality and Feminist Politics', European Journal of Women's Studies, 13(3): 193-209. 


\title{
5. Unpacking Internalized Racism: Teachers of Color Striving for Racially Just
}

\section{Classrooms.}

Rita Kohli, Ph.D.

\author{
by Rita Kohli
}

Assistant Professor

Department of Elementary Education

Connie L. Lurie College of Education

San José State University

rita.kohli@sjsu.edu

\begin{abstract}
Within racial inequitable educational conditions, students of color in US schools are susceptible to internalizing racism. If these students go on to be teachers, the consequences can be particularly detrimental if internalized racism influences their teaching. Framed in Critical Race Theory, this article investigates the process pre-service teachers of color took in unpacking their internalized racism as they strive for racially just classrooms. In-depth interviews and focus groups were conducted with black (4) Latina (4) and Asian American (4) women enrolled in a social justice-oriented urban teacher education program in California. Data revealed that participants in this study 1 ) had experienced racism and internalized racism in their K-12 education; 2) had done self-work prior to enrolling in their teacher education program to begin the process of unpacking internalized racism; and 3) felt that critical dialogues about internalized racism within teacher preparation was essential to develop pedagogy that challenges racial inequality. This study adds to the field by taking a cross-racial approach to understanding the struggles of teachers of color with internalized racism in their own lives. It additionally outlines an important process many teachers of color go through to develop racially just classrooms.
\end{abstract}

Key words: teachers of color, teacher education, school racism, internalized racism, Critical Race Theory, urban education, pre-service teachers

Ashley experienced a lot of racism within her education both blatant and subtle. As one of few black students in her predominantly white school, peers would repeatedly call her the "n-word" without repercussions from staff or teachers. Other students would differentiate her from their disdain for the larger black community by saying, "you're a cool black person," or "you're a white-black girl," or "you know, you're a proper black person." 
Teachers too participated in the racialization of Ashley. Some teachers embraced the way she spoke. "I was often put up on a pedestal for being the model black student. I was always taught, 'Well, Ashley's different.' Or 'Ashley's very articulate; her vocabulary is extraordinary." Based on this experience, Ashley internalized a superiority to her community. She shared,

I had this really negative outlook on black communities, even my own. I'm from Oakland, going to see my grandparents, or going back to Oakland was like, "Hell no, I would never live here. Look at what they do to their communities." I just had no analysis or critique. I felt that all black people that aren't like me are worthless. And when I would hear things from white people that were racist and nasty, "You talk proper, or you're not ghetto, or you're clean, or your hair is nice" I would take that as a positive. I was proud to be that way.

These comments reflect internalized racism, a concept that explains when people of color ${ }^{\mathrm{i}}$ consciously or unconsciously accept a racial hierarchy (Perez Huber, Kohli and Johnson, 2006). Having internalized racism has many consequences for young people of color. It can impact their self-esteem (Cross, 1971; 1995; Cokley, 2002), their perception of their family or community (Pyke \& Dang, 2003; Kohli, 2008), or their performance in school (Harper, 2006; Weissglass, 2004). For Ashley, her experiences in school convinced her of the inferiority of her racial community. While this is a problematic belief for any young person to have, it is even more detrimental if such a worldview continues into adulthood. I met Ashley when she was enrolled in a teacher preparation program. She had done a great deal of work to overcome her internalized racism before she entered teaching, and now had the specific goal of providing students of color a racially empowering education. However, what would be the consequences if she had not dealt with the impact of her racialized experiences? How might her past experiences with racism affect the education of her students?

If teachers of color experience internalized racism, they can unknowingly replicate racial hierarchies within schools. Thus, it is important for us to look at the process by which teachers of color can unlearn internalized racism in their journey towards being an educator. The purpose of this study is two-fold: 1) to contribute empirical data about internalized racism in schools from a cross-racial perspective through the narratives of black, Latina and Asian American women educators; and 2) to shed light on the process teachers of color can 
engage in to unpack their experiences with internalized racism so they do not replicate racial hierarchies in their own classrooms.

To contextualize this study within the field, I first introduce Critical Race Theory (CRT), the concept of internalized racism, and research relating to teachers of color. CRT helps us focus on the racialized experiences of people of color, and internalized racism unpacks the consequences for people of color when they accept the racism. While internalized racism has a long history and has been conceptualized apart from CRT, these lenses used together allow us to better understand the lasting impact of racism on communities of color. I then outline the methods of the study, including sample, setting and the structure of qualitative interviews and focus groups.

\footnotetext{
${ }^{\mathrm{i}}$ The term "people of color" refers to racial minorities within the US. This includes individuals of African, Asian, Pacific Islander, Latina/o, indigenous or mixed race descent. The racial categories of inclusion within this term also apply to the terms "teachers of color," "students of color," and "communities of color" used throughout this paper.
}

Finally, I share my findings as they relate to teachers of color's personal experiences with internalized racism, their self-work to unpack internalized racism, as well as their reflections on internalized racism in their own teaching.

\section{A Critical Race Theory Framework}

CRT is a theoretical framework used to analyze race. What sets it apart from other theories of race and racism is that it centers the perspectives of the marginalized. CRT scholarship understands the racialized experiences of people of color as valid evidence within research about racism, and places their struggle for dignity and equality as a central concern. It was developed amongst US legal scholars in the 1970s and has extended to many fields including Education (Ladson-Billings \& Tate, 1995; Solórzano \& Delgado Bernal, 2001; Yosso, 2005) to heighten awareness about racism in schools. For the purposes of this study, I introduce CRT into the discussion of teacher preparation, as it reframes analysis and understanding of race and racism in K-12 schools. CRT allows us to center the racialized experiences of teachers of color to recognize internalized racism as salient in their development as educators.

CRT scholars of education have developed the following five tenets to guide research: a) centrality of race and racism; b) challenge to the dominant perspective; c) commitment to social justice; d) value of experiential knowledge; e) interdisciplinary (Solórzano \& Delgado Bernal, 2001). Collectively, these tenets offer scholars the historical, legal and social analytical evidence to foreground race and racism within educational inequality. By 
centering the racialized experiences of communities of color as it intersects with other factors such as gender, class, citizenship, disability and sexual orientation, CRT offers a transformative lens for examining and challenging inequality that honors the complexity of discrimination in people's lives. Further, CRT unapologetically identifies the perpetrators and victims of racism. It does this so the marginalized can have language to name their experiences, feel a sense of community in their experiences, and can find a voice to challenge injustice.

\section{Internalized Racism}

Internalized racism as a concept has a long history of conceptualization in both colonial and post-colonial contexts (Woodson, 1933; Clark \& Clark, 1947; Fanon, 1963; 1967). Building upon a CRT framework, internalized racism helps us focus beyond experiences with racism to the lasting impact of racism on people of color. For this study, I operationalize it as 1) a phenomenon that, like racism, impacts all communities of color, 2) can be triggered by cumulative exposure to racism, and 3) results in the conscious or unconscious acceptance of a racial hierarchy where the culture, values and beliefs of the dominant culture are prioritized over the culture values and beliefs of racial minorities. (Perez Huber, Johnson \& Kohli, 2006). It is exhibited in daily life in various ways, including when people of color refer to straight hair as "good hair," equate light skin with beauty, or view Western suits as distinguished, while curly hair, dark skin and traditional cultural clothing are seen as less attractive or desirable. However, because our self and worldviews are fluid and ever changing, it can be problematic to pathologize someone as embodying internalized racism. Instead, internalized racism must be seen as something complex and fluid in its manifestation.

While not always named as such, internalized racism has been theorized in various contexts over time, and predominantly in the black community both in the US and abroad. Carter G. Woodson (1933), in the MisEducation of the Negro, argued that through exposure to racist curriculum within segregated school conditions, black youth were socialized to believe in white superiority. In 1947, Kenneth and Mammie Clark empirically tested racial preferences of African American youth through the noted doll study, and found that many black children in the US had internalized the inherent racism of racially segregated conditions, and thus developed a racial inferiority complex to whiteness. Frantz Fanon (1963) conceptualized the term colonized mind to explain the psychology of Algerians oppressed by European control. An international concept that impacts all colonized nations, 
he argued that when a dominated community has been subjected to a hierarchy of power for so long, they no longer see the value of their native culture and instead wish to embody the culture of their oppressor (Fanon, 1963). In the 1970s, William Cross developed the Nigresence model, which defined internalized racism as when racism permeates the psyche and described the stages of coming to consciousness (Cross, 1971). Cross (1995) also established that African Americans can have a healthy self-esteem, yet still have negative perceptions of his/her racial group. Using Cross' model, different scholars have conducted studies to test for internalized racism within African Americans and had similar findings (Taylor \& Grundy, 1996; Cokely, 2002).

This scholarship is essential in setting the groundwork for understanding internalized racism, but few scholars have attempted to understand this concept outside the African American community. Racism is a shared experience by all racial and ethnic minorities in the US (Omi \& Winant, 1994), thus all communities of color are susceptible to internalizing its impact. CRT legal scholar Laura Padilla (2001) studied internalized oppression with Latinos, describing it as "the turning upon ourselves, our families and our people -the distressed patterns of behavior that result from the racism and oppression of the majority society" (Padilla, 2001, 1). Native American scholar Lisa Poupart (2003) used the term internalized oppression to describe when indigenous people have learned and internalized Western practices that have been used to oppress their own community, such as drinking alcohol or domestic violence. She emphasized that when indigenous communities adopt Western perspectives, they view their community and culture through a lens that deems them as racially and culturally subhuman. Recognizing Padilla (2001) and Poupart's (2003) theoretical contributions alongside scholarship on African Americans, it is clear that racially oppressed people have a long history with internalized racism.

What is missing in these frameworks, however, is an interracial analysis of internalized racism within our current dejure desegregated school system. Over eighty years have passed since Woodson's critique of curriculum, and over sixty years since the Clark doll study (1947), yet schools continue to socialize youth of color to adopt and normalize the dominant culture (Apple, 1991; Loewen, 1996). From the time children are five years old, they attend schools that are fraught with inequalities across racial and class lines (Oakes, 2002). Many researchers have demonstrated the impact of racism in schools on the trajectories of students of color; tying racism to the underrepresentation of racial and ethnic minorities throughout the educational pipeline (Oakes et. al, 2004; Oakes \& Saunders, 2008; Perez Huber, Huidor, Malagon, Sanchez, \& Solórzano, 2006). Few studies, however, have 
examined the lasting impact of racism in schools on the self and worldview of diverse students of color (Perez Huber, Johnson \& Kohli, 2006; Kohli, 2008).

If a school reprimands a student for speaking Spanish in class or on the playground, the school is also teaching that child that English is superior to Spanish. If a school only offers Advanced Placement courses in British Literature or European history, the subtle message to students of color is that Europeans have offered more significant contributions to society than other non-white, non-Western communities. These racial hierarchies become most dangerous, however, when the students begin to believe in them. They carry these hierarchical understandings of the world out of school into their communities, which can impact the way children feel about themselves, their families and friends. This can additionally impact their comfort, wellbeing and success throughout life. Even more detrimental, if students grow up and become teachers without a space to critically reflect on and heal from their experiences with internalized racism, they can also carry problematic beliefs into classroom and replicate the cultural alienation students of color experience in schools. Thus, it is important that we better understand internalized racism in schools, as well as find ways to support teachers of color as they unpack their belief systems (Gay, \& Howard 2000; Martinez, 2000).

\section{Teachers of Color}

With the closing of non-white schools during desegregation, non-white teachers were forced out of the profession (Bell, 2004). Unfortunately, even today teachers of color continue to be a small minority of the population of educators in the United States. Currently, $84 \%$ of all public school teachers are white (Feistritzer, 2011); and more than $40 \%$ of schools do not employ even one teacher of color (National Collaborative for Diversity in the Teaching Force, 2004). These dismal statistics tell us that the majority of youth in the US grow up with few or no minority teachers within their entire academic career. Within education literature around improving equity, one of the most common responses is that we must increase the numbers of racial minority teachers. The more students of color see teachers who look like them and who understand their culture, the more culturally relevant and meaningful their education will be (Quiocho \& Rios, 2000; Sakash \& Chou, 2007; Villegas \& Jordan Irvine, 2010).

However, building on the framework of internalized racism, being a person of color does not guarantee you immunity from seeing the world, or parts of the world, with a perspective that privileges white culture. Typically, many teachers of color themselves have 
been educated by an oppressive schooling system that promotes white cultural values, and oftentimes we are socialized to see non-white cultural knowledge as inferior to that of the dominant culture (Apple, 1991; Clarke \& Flores, 2001). It is fundamental that we provide space for them to reflect on and heal from racism before they enter the classroom. Grounded in Critical Race Theory (CRT) and Internalized Racism, this study attempts to document that process.

\section{Methods}

The application of CRT calls for researchers to implement a socially just approach to methods as well as research questions and frameworks. This guides researchers to not see participants as data sources alone. Those who share their stories within research studies are people, with voices, complex lives and struggles. The tenets of CRT demand that research validates the racialized realities of participants (Solórzano \& Delgado Bernal, 2001), benefits them and the communities they come from (Solórzano and Yosso, 2001), and co-constructs meaning with participants (Pizarro, 1998).

This qualitative study explored the narratives of teachers of color and their experiences with internalized racism in their education, but it also was designed as a pedagogical process through which the participants were given space to collectively dialogue and unpack their internalized racism and share the ways in which they are working to prevent its manifestations in their students. Data used in this article was collected from a larger study through individual interviews, focus groups, and individual reflections on the focus groups.

\section{Researcher Positionality}

As the primary researcher, I completed all data collection, including the facilitation of interviews and focus groups. With a PhD in Race and Ethnic Studies and Education, I had experience guiding complex discussions about race and racism. Additionally, as a woman of color and a former teacher, I experienced internalized racism both personally and in the classroom. While there may be some limitations to being connected to the phenomenon being studied, it seemed to serve as a strength during data collection. Internalized racism is something multifaceted, sensitive and difficult to capture. While it is not the fault of the victim, internalized racism is often intertwined with guilt, shame or regret, and it takes trust and vulnerability to share something so personal. Guided by CRT, it was essential to my work that I built genuine relationships with participants (Pizarro, 1998, Solórzano and Yosso, 2001). 
I utilized a method that I refer to as reciprocal vulnerabilty, where the researcher shares personal experiences with oppression to establish collective and mutual trust. This method is most effective when the researcher can engage interviews as dialogues that involve openness and vulnerability from both sides. Thus, in this study, I facilitated the focus group interviews, but also shared my own experiences in response to the questions. This dialogue led to participants' comfort and candidness during the interviews. It was also quite personally impactful. While using reciprocal vulnerability can be an effective structure to connect to participants and create a sense of balance within a sensitive discussion, it is also important that a researcher consider the ethical implications of sharing this data within articles or presentations. Therefore, I reviewed all data with participants before and after coding to ensure their comfort with anything I might include.

\section{Sample}

Participants were recruited from a social justice teacher preparation program in Los Angeles, California. In 2007, the program had 170 students enrolled in the credential program; 107 were students of color, a majority of students were women of color (aggregated data not available; TPP Data, 2008). After obtaining permission from the director of the program, participants were recruited in their social foundations classes through presentations, with the incentive of $\$ 100$ worth of social justice curriculum. Forty-four women selfselected to participate in the study, and twelve Latina (4), black (4) and Asian American (4) women were purposefully selected from that pool to ensure a balance of race, ethnicity, and teacher grade and subject matter. The women were all in their twenties, and there was diversity in their comfort levels and experience discussing race and racism.

\section{Data Collection}

Individual Interview: The data collection began with individual interviews, where participants were encouraged to share educational experiences with racism and internalized racism in their own lives, as well as what they observe in schools today.

Focus Group Interviews: Each woman was also assigned to a 6-person focus group with balanced racial demographics for three additional interviews. These interviews were designed as a space for the women to dialogue about racism and internalized racism in schools in an interracial setting. The first focus group was a discussion of racism and internalized racism in their own education, the second addressed their observations with 
racism and internalized racism in the schools in which they work, and the third was a space for them to strategize how to address racism and internalized racism in their classrooms.

Reflections: Participants were asked to write a reflection at the end of each focus group session to gage their individual understanding of the conversation.

Sample Questions: Questions that guided the interviews included, "What experiences did you have with race or racism in your K-12 education? How did these experiences impact your self or worldview? How might these experiences influence your teaching? Do you see race and racism playing out in the school that you currently work in? Do you see these experiences impacting the self or worldview of youth of color in schools today? How might you improve the racial climate of schools today?"

\section{Data Analysis}

All individual and focus group interviews were transcribed throughout the study. Data analysis was guided by CRT methodology, as outlined earlier, which encourages a coconstruction of sense making of data with participants (Pizarro, 1998); and grounded theory, a method by which themes are chosen based upon patterns that emerge within the data (Flick, 2009). I read and re-read all the transcripts, noted reoccurring themes and themes related to the research questions, and sorted the data into categories (Flick, 2009). I also asked participants to share in their reflections how they made sense of the experience, and structured findings around their notions of what was salient or important.

This article presents three main themes: 1) teachers of color's experiences with internalized racism, in which I highlight the susceptibility of black, Latina/o and Asian American students to internalizing racism; 2) teachers of color self-work to unpack internalized racism; and 3) teachers of color challenge to internalized racism in the classroom, which highlights teachers' observations with internalized racism and pedagogy to challenge racial inequality in the classroom.

\section{Teachers of Color's Experiences with Internalized Racism}

The women in the study all endured racism in their schooling (Kohli, 2009). When encouraged to discuss the consequences of the racism, some explained that they were able to deflect its impact through support networks in their family or through the intervention of exceptional teachers. However, numerous participants did not have those means of defense. They revealed a deep connection between repeated experiences with racism and feeling racially inferior. From intellectual inadequacy, to an embarrassment of their family, to 
wishing they were white, many women told heartbreaking accounts of internalized racism from elementary school through college.

At the beginning of this article, we heard the impact of internalized racism on the way Ashley saw her racial group. In addition to those deficit beliefs about the black community, Ashley shared that she developed a self-hate relating to skin tone and hair texture. With no other black students in her elementary school, or teachers that understood her hair, Ashley began to feel shame about her appearance, and wish that she could look White.

I wanted nothing more in elementary school than to be "normal"- I thought normal was to be like the White kids. I had so many issues around standards of beauty. I remember at times, all the girls doing hair at lunch, and me not being able to play, or getting lice checks, and I'd have my hair all braided, and they would undo it, but they couldn't put it back, so I just looked crazy all day. Like, "Ashley stuck her finger in a light socket," kind of thing. So all of that together just make me so ashamed of my hair and the way I looked, and I just always wanted- can I just have long straight blond hair, and everything would just be better.

Although the school staff was not maliciously attacking Ashley, their ignorance about black hair texture caused them to overlook real differences between her and her White peers. These experiences caused Ashley to believe that being black was something to be ashamed of, rather than something to feel pride about. This racial inferiority complex plagued her for many years as she invested hundreds of dollars into straightening her hair, as she says, "trying to emulate white standards of beauty." It was not until she developed a consciousness about racial hierarchies in college that she began to believe her natural hair was beautiful. As shown by Ashley's experience, a lack of cultural understanding in school can impact a child's standards of beauty, which can last for years.

Many women in the study shared similar experiences to Ashley, where racial hierarchies presented at school resulted in lasting internalized inadequacies about their family and/or themselves. Janet was the only Latina in her military base elementary school. Born and raised in Southern California, English was her primary language. One afternoon late into the school year, her Spanish-speaking mother came to pick Janet up and called to her daughter in her native tongue. Hearing this, Janet's teacher rushed up to them and commented that she was not aware that Janet spoke Spanish. Although she had been 
succeeding in class the whole year, the teacher began to doubt Janet's English abilities and felt she should be tested for ESL. The teachers' doubts led Janet to believe that she was not smart, and despite her success, she began to dislike school. She stated,

I remember thinking I wasn't smart enough- I never wanted to go to school. I remember my mom always trying to get me to read more, studying. And I remember just saying, you know, "What's the point?" I just didn't have confidence in myself... As a kid, you're kind of like, well, why do I have to take this stupid test? I speak English, just like all the other kids. I didn't look like all the other kids, but I spoke perfectly fine. I was doing really well, but I just remember not wanting to be there.

Unfortunately, based on the way students look, their names, or their bilingualism, schools sometimes suppose that non-White students are English Learners (Kohli, 2008). Englishspeaking students are, thus, mistakenly filtered into ESL classes. Even though Janet had been speaking English in class all year, it was assumed that because she lived in a Spanishspeaking home she must be deficient in English. The school's unfounded questioning of Janet's English language abilities caused her to internalize this racism, doubt her intellectual prowess, and disengage with school.

Sonia is a Sikh, South Asian woman who grew up in a white community with very few peers from her religious community at school. She explained that her culture was "invisible" in the curriculum, and thus she felt no pride about it. Instead, she used to wish she was white. Sonia shared an incident where her experiences with institutionalized racism prevented her from defending herself and her culture.

In elementary school the bus used to pick us up right across the street from our house, and my grandfather had walked me to the bus stop and then was going to go take a walk. I remember this one kid said something about my grandfather because he wore a turban like, 'whose that dude wearing underwear on his head?' And I remember not saying anything. I was in fourth grade, so I can understand why I didn't say anything. But, it's just not having those tools to defend myself, and to defend my own community. I think I felt very powerless because I already didn't have pride for my community. 
In this example, Sonia experienced a racial slight, where her classmate confused a religious marker for underwear. While the child's comment reflects a larger structural issue of cultural illiteracy, Sonia felt the real tragedy in the situation was not having the tools to challenge the racism. She attributed her lack of power to an internalized shame of her community.

The examples above are from a diverse group of women who internalized the racism exhibited in predominantly White schools. However, conflict within or between communities of color can be just as damaging to a students' self or worldview. Even the women that attended schools that were $100 \%$ students of color expressed that they internalized a racial and cultural inferiority. One example was Elaine, a Korean American woman who attended a predominantly Latina/o elementary and middle school in the South. She had many negative experiences of school where she was teased for her language, and her phenotypically East Asian appearance. She shared that on several occasions she told her teachers that children said "ching-chong" to her, and called themselves "chink-patrol," but teachers were never responsive. One teacher even said, "There's nothing I can do." These repeated experiences, and a lack of intervention or cultural validation by her teachers caused Elaine to feel shame about both her language and her family.

Korean was my first language, but I lost that as soon as I got into school and I feel that it was because I was not around other Korean students and it wasn't something that my teachers ever said, "Oh, great, you're bilingual," you know, just never presenting it to the class that that was an asset and that was something good... My mom isn't a soft-spoken lady; she has a very loud voice and a lot of times when she was speaking in Korean, I would be embarrassed in public because I felt like people would think, "Oh, Asian languages sound like all ching-chong-chong."

Elaine's teachers never placed value on her bilingualism and had peers at school ridicule her identity. Through these repeated experiences she began to believe that her mother was contributing to the problem when she spoke in Korean. The cumulative racism Elaine endured in school caused her to internalize inferiority about the language of her family and feel embarrassment around her language and her mother. She stopped speaking in Korean, and only began to regain it when she studied the language in college and moved to Korea after graduation to teach English.

For many participants, they internalized racism most in their K-12 schooling. For 
JoAnn, however, college was a place that heightened her internalized racism. She grew up in a working class Latina/o neighborhood in the Los Angeles area, attended racially and culturally homogenous schools, and spoke English with an accent that reflected her community. When she got to college, she was judged for the way she spoke.

Where I grew up, everyone talks like this, but it's only when I started college people pointed it out. But it's cute, don't worry, it's cute- you sound like a chola. 'I'm a chola?!' They start already putting you in a box [and] you begin to internalize that. Like I don't speak a Standard English, I don't have a white accent- I'm never going to fit in. When I open my mouth sometimes, people don't think what I say is as articulate because of my accent- or I'm not as smart. Speaking in class, I would get embarrassed.

JoAnn's high school was fraught with low-expectations by teachers and administrators, which had an impact on the life trajectories and goals of many of her peers. Despite the doubt of her high school counselor, JoAnn went to community college and transferred to a prestigious four-year university. She entered college feeling like an accomplished scholar, but was reduced to the stereotype chola (a female gangster) because of how she spoke. This experience made her feel as an outsider and caused her to stop participating in class.

This study provided space for the teachers of color to dialogue about their educational experiences regarding internalized racism. Many participants shared that they had never realized that enduring racial slurs, feeling invisible, and the mistreatment of teachers were common experiences of women of different racial and ethnic groups (Kohli, 2009; Kohli, 2012), and found it powerful to understand that internalized racism was a common experience for women of color. Others shared that it was helpful to discuss this complex topic openly, as it was at times connected to feelings of shame or guilt. Data revealed that guided dialogue helped them develop a more critical understanding of the impact of racism on their self and worldview.

\section{Teachers of Color Self-work to Unpack Internalized Racism}

From elementary school through college, the participants shared experiences with racism that culminated into feelings of internalized racism. For some women, it manifested in the way they saw themselves, their intelligence, their beauty, and for others it affected the way they saw their family and community. However, the participants were all enrolled in a 
social justice teacher education program, inspired to challenge racial injustice in schools. Somewhere along the way, they had done intense work to overcome feelings of inferiority and develop a more positive sense of their cultures and communities. Participating in the individual and focus group interviews enabled them to dialogue with each other and gain insights around their struggles, as well as ways they have challenged internalized racism.

The women shared that the work to unlearn internalized racism occurred in many ways, including joining cultural groups, learning the history of their people, and studying race and racism. For many, this began in college. Janet shared, "When I got to college, history was very empowering because I got to learn about myself." Imani felt similarly as she described her Bachelor's degree in Pan-African studies. She spent her college education learning a history that she was denied in her K-12 education, and developed a great amount of pride in understanding the role of Africa in World History. It was this foundation that inspired her to be a high school teacher, but also helped to protect her from internalized racism.

Even as adults we are not immune to racial hierarchies around us, but Imani felt that consciousness was an important tool in thwarting internalized racism. She explained how racial bias was largely integrated into the credentialing process. She did not initially pass the California Secondary Examination for Teachers (CSET) for History, a test required to gain a California teaching credential. While it could be easy to doubt herself in this situation, Imani's knowledge of self allowed her to see the role of Eurocentric bias in her performance.

I didn't pass the social studies CSET; I'm taking it again. [There was] not one question about Africa for World History. How insulting. How dare you talk about the world, and not talk about Africa? As though we're irrelevant. I think that that probably has something to do with my motivation to study for the test. Here I am, I have to learn everybody else's history but my own in order to pass. In a sense it's brainwashing of some sort. They're telling me that this is what's important. And if I didn't have the consciousness or pride that I have now in who I am, that could very easily skew me to think that European history is more important and this is the history I need to be focused on.

The CSET- a gatekeeper to teaching- emphasizes European history and ignores African history completely. Imani argued that this test could easily instill the message in teachers that African history and people are irrelevant, or unimportant to discuss in the 
classroom. She shared, however, that it was her consciousness and pride that protected her from adopting those beliefs as a teacher.

Even though many participants began to unlearn racial hierarchies and challenge their racial misconceptions in college, internalized racism is something that develops over a lifetime and is reinforced on a daily basis by racial hierarchies in the world around us. It is something difficult to completely overcome. Participants joined this study looking for a place to further unpack their racialized educational experiences and gain tools to create racially just classrooms. Sonia was fearful that racially problematic messages she internalized from her family would impact her teaching. She shared,

My dad really feels like we owe [white people] something because we're in their country, so growing up, they instilled that in us. My parent's mentality was- study hard, and then you can have that life... Leave your community, so you can become one of them- and still to this day, that's their message. I have to fight that. But it really makes me wonder how that's going to affect me as a teacher. What am I going to be communicating to my students about the way that I grew up? I hope that I can step back and check myself on a lot of those things.

Sonia's parents instilled a message that she felt affirmed a hierarchy of white cultural superiority. Although having spent time challenging and unpacking her beliefs, she was unsure how it might impact her teaching, even unconsciously. Martinez (2000) interviewed Latina/o pre-service teachers about their discriminatory experiences in their own schooling. She argued that these negative experiences created an "ideological baggage" that shaped their motivations and goals as teachers. Much like ideological baggage, as Sonia feared, internalized racism can have an unconscious impact on the pedagogy of a teacher, particularly if not acknowledged or addressed. As a teacher, it was important to her that she was able to continuously evaluate herself and address her biases, and was happy to have the space of the focus groups to do this reflective work.

Ashley agreed with Sonia that it was important to continually challenge internalized racism. She shared,

I think it starts with dialogue. I think we really need to start talking about these issues. Like why is it that this is my first time sharing my racial 
discrimination stories [with teachers in this program]? You know, I feel like that's a good start. Now I can think about, “Oh, yeah, how's that affecting my teaching and how am I going to interact with my students?"

Ashley felt it is crucial for teachers of color to critically deconstruct their experiences with injustice in schools and internalized racism, as not to carry it into the classroom. She raised, however, that she was not finding that space within her teacher education training, but was glad to be part of the focus group discussions of the study.

JoAnn reiterated Ashley's sentiment. She said, "When you go into your classroom with black and brown kids and you have all this internalized racism that you haven't dealt with, you can't even have conversations like this. You need to deal with that." In addition to discussing race and racism in schools, JoAnn also felt that having a community of teachers who have shared the same experience could be helpful in overcoming that internalized racism. Unfortunately, as outlined earlier, limited diversity in the teaching force often leaves teachers of color without many colleagues that share their positionality. Thus, it becomes all the more pressing that we provide space for teachers of color to collectively discuss internalized racism as it connects to schooling.

\section{Teachers of Color Challenge Internalized Racism in the Classroom}

As the Clark study demonstrated in 1947, many black youth internalized American racism, which caused them to believe in their own inferiority to whiteness. This study was evidence used to support desegregation in the ruling of Brown v. Board of Education of Topeka. However, while forced integration dealt with the symptoms of racism- segregation, it never really dealt with the underlying disease (Carter, 1988). In 2006, sixteen year old Kiri Davis replicated the Clark doll study in a documentary entitled "A Girl Like Me." Although almost sixty years later, Davis unfortunately found the same results- black children consistently preferred white dolls to black dolls, demonstrating a belief in white superiority and black inferiority. It may seem obvious, but when we do not address the roots of racism or internalized racism, we cannot expect it to disappear.

In addition to discussing their own experiences, the women in the study shared that they encountered many students who had internalized racism. Some students believed that they were intellectually inadequate, while others were self-deprecating and looked down on themselves, their culture and their community. While the teachers entered the study interested in addressing race and racism in the classroom, the process of having dialogue 
about their personal experiences and observations was motivating to them. Not only did they express feeling a "sense of community to reflect and heal with," several women shared that they felt "pumped" and "excited" to think about and intervene specifically on internalized racism in their schools.

In a dialogue about internalized racism, Elaine made a connection to her guiding teacher, who continuously mispronounced the names of her recent immigrant students. The first and second graders, not recognizing their skewed names, would not respond, leaving the teacher angry and yelling at them. Elaine stated,

The teacher called someone whose name is Fidel, "Fiddle, Fiddle," and the student is not responding because that's not his name. You're not going to respond to your name if you don't recognize it. And then she berates him, yells at him like, "Why aren't you answering me? Why aren't you answering me?" and of course imagine how confused [he was]. It was clear that [he was thinking]... 'This teacher is yelling at me because I'm doing something wrong. I don't know what I'm doing, but I'm being bad.'

Elaine, who herself had endured the cultural misperceptions of teachers, was very aware of how the teacher's actions in this classroom were contributing to the student's negative sense of self. She argued that the teacher was not sensitive to the students' names, their recent arrival in the US, and their limited English skills. Because students did not understand what the teacher wanted, or that the teacher was acting in a culturally and racially biased way, these young children began to internalize that they were doing something wrong. As she shared this observation, she also expressed a dedication to creating a classroom that was culturally sensitive and affirmed the identities of all children and their linguistic abilities.

It is not only overt racial slights that can lead to internalized racism. Carolina is a Mexican-American woman who taught in a 100\% Latina/o elementary school. During her observations she noticed that many students had developed negative perspectives about their racial/ethnic group through the media. She also felt that the teacher was not intervening on these perceptions and this resulted in students looking down on themselves. She commented,

A lot of times I hear [the students] pretty much bash on their own race, and I think a lot of that has to do with them hearing all these negative stereotypes. In the media, that's all that's being portrayed. All negative, negativity about our 
race- and it's not being talked about in their classroom. They're not being taught about their own race in the classroom, and so they start beating themselves up for it.

Carolina expressed that the students in this elementary school were exposed to negative images about their ethnic community through the media. With no intervention in school, and a cultural and racial invisibility in the curriculum, she felt that the students began to develop a cultural inferiority complex. When space is not created in school to acknowledge and deconstruct the negative racial messages in our society and media, students are often unable to counter these beliefs and begin to internalize them. Carolina entered the study with limited language to discuss race or racism, but shared that through dialogues about internalized racism, she had a heightened awareness of and better skills to intervene on racially hierarchical messages in the world through the curriculum. In her classroom, Carolina began to incorporate critical media literacy and Mexican history into the curriculum to give students the tools to challenge racism they might face.

Ashley felt similarly that black students at her school did not have ethnic pride, and that much of this attitude came from the media. She agreed with Carolina that teachers were not doing anything to mediate or intervene on their perceptions of white superiority and black inferiority, which resulted in the continuation of black self-hate. Ashley commented,

What plays out with them the most is white supremacy and teasing each other about being too dark, having nappy hair, having parents that look a certain way, or dressing a certain way, or not having things that are associated with wealth- that are associated with mostly white wealth. But it's just these undertones of white supremacy that are never really discussed, and I think teachers hear it, and no one EVER stops to talk about it.

Ashley described many examples of black students accepting the racial hierarchy that deems dark skin and "nappy" hair as less desirable than light skin and straight hair. Having internalized racism about white standards of beauty when she was young, and overcoming that painful self-deprecation, Ashley was very aware of the ways in which her black students were subscribing to ideas of white superiority. It is also important to note that while Ashley had internalized racism in a predominantly white school setting, her students were internalizing the same racist beliefs in a predominantly black school setting because 
regardless of the demographic context, there are many invisible factors in society and in schools that promote white superiority and non-white inferiority, (Clark \& Clark, 1947; Davis, 2006; Perez Huber, Johnson \& Kohli, 2006; Woodson, 1933). Ashley was very committed to promoting self-love and ethnic pride as a means to disrupt the continuing cycle of internalized racism.

Cultural or racial invisibility in the curriculum as a cause of internalized racism was a re-occurring theme in the interviews. Deanna, an African American woman, also shared an example of her black middle school students developing a negative perception of their community and neighborhoods because of an invisibility of social issues in the classroom. Rather than having the structural understanding of why many low-income neighborhoods have high rates of homelessness or unemployment, her students would see community members out of work or homeless and blame them. She describes,

So we were trying to get them to think critically about their neighborhood and we were saying, "When you drive by and you see a lot of black people on the streets, homeless or hanging out at the liquor store or not working during the daytime, what do you think? Why do you think they're there? How do you think they got there?” and a lot of them said, “Oh, they're lazy. They're just lazy. They don't want to work." They're not being taught to think about these things. They just think things just got that way because that race is predestined to be that...or that it's that race's fault.

Deanna's discussion with these students revealed a very problematic, but common, sentiment, the belief in the meritocracy (Loewen, 1996). When youth are indoctrinated with these ideals, but live in communities where there are high rates of poverty, students can begin to believe that their community is the cause for its struggles. This idea can leave low-income youth of color internalizing a racist view that blames their families and communities for their poverty. As Deanna points out, this attitude is in part related to the fact the youth in her classroom were "not being taught to think about these things." Recognizing this as a problem, she was committed to intervening on this internalized racism by infusing critical discussions about social issues in her classes.

Imani observed that her students had internalized deficits about the historical contributions of African people. When she asked, "What do you know about Africa?" students responded with, 
“Oh, people are sick, people are dying,' all this negative stuff. Even the black students would say negative stuff and I'm like, 'Well, I understand why this is the only thing you know because this is the only thing that's portrayed,' and then I would try to tell them the real deal because so much of it is this misconception. All that's in the media, all that anybody will ever know about Africa is all the negativity. I feel so much like it needs to be put out there because ...my heart goes out to them, that's the information I feel like they need.

Because her father is African and her mother African American, Imani had tried to make sense of her identity. She studied African history for many years and felt a responsibility to share this with her students. She began to address the cultural invisibility by changing the way US history was taught. For example, when she taught about slavery, she began her lesson with the ancient civilizations of Africa including, Ghana, Mali and Sunghi, and shared that people from all over the world came to Timbuktu to learn from their knowledge. Imani not only observed the deficits that students had internalized, she also was able to identify the root causes for the bias and create curriculum that would develop positive perceptions of Africans and their contributions to the world. Her analysis and action was directly tied to her cultural knowledge and pride, as well as the way she had dealt with her own internalized racism.

As we see in the stories of the black, Latina and Asian American teachers here, their consciousness and self-work to unpack internalized racism was essential to their trajectories as social justice teachers. Reflecting on their own experiences with internalized racism and their process of addressing it, the teachers of color in this study expressed that they were better able to articulate the internalized racism their students were enduring. Participants shared lessons and strategies they were using to address the internalized racism they were seeing. Even after the scope of the study, many of the women continued to meet because they appreciated the group as a resource in their struggle for educational justice.

\section{Summary and Conclusion}

As we think about the journey of teachers in this study, we see how much effort it takes to unpack internalized racism. They began their schooling experiences exposed to racism and endured its lasting impact throughout their academic careers. However, before 
they became teachers, they went through a great deal of self-work to unlearn the racialized hierarchies they had been socialized to accept. Even so, because internalized racism is a fluid experience that is cumulative and ongoing, it can be difficult to ensure that teachers will not replicate racial bias in the classroom. For the women in this study, it was essential that they participated in dialogue about their experiences with racism and internalized racism specifically in the context of school. By acknowledging their own victimization with racism in school, and its impact on their self and worldview, it became easier for the participants to identify internalized racism within their students and think through strategies to address it in the classroom. Additionally, the fact that these dialogues were interracial was important to their understanding of internalized racism across various communities of color, and allowed for the teachers to see the urgency and be better equipped to serve multicultural classrooms.

Through the lenses of CRT and internalized racism, this study brings light to the racialized realities of a multiracial group of teachers of color, and emphasizes their strength to challenge racism and inequity within education. The narratives woven throughout this article allows us to see how teachers of color can build on their experiences to think about culturally relevant, racially conscious teaching strategies. When considering the preparation of pre-service teachers of color, we must learn from their stories, and recognize that they bring many tools and insights to the classroom that can aid in the challenge to social and racial injustice in the lives of students of color.

\section{References}

Apple, M. (1991). The Politics of the Textbook. New York, NY: Routledge Press.

Bell, D. (2004). Silent Covenants: Brown V. Board of Edcuation and the Unfulfilled Hopes for Racial Reform. New York, NY: Oxford University Press.

Brown v. Board of Education of Topeka, 347 U.S. 483 (1954).

Carter, R. (1988). “1988 Survey of Books Relating to the Law: The NAACP's Legal Strategy Against Legal Segregation, 1925-1950. By Mark Tushnet.” Michigan Law Review, 86, 1083-1095.

Clark, K.B. and Clark, M.P. (1947). Racial Identification and Preference in Negro Children. In Readings in Social Psychology, ed. T.M. Newcomb and E.L Hartley, pp. 169-178. New York, NY: Holt. 
Clark, E.R. \& Flores, B.B. (2001). "Who am I? The Social Construction of Ethnic Identity and Self-Perceptions in Latino Pre-service Teachers." The Urban Review, 33(1): 6986.

Cokely, K. (2002). “Testing Cross's Revised Racial Identity Model: An Examination of the Relationship Between Racial Identity and Internalized Racism.” Journal of Counseling Psychology, 49(4): 476-483.

Cross, W.E. 1971. The Negro-to-Black conversion experience. Black World 20: 13-42.

Cross, W.E. (1995). “The Psychology of Nigrescence: Revising the Cross Model.” In J.G. Ponterotto, J.M. Casas, L.A. Suzuki, \& C.M. Alexander (Eds.), $\underline{\text { Handbook of }}$ Multicultural Counseling. Thousand Oakes, CA: Sage.

Davis, K. (2006) A Girl Like Me. Documentary accessed at: http://www.youtube.com/watch?v=17fEy0q6yqc

Fanon, F. (1963). Wretched of the Earth, New York, NY: Grove Press.

Fanon, F. (1967). Black skin, white masks. New York, NY: Grove Press.

Feistritzer, C. E. (2011). Profile of Teachers in the US 2011. National Center for Education Information.

Flick, U. 2009. An introduction to qualitative research (4th ed.). Thousand Oaks, CA: Sage.

Gay, G. \& Howard, T.C. (2000). "Multicultural Teacher Education for the $21^{\text {st }}$ Century." Teacher Educator, 36(1): 1-16.

Harper, S. R. (2006). Peer support for African American male college achievement: Beyond internalized racism and the burden of 'acting White.' Journal of Men's Studies, 14(3), 337-358.

Kohli, R. (2008). "Breaking the Cycle of Racism in the Classroom: Critical Race Reflections of Future Teachers of Color." Teacher Education Quarterly, Teacher Education Quarterly. 35(4): 177-188.

Kohli, R. (2009). "Critical Race Reflections: Valuing the Experiences of Teachers of Color in Teacher Education," Race, Ethnicity and Education, 12(2): 235-251. 
Kohli, R. (2012). "Racial Pedagogy of the Oppressed: Critical Interracial Dialogue for Teachers of Color.” Education, Equity and Excellence. 45(1): 181-196.

Ladson-Billings, G. \& Tate, W. "Toward a Critical Race Theory of Education.” Teachers College Record, 97:1, 47-68.

Ladson-Billings, G. (2001). Crossing over to Canaan : the Journey of New Teachers in Diverse Classrooms, San Francisco, CA: Jossey-Bass.

Loewen, J. (1996). "Gone With the Wind: The Invisibility of Racism in American History Textbooks.” Lies My Teacher Told Me. New York, NY: The New Press, p.138-170.

Martínez, E. (2000). “ Ideological Baggage in the Classroom: Resistance and Resilience among Latino Bilingual Students and Teachers." in Immigrant Voices: In Search of Educational Equity. Trueba, E. \& Bartolomé, L., Lanham (eds.): Rowman \& Littlefield Publishers.

National Collaborative on Diversity in the Teaching Force, (2004). "Assessment of Diversity in America's Teaching Force: A Call to Action.” Washington D.C.

Oakes, J. (2002). “Keeping Track, Part 1: The Policy and Practice of Curriculum Inequality.” Equity Materials.

Oakes, J., Rogers, J., Silver, D. (2004). Separate and Unequal 50 Years After Brown: California’s Racial “Opportunity Gap”. Report published by UCLA/IDEA Institute for Democracy, Education and Access.

Oakes, J. and Saunders, M. (2008). Beyond Tracking: Multiple Pathways to College, Career, and Civic Participation. Cambridge: Harvard Education Press.

Omi, M. \& Winant, H. (1994). Racial formation in the United States: From the 1960's to the 1990's. New York, NY: Routledge Press.

Padilla, L.(2001). “But You're Not a Dirty Mexican: Internalized Oppression, Latinos \& Law. Texas Hispanic Journal of Law and Policy, 7: 59-133.

Perez Huber, L., Huidor, O., Malagon, M., Sanchez, G., \& Solórzano, D. G. (2006). Falling through the Cracks: Critical Transitions in the Latina/o Educational Pipeline. Latina/o Education Summit Report, UCLA Chicanalo Studies Research Center. 
Perez Huber, L., Johnson, R. \& Kohli, R. (2006) "Naming Racism: A Conceptual Look at Racism in US Schools.” Chicana/o Latina/o Law Review. v. 26.

Pizarro, M. (1998), “'Chicana/o Power!' Epistemology and Methodology for Social Justice and Empowerment in Chicana/o communities." Qualitative Studies in Education, 11(1): 57-80.

Poupart, L. (2003). "The Familiar Face of Genocide: Internalized Oppression among American Indians.” Hypatia. (Project Muse Article)

Pyke, K. \& Dang, T. (2003) "Fob" and Whitewashed": Identity and Internalized Racism Among Second Generation Asian Americans. Qualitative Sociology, 26(2): 147-172.

Quiocho, A. \& Rios, F. (2000). “The Power of their Presence: Minority Group Teachers and Schooling." Review of Educational Research, 70(4): 485-528.

Sakash, K. \& Chou, V. (2007). Increasing the Supply of Latino Bilingual Teachers for the Chicago Public Schools. Teacher Education Quarterly, 34(4): 41-52.

Solórzano, D. \& Delgado-Bernal, D. (2001). "Examining Transfomational Resistance Through a Critical Race and LatCrit Framework: Chicana and Chicano Students in an Urban Context," Urban Education, 36(3): 308-342.

Solórzano, D. \& Yosso, T. (2001), "Critical race and LatCrit theory and method: counterstorytelling." Qualitative Studies in Education, 14:4, 471-495.

Taylor, J. \& Grundy, C. (1996). "Measuring Black Internalization of White Stereotypes About African Americans: The Nadandolitization Scale. In RL Jones (Ed.). Handbook of Tests and Measurements of Black Populations, Vol 2. Conn \& Henry: Hampton, VA.Woodson, C. (1933) MisEducation of the Negro.

Teacher Preparation Program, 2007-2008 Enrollment Data.

Villegas, A. \& Jordan Irvine, J. (2010). "Diversifying the Teaching Force: An Examination of Major Arguments." Urban Review, 42(3): 175-192.

Weissglass, J. (2004). "Racism and the Achievement Gap.” Education Week, 20(3): 49-72. Woodson, C. (1933) MisEducation of the Negro, Trenton, NJ: Africa World Press. 
Yosso, T. (2005). Critical Race Counterstories along the Chicana/Chicano Educational Pipeline. New York, NY: Routledge Press.

\section{Dealing with racist incidents: what do beginning teachers learn from schools?}

\section{Sarah Pearce}

\section{Goldsmiths College, University of London, UK}

\section{s.pearce@gold.ac.uk}

This article focuses on how schools respond to racist incidents, and what new teachers learn from their involvement in those processes. It analyses four incidents involving the pupils of four beginning teachers. The article suggests that in each case, schools either partly or wholly avoided addressing the incident, and that this avoidance can be understood in terms of the colour and power evasive discourse, which is the dominant discourse on race in Western societies, and in most schools. One aspect of this discourse is that racism is defined on the basis of individual intentions, not outcomes. The article argues that it may be possible to adopt a more race cognisant approach with student teachers and staff in schools, building on nascent understandings of institutional racism, which shifts the focus to outcomes rather than intentions. The article demonstrates this approach, analysing each incident in terms of its consequences for the learning of the new teacher, and for the promotion of race equality in the school. While the small number of incidents may initially appear heartening, their negative impact on both teacher confidence and children's understanding may be significant. The findings suggest that in the changing context of initial teacher education in England, approaches to supporting both schools and new teachers in this often misunderstood area are much needed, and that one way forward may be to give teachers time and support to critically reflect on and discuss their experiences.

Keywords: race, racist incidents, institutional racism, student teachers, beginning teachers, whiteness

\section{Introduction}

Racism remains an important problem in UK schools. In 2012 the BBC's news website reported that the number of racist incidents logged by schools rose steadily between 2007 and 2010, the year in which the current Coalition Government removed the obligation for schools to keep records (BBC 2012) ${ }^{1}$. In some areas, the number of reported cases increased by $40 \%$ 
in that period. The BBC website reported a leading anti-racism campaign group describing the 88,000 cases as 'the tip of the iceberg', since such cases are very often under-reported (BBC 2012). Yet one popular newspaper reported the story of the release of the figures under the headline, '88,000 children branded racists' (Daily Mail, 2012). In taking this stance, the newspaper drew on the dominant discourse on race in British society and elsewhere, which fails to understand the purpose of monitoring such incidents, and sees racism only as extreme and violent acts, rather than a subtle and pervasive feature of our social structures. The headline suggests that the act of logging a racist incident automatically defines the individual involved as 'a racist': racism is only ever understood as personal prejudice. But some of the individual cases quoted in the story suggest another aspect of this discourse: some senior managers in school appeared to have defined any direct reference children made to race as a racist incident. According to this colourblind way of thinking, any form of race consciousness is equated with racism, and any discussion about race is therefore to be approached with trepidation.

In this article I suggest that this reluctance to engage with the meaning and consequences of racism is also common in English schools. In it, I present a detailed analysis of four incidents which took place in four different primary schools in London. In accordance with accepted best practice at the time ${ }^{2}$, they were all defined as a racist incident by one or more of the people who witnessed it. In analysing the incidents, I draw on two theoretical sources. First, the somewhat discredited concept of institutional racism. The value of this term is that it shifts the focus from individual intentions to the outcomes of institutional practices. I argue that this is the key shift that needs to take place in the attitudes of those in schools who continue to define racism solely in terms of individual aberrant behaviour. In this article, following this approach, I examine the accounts of the four incidents for evidence about how each incident was dealt with, the extent to which that response advanced the cause of race equity in the school in general, and what the new teacher learned about their role in promoting race equality in particular. The second theoretical resource I draw on to support my analysis is Ruth Frankenberg's (1993) seminal model of three discourses of race. This enables individuals to understand notions of race and racism as constructed, and to see that there exists a degree of agency in the stance we take on racism.

\footnotetext{
${ }^{1}$ The removal of this requirement coincided with the new Equality Act which drew together several separate anti-discriminatory laws, including the Race Relations Amendment Act, in order to make the law less bureaucratic. A further consequence of this is that it is no longer possible to know the scale of the problem of racism in schools.
} 


\footnotetext{
2 The MacPherson report recommended that a racist incident should be defined in the first instance as 'any incident which is perceived to be racist by the victim or any other person' (MacPherson 1999). This definition has been widely accepted in local authorities and schools in the UK.
}

\section{Definitions of racism in popular and academic discourse}

In 1999, the publication of the MacPherson report into the failings of a police investigation into the racist murder of Stephen Lawrence briefly challenged the dominant definition of racism in mainstream UK society. In its use of the term institutional racism, the report shifted the focus away from popular definitions of racism as a marginal, aberrant phenomenon, to more subtle and pervasive processes (MacPherson 1999). It stimulated an unprecedented level of national debate. Yet within days, politicians began to distance themselves from the term, and the change in perspective it signalled, (Gillborn 2009). While it is widely agreed that MacPherson's use of the term lacked a historical dimension, or a clear sense of how institutions are related to wider structural inequalities (Bourne 2001, Warren 2007), it did begin to raise public awareness of the more insidious forms of racism.

Ruth Frankenberg's (1993) work maps the different conceptualisations of race that gave rise to the controversy over the MacPherson Report over a decade ago, and- as the media debate over the number of racist incidents in schools shows- continue to cause misunderstandings. Drawing on earlier work by Omi and Winant (1986), she identified three discourses, namely essentialist racism, colour and power evasiveness, and colour and power cognisance. Each of these emerged at a particular point in history, thereafter existing alongside rather than replacing the preceding one. While colour and power evasiveness is a discourse that seeks to overemphasise the similarities between people, the other two discourses prioritise difference, but in radically different ways. The racist discourse upholds a belief that race is an intrinsic marker of individual value or ability, and the biological superiority of white people. Colour and power cognisance involves an acknowledgement that race structures societies, and that the result is inequality and injustice. It is also an assertion of difference not on the terms set by the white dominant culture: a refusal to submit to merely being the 'Other'. Difference in this discourse implies autonomy, rather than inferiority, in terms of what is culturally and ethically valued.

Though the three discourses co-exist, and at times intermingle, Frankenberg suggested that in the context of the USA colour and power evasiveness currently dominates. I argue that this is also the case in contemporary Britain. Within this discourse, sometimes called colourblindness, the attitude that 'we are all the same under the skin' prevails. Frankenberg 
preferred the term, 'colour and power evasive' because it encapsulates the strategy of appearing to recognise and value cultural differences, while refusing to acknowledge the role of race in structuring social inequalities. Bell and Hartmann (2007) refer to this phenomenon as 'happy talk'. Moreover, colourblindness invokes a metaphor of disability, as if the problem is that individuals genuinely cannot see the issue. Pollock's (2004) term 'colourmute' is sometimes preferred as a way to highlight the fact that the real problem is not a lack of recognition of the significance of race, but an unwillingness to discuss it openly.

Within the colour and power evasive discourse racism is always and only defined as a matter of personal prejudice. Consequently, the non-racist way to behave is to ignore the issue all together. More recently Dickar (2008) and Buehler (2012) have argued that while many white teachers are indeed unwilling to engage with issues of race, this reluctance sometimes stems, not from a desire to appear non-racist, but from an acute sense of the complexity and personal threat involved in race talk. Regardless of the motivation, the effect of such evasiveness is to maintain race inequity. And, following the logic of my argument about the primacy of outcomes over intentions, motivation is not the key concern here. What matters is the consequence of these evasions. The consequence of some teachers' mistrust of the process of reporting racist incidents is that patterns of collective injustice are not identified, and therefore not addressed (Parsons 2009). The consequence of some teachers' definitions of children's comments about skin colour as racist is that race talk is prohibited. In both cases, progress is blocked.

\section{The policy context}

During the period in which the data for this article were collected, and until 2011, English schools were required by law to have a policy on promoting race equality, and to monitor and assess the impact of their policies on different racial groups. This legislation can be understood as drawing on the colour and power cognisant discourse in requiring schools to identify children's ethnic backgrounds and to log racist incidents as a route to identifying and eradicating patterns of race inequity. Supporting documents encouraged schools to discuss racism and any perceived inequalities openly with all interested parties (CRE 2002). Yet the dominant discourse in schools was and is colour and power evasive: as such open discussions about the emotive and confrontational issue of race, highlighting children's ethnic differences, and dealing proactively with racist incidents were all practices which were likely to be resisted. Several research studies found that this was indeed the case: schools were 
found to be the slowest of public institutions in their response to meeting the new requirements (Schneider-Ross 2003), and only a minority had progressed beyond the stage of drafting a policy to evaluating the impact of it (Parsons 2009). Experienced school staff, too, were found to lack an understanding of racism that went beyond overt verbal and physical aggression (Gillborn 2002; Pearce 2005; Parsons 2009).

It is difficult not to see this period as a time of lost opportunity: accompanying the new legislation with an intense period of in-service training about the meaning of institutional racism might have enabled staff to understand, support and then genuinely implement the new legislation. In other words, there was no co-ordinated attempt to support teachers in moving away from the colour and power evasive discourse, and old conceptualisations of racism, which was- and remains- a fundamental part of the problem.

The widespread lack of compliance with both the spirit and the letter of the law is of particular concern given that these requirements have been superseded by the single Equality Act of 2010, which draws together several so-called protected characteristics, including race, gender and disability. The justification for drawing together legislation on several aspects of inequality is that simplifying the legislation makes the law easier to understand and comply with (Equalities Office 2011) but there is a danger that, while colour and power evasiveness remains the dominant discourse in schools, if there is no positive and specific requirement to address race equality, it simply will not be addressed. Schools could now remove race from their agenda altogether, and remain compliant with the law.

\section{Addressing race and racism in initial teacher education}

Research has shown that those teachers who understand racism as more than personal prejudice often have some personal experience of disadvantage, or themselves come from non-dominant backgrounds (Ullucci 2011; Pearce 2012). This has important implications for recruitment practices, but while white middle class students constitute the majority of those applying to become teachers (Hick et al 2011), arguably the best place to address teacher awareness is during pre-service education. Several studies have documented student resistance to teacher educators who have attempted to focus explicitly on white power structures (e.g. Aveling 2002; Solomon et al 2005; Lander 2011). Other projects have focused on requiring students to rethink their attitudes by engaging with unfamiliar cultural settings, or exploring non-dominant perspectives through film and other materials (e.g. Aveling 2006; Rich and Castelan Cargile 2004; Houser 2008). Such work is important and 
must continue. But in most institutions, the intensive nature of the training programmes, together with a lack of confidence among some staff, make such complex and sensitive projects on race and racism unlikely to become standard practice (Hick et al 2011). In England, from September 2013, individual schools will bear most of the responsibility for student teachers' learning. It seems unlikely that such intensive work will be carried out as part of school based training.

In this context, it may be prudent to begin to look for ways to address race and racism which can be accommodated in schools. Picower (2009) has shown that there is potential in enabling beginning teachers to reflect on their experiences and to engage in discussion and reading alongside their teaching load, and Buehler (2012) argues that when talk about race is seen as acceptable among staff, it opens up possibilities for change in schools. There appear to be three factors in enabling the kind of reflectiveness that is essential for such dialogue. First, a mentor who models and promotes reflection (Turner 2012); second, the space and time to reflect; and third the opportunity for open dialogue with others. In identifying the significance of reflection, Turner draws on Schön's (1991) formula for reflective practice, which includes framing and reframing a problem, or looking at it in different ways. My suggestion that, in reflecting on racist incidents, the focus should be on the outcomes, rather than the intentions, may be seen as an example of reframing a problem. And this may enable more beginning teachers to understand how racism operates independently of individual consciousness. This may also link to mentors' understandings of institutional racism as focusing on institutional outcomes rather than individual intentions.

\section{Methods}

The data presented here are drawn from an ongoing longitudinal study of a group of nine teachers, from their final year on a primary teacher training course in London, to what is now their sixth year in teaching. The overall aim of the project is to examine what individual and institutional factors enable or inhibit new teachers in developing an approach to teaching that addresses race inequity and ethnic diversity. The project is informed by critical whiteness studies, seeking to uncover white hegemonic practices in terms of staffing, curriculum and policy development and interpersonal relationships.

All of the participants were women, aged between their early twenties and early forties at the start of the project. They all expressed a commitment to diversity and race equality. Five of the participants described themselves as white British, two had African-Caribbean 
backgrounds, one was from a Somali background, and one had a mixed white British-Greek Cypriot heritage. All but one of the women had been born and brought up in London, and all but one identified themselves as being from a working class background. They were voluntary participants, drawn from a humanities course I had taught in their final year of their $\mathrm{BA}(\mathrm{Ed})$ course.

The project adopted a narrative approach to understanding the teachers' experiences, seeking to make connections between their personal biographies, their work in their own institutions, and wider social and political issues (Beattie 1995; Erben 1998). The data were collected through annual in-depth individual interviews, my questions focusing on eliciting detailed descriptions of incidents and conversations related to race and ethnicity, and the participants' extended reflections on these. Each interview was digitally recorded, and in the first and second rounds lasted between 60 and 90 minutes. I sent each individual transcript to the interviewee for verification. On one occasion a participant emailed an unsolicited narrative of an incident, and her reflection on it, to me. The data were coded using the constant comparative method of Glaser and Strauss (1967), and NVivo software was used to organise the codes. The words of the participants are quoted at length to enable the reader to get as clear an understanding as possible of their perspective on the incidents. All names used are pseudonyms.

This article draws on data collected from the first two rounds of interviews: those undertaken in 2007, just after the participants' final teaching practice, and in 2008, during their first year of teaching. Over the course of those two years, participants relayed several subtle examples of racism, some of which are discussed elsewhere (Pearce 2012). But there were only four events which were formally recognised and addressed as racist incidents in the classroom. This low number could be seen as encouraging: but it must be a matter of concern that none of the incidents was handled in a way that typifies best practice, and this suggests a lack of support for race equality in these schools.

It is important to note that we only have a partial view of the incident: it is witnessed and reported by the student or new teacher. The perspectives of the children involved, and the senior manager are either unknown or are relayed only by my informant. Furthermore, there exists only an initial account of the incident itself, and some questions remain unanswered about the detail of what occurred. Despite these limitations, this data is a valuable source of evidence of the ways in which racist incidents are dealt with on the ground, which, given the 
sensitivity of the issue, is inevitably very difficult to acquire. More important, what is under analysis here is not the incident itself, but, first, the immediate response to each incident, second the impact on race equity in the school as an institution, and finally what the new teachers' reflections on the incident suggest about what they learned about how to deal with racism in schools.

\section{Findings and analysis}

\section{Leah}

The first incident was related by Leah, a teacher in her early twenties, who came from a mixed white and Greek-Cypriot background. She had grown up near the school in which she had taken up her first post. Most of the children were from Bangladeshi backgrounds. Early in the year, as Leah began her first year in teaching, one pupil had been excluded from school for bullying the only Somali girl in the class:

I suppose I had a problem with the school's way of dealing with it. Because they needed to find a child that was responsible. Rather than saying it's a broader issue, they were like, 'who's responsible?' ...And I was really shocked because I didn't think that that's what it was at all, I didn't think it was one child. But that was what was told to me, and ... I felt that was really bad practice. And I felt powerless to do anything about it.

Leah remembered the first incident as one in which the school's approach had been to identify one individual as responsible for the problem, although this did not accord with Leah's own reading of the situation. It is not known whether this incident was considered a racist one, but the strategy of highlighting the behaviour of one child for actions which may have been common to most of the class appears to have been an attempt to contain the problem. They were prepared to deal with one child, but not with a wider and deeper problem which acknowledging the involvement of most of the class would have involved. The outcome of this decision was that the bullying continued.

Leah then related the latest incident involving this girl:

'They said, 'let's follow her in the dinner line, and make sure we sit on her table. When we get to her table, we're going to take the gravy from our plates and smother it on our faces... and they did that. And then we're going to go into the playground and they were chanting round her and bullying her. It took me a long time to get to the bottom of this 
and find out all of this. Because at the end of lunchtime they were all crying. I asked what happened. None of this came out. It was, 'her brother said he was going to hit me,' and 'she said she's going to get guns and kill all the Bengali people.' I got seven of the children to write their version of what happened. And then it came out. And I interpreted that as a racist incident, and I told the head, and I wrote it all down in the Concerns book. And I'm really not happy with the way they dealt with it. They backed me up when I was in the office. They're like, 'oh yes this is terrible, you need to come to us if you're concerned.' And then the next day they pulled the children out. I don't know what they said to the children. Then they came back in the class, and they said, 'well, we've decided that it wasn't a racist incident. It's just children being silly. And we've decided that we mustn't do silly behaviour.' I just couldn't believe that they were getting away with it! I know that sounds terrible, but they'd manipulated the Headteacher into believing that, [adopts a meek childish voice] 'we were being silly; we were playing with our food.' Which really upset me. What do you do?

Leah herself identified this incident as racist, and followed the well-established formal procedure for dealing with racist incidents in the school. The initial response of the senior management team was supportive. But the following day, the incident was redefined in deracialised terms: the children were just 'being silly'. It is possible to see the elements of the colour and power evasive discourse in the actions of the senior management team here, who seek to remove race from the analysis. In terms of the outcomes of the incident, the girl at the centre of these events was left in the situation, with her tormentors. There was no attempt to challenge their thinking, or give a clear message that their behaviour was unacceptable and carried serious consequences: it was mere silliness. Redefining the incident in this way served the same purpose as the strategy of acknowledging only one perpetrator earlier in the year: it contained the incident so that no far-reaching action was deemed necessary. It is likely that the behaviour of the children was a reflection of tensions between some members of the Bengali and Somali communities in the local area, and that the senior management team was unwilling to get involved in these complex and controversial issues. The concept of performativity (Ball 2003) offers a way to understand why, in a tightly monitored environment, maintaining the appearance of harmony may be more important than risking the disruption and negative publicity that may come with an open engagement with the problem. In this audit culture, as long as the policy document meets the requirements, the day to day practice, being outside the reach of the auditors, need not match (Ahmed 2007). Such 
institutional pressures to silence race talk accord with individual teachers' desire to avoid the personal risks associated with addressing complex and controversial issues (Dickar 2008).

What did Leah learn as a result of her involvement in this incident? Having already experienced what she considered a mishandling of an earlier incident, she felt a pattern was beginning to emerge:

I always feel that I'm undermined in my decision or my perspective on the situation. So I feel like I'm following the procedure through very clearly. I say, that's unacceptable, fill out a behaviour sheet. It seems to me that little issues are made really big, and issues that are big are made really little.

Leah followed the policy in good faith, but in doing so she was not supported by her managers. This left her in a very difficult situation in her classroom. She identified the behaviour of several of the children in her class as racist, but that judgement was overturned, and she now had to continue to work closely with those children. In terms of student teacher learning, something important happened in the course of the interview. As she talked about other incidents and difficulties that she encountered over the course of her first year, Leah started to analyse her situation, and articulate her own emerging philosophy. She began to think about the new class she would be taking on that autumn:

The class coming up has got very similar issues. So what does that suggest? That suggests this is a whole school issue- I know it's a whole school problem! I can see that, and I feel disheartened because I feel as one individual how much impact can I have if we're not cohesive as a school?...I'm not in tune with their values or their educational ethos at all.

Leah felt that her values and her continuing commitment to issues of equality left her isolated in the school. She was unable to talk to her school mentor, because she was the senior manager involved in what Leah regarded as the mishandling of the racist incident. She therefore looked to me as her former tutor and mentor for support and guidance:

I think what I'm saying is there is no help in the school, there's no structure to solve these issues...So if I'm going to make a difference next year, I need a direction to go in. And I need a structure that I can take, and I don't have that at the moment. I don't know if you're able to help? 
Leah's developing understanding of her situation, and her plea for help, supports the suggestion by Turner (2012) and Picower (2009) that reflection can be a positive tool for developing teachers in school, but that there is a need for reflective mentors, and for the time for dialogue to make such reflection sufficiently complex and purposeful.

\section{Susan}

Some insight into how beginning teachers may begin to develop this progressively complex understanding of their situation is offered by Susan's reflections on the second incident. This took place in a class of six and seven year olds in a school in a suburb of London, in which around $75 \%$ of the children were of African-Caribbean heritage, the remainder from a diverse range of backgrounds. The student teacher, Susan, was white, and her class teacher mentor was black.

A black girl said she didn't like white people, and then another girl on that table said the same. And there was a white boy on the table, struggling very much within that environment. I heard it first and took it to the class teacher, because I just thought, 'I'm not quite sure what to do with this', and then she heard it again. The class teacher had a chat with them about it, and then took it to the parents, and said it wasn't acceptable. It was done very well actually, I have to say. And I said, 'well what is the formal procedure?' She'd had the class for two years and she didn't want to make it a formal thing. I mean they are only young, only six, seven. But she did want to talk, so we did a PSHE [personal, social and health education] session about it... The children knew the word racism... And the children talked about how, you know, what you look like, whether you're a girl or a boy, everyone is the same, you know. Everyone's the same but different, and that's OK, that's how it's supposed to be. And it was very much along that line of talk. And the children inputted really well, and they were clearly very aware of it. So I mean I thought it was handled very well. And very fairly. That was one of the main things I wanted to say really.

Susan started by telling the story of the incident as an example of a racist incident which was handled well. The comment was identified by the teacher as racist, and there was an open discussion with both children and parents, and a clear message was sent about the teacher's, and by extension the school's, uncompromising stance on any form of prejudice. Yet closer examination suggests that the situation was not as clear cut. In the first place it should be noted that Susan mentions the white boy on the table, suggesting that the incident was more 
serious because there was an immediate 'victim'. This kind of stance defines racism as limited to the overt insulting remarks or actions, not in racialised ways of thinking which permeate society. It might be pertinent to ask whether the incident would have been interpreted as racist if no white child had been present. In the second place, while it is not possible to know what discussions took place between the teacher and the girls, nor with their parents, it does not appear that there was any acknowledgement of the negative feelings of the girls, and their own experiences or awareness of racism, which may have provoked their remarks. In terms of the broader discussion with the whole class, too, it appears that the teacher's strategy was to minimise the problem: her reference to everyone being 'the same but different and that's OK', her reference to girls and boys, and personal appearance, seem intended to move the discussion away from racism, strategies associated with the colour and power evasive discourse. Thus, in terms of outcomes, it does not appear that a strong message about racism was sent to the children as a result of this incident. Susan considered the way the teacher dealt with the incident in terms of the children's learning was a good model for her, as a beginning teacher, and one who was initially unsure of the appropriate action to take. Yet even in this first, positive, telling of the story, she was aware that the teacher did not follow up by formally recording and reporting the incident, as schools were then required to do.

Despite Susan's initial report of the story as evidence of good practice, she broke off in the middle of a discussion later in the interview and abruptly returned to the incident:

It was difficult, I mean with the girls saying that, it was difficult. I didn't feel knowledgeable enough to deal with it on my own, but I guess I would kind of discuss it with somebody. If I hadn't had my class teacher to discuss it with, because I mean, she said it was very uncharacteristic of these girls, and she knows them much better than I do, so that's fine. But also it could be a wider thing that's going on in the playground that's you know been brought into the classroom and maybe that should be something the school should know about... But I don't think that happened. And I did say to her, you know, 'is there a procedure?' And she said she didn't want to take it that far at this stage.'

There are clues here to the teacher's own stance on racism. The contrast between her proactive approach with the children and their parents, and her refusal to report the incident formally suggests that she may not support the practice of logging. Drawing on the colour 
and power evasive discourse, she may have viewed the process as a punitive one, which would label the girls themselves as racist. That the teacher was herself from a minoritised background does not appear to be the primary driver in her decision making here: her actions may be read as enacting institutional (i.e.white hegemonic) norms.

Susan's attitude to the incident also appears in more complexity here. Moving on from her first telling of the story as one in which she felt she had learned how to deal with a racist incident positively, she reflected on her own lack of preparedness to deal with such issues, and the importance of having someone to talk to about such sensitive matters. But her reference to the possibility of the girls' remarks being part of 'a wider thing that's going on in the playground' shows that she had an understanding of racism as best understood as a discourse, which can be drawn upon by anyone, rather than a committed stance adopted by a few malevolent individuals. She then drew on a different aspect of the race cognisant discourse, reflecting on the part her own racial location may have played in the incident:

And it did make me feel uncomfortable, because initially you kind of go through all kinds of thoughts. You know, they had this black teacher for two years and then suddenly a white teacher comes in...is it me they are talking about? Has it come up because it's me? Because I'm white and she's black and they are having to get used to this new person who they don't feel comfortable with. It could be that. It could have been that.

Susan was aware that her own racial identity might have been a significant factor in the classroom. In contrast, other studies have shown that white teachers often lack awareness (or strategically resist acknowledgement) of their own racial location, and the part it might play in influencing relationships with colleagues and pupils (Pearce 2005; Lander 2011).

What is most significant about these extracts is the way in which an initially straightforward narrative of a positive handling of a difficult situation was revisited, and a more complex and personally challenging perspective added. As with Leah, above, it may be that the interview gave Susan time, and gave issues of race status, which empowered her to reflect on her involvement with this incident in a much more analytical way. Like Leah, she did not discuss this most complex aspect of the problem with her teacher mentor.

\section{Debbie}


The third incident took place in a mainly white school in a suburb of London during Debbie's final teaching practice. Debbie, her teacher mentor, and all of the staff at the school, were white. The story involved Shakira, a six year old girl whose white mother and black father had recently separated under acrimonious circumstances.

There was one day when the teacher was off somewhere else... and [Shakira] had had an argument with one of the other girls in the class, who was also black, at playtime. [She] had said to the other girl, 'you're black and I don't like you 'cause you're black'. [Deep sigh] And I just knew...there's a real sense of sadness about this child, so I said, you know, 'now is not the time to deal with this. I'm going to have to chat with you at lunchtime. I'm not keeping you in, I'm not punishing you, I'd just really like to have a chat with you,' ... because you know you've got to get on with the lesson. And I kept them both in for five minutes and we had a short chat about it...because I made a judgement that the black girl...um... was pissed off about it but I think genuinely accepted the apology. But what I really wanted to do was talk to Shakira and find out what she was talking about...because whatever she saw herself as people would see her as black. And she's saying 'I don't like you because you're black'. I just found this difficult.

So I was talking to her, saying you know, "what did you mean by that? Why did you say that?' And she was saying all black people do is cause misery...they just upset people, they're always fighting, you know, just absolute, negative, negative, about everything and I sort of felt totally out of my depth, I didn't know what to say, what to do, and I was really, really ...you know I thought I just don't know how to deal with this at all. And I said to her, you know, 'what are you? Are you black or are you white, what do you think you are?' And she said 'I'm black', and she just started to cry. It was really, really hard actually. So I spoke to the teacher about it and she kind of dismissed it a little bit really [breaks off, visibly upset].

In this incident, Debbie identified Shakira's comment as a racist one, and appeared to address the needs of the victim in the first instance, while taking care not to demonise Shakira. She then sought to understand what provoked her to make this remark. In doing so, she asked Shakira to identify herself in racial terms, which revealed something of the girl's underlying pain and confusion. Realising that she was out of her depth, she then went to her class teacher, who did not feel the need to act on Debbie's report: she dismissed the incident. 
Retaining the focus on outcomes, it appears that Shakira was left to deal with her confusion and distress about her identity without support or guidance.

Once again, drawing on the model of discourses of race, we can identify colour and power evasion in the teacher's dismissal of the issue. But her response also illustrates how discourses can overlap, and an individual can draw on more than one discourse to make sense of their situation. The teacher's reluctance to respond to Shakira's situation may have drawn on elements of the racist discourse: within the school she was identified as a problem: she was low achieving, with a family deemed hard to reach, unsupportive and needy. A deficit discourse, based on her race and social class position, appeared to work together to create a situation in which the child was seen as beyond help: she was dismissed.

In a sense the teacher also dismissed Debbie's learning: she understood that she would not be supported in her attempts to engage with the children's identity development, or to address racism proactively. She learned, then, that, in that school at least, such activities are deemed, at best, marginal to the work of teaching.

\section{Natalie}

The fourth incident took place in a very diverse class of nine and ten year olds in South East London during Natalie's first year in teaching. Natalie grew up and still lived in the local area. She was in her late twenties and from an African-Caribbean background. The story of the incident was relayed to me via email:

During lunchtime a group of children were playing truth or dare... 'Naturally' the topic reached boyfriend/girlfriend... Ania (a Polish girl) said to two other girls that Micah was 'too black', apparently in reference to whether or not she would date him... Two girls who Ania had made the comment to came to me and told me, Chelsea (white British) and Yasmin (Somali)... The school's policy is to report any racist incident immediately to the EMA [Ethnic Minority Achievement ] co-ordinator. Which I did. All the children involved were emotional. I know I dealt with it in line with the school policy, which was also in line with how I felt. All children involved understood the seriousness of the words. But what now? I was told by our EMA to leave it, but that is not working for me.

The two girls interpreted Ania's comment as racist, and therefore told their teacher. Natalie shared their interpretation, and followed the school policy, which involved informing the 
EMA co-ordinator. Again, we only have a partial view of the incident here. Natalie reported that the deputy Headteacher spoke to Ania, and the EMA co-ordinator then appeared to feel that the incident had been dealt with. But this was not the case for the girls, who continued to struggle with the questions and conflicts the incident had stirred up, nor for Natalie, who had to respond to them. The following day she noticed that Yasmin in particular was still upset by the incident:

She felt uncomfortable for getting someone in trouble [but] she then continued to say that she felt annoyed that Ania had judged Micah on the colour of his skin...she couldn't see why Ania had that right. ..Her feeling of guilt and irritation was obvious and looked as though it was tormenting her.

It is clear that Yasmin was struggling to deal with an encounter with racism at close quarters, and needed support. Natalie was sensitive to Yasmin's mood, and gave her that moral support, but good policies on racist incidents would include time for all those involved in the incident to work through their feelings. The incident shows how such situations affect a wider group of people than the immediate perpetrator and victim. Natalie was also left unsupported here. She had to deal with the feelings of both Yasmin, and Ania, without guidance from more experienced colleagues: she is advised to 'leave it'. Here again we see the colour and power evasive discourse at work. According to this discourse, addressing race directly creates more problems than it solves: it stirs up strong feelings and threatens good discipline (hooks, 1994). The safest course is therefore to avoid the issue all together. But the outcome of this approach is to leave everyone involved feeling insecure and confused. In the absence of colleagues at school who were willing and able to offer a more proactive approach, Natalie, like Leah, wrote to ask for support to understand what she was dealing with:

As for Ania, I would love to know where those messages come from. Adults at home? TV? School? Sarah, would that be a hidden curriculum?...I do feel once the emotions have died down I will tackle the issue, and thank you for your suggestions. But can you really change a child's attitude to race if there are stronger negative messages surrounding them beyond the classroom?

Natalie was led to reflect on how racist attitudes develop, and drew on her training to try to make sense of her experience. She also decided to do some follow up work with her class, suggesting that she continued to adopt a race and power cognisant approach, in spite of the advice of her senior colleague. 


\section{Discussion}

To what extent can these cases be considered examples of institutional racism? It will be noted that none of the incidents was formally logged, and therefore none of them would have been reported to the local authority. According to Parsons and Hepburn (2007) that omission does lay the schools open to this charge. This suggests that even a legal duty is not enough to require schools to address racism when the need for the law is neither fully understood nor accepted. Each of the senior management teams' responses to these individual incidents can be read as informed by the discourse of colour and power evasiveness, which sometimes dovetailed with the demands of performativity. This led to a response in which a proactive stance on racism was sacrificed to the minimisation and containment of the issue so that there was no disruption to school life, and no need to address sensitive and personally threatening issues on the part of individual managers. The outcome for the children involved was that, in the worst case, the perpetrators faced no consequences, and the victim was unprotected. In the other three cases, while the immediate behaviour was tackled, there was no follow-up, and no logging to ensure that any patterns of racism could be identified and addressed at a whole school level. There is no evidence to suggest that any of the children involved in these incidents received an unequivocal message about what racism is, and why it is wrong, still less that any such message built on an existing school ethos which was supportive of diversity and equality.

Reviewing the incidents in terms of what the beginning teachers learned, it seems clear that their involvement shook their confidence in dealing with incidents in the future. This was partly because it enabled them to see the complexities of what is involved for the first time. But three of the four felt abandoned by their mentors to some degree, and the fourth, Susan, did not feel able to discuss her concerns with her mentor in any depth. Similarly, three of the four saw that the incident revealed the lack of commitment to challenging racism in their schools. Susan, whose teacher perhaps reacted with the most energy to the incident in her class, was less critical, but still aware that her teacher had omitted a crucial step in not reporting the incident. 
The overall picture presented supports the findings of quantitative studies on schools' lack of compliance with both the spirit and the letter of recent race equality legislation (ScheiderRoss 2003; Parsons 2009). In the context of the Equality Act, in which race is subsumed with other aspects of identity, it is unlikely that vigilance on racism will increase in schools. At the level of policy, then, there is currently little hope for improvement. Perhaps we may look to students. This research adds to the body of evidence that suggests that there are new teachers who are willing to challenge racism, and that those most likely to do so are those with some experience of disadvantage, and those who themselves come from non-dominant backgrounds (Haberman 1996; Ullucci, 2011; Pearce 2012). This has implications for the kinds of candidates we recruit onto initial teacher education courses- a point that has been made many times before (Haberman 1996; Levine-Rasky 2001; Hick et al 2011).

\section{Conclusion}

These findings also add to calls for more and better support for teachers in the early stages of their careers. As more responsibility for early teacher development falls to schools in England, that support needs to be planned in the context of school life. Providing a 'learning space' (Solomon et al 2005) in which new teachers can think, talk and thereby make sense of, their experiences beyond their initial training phase may be one effective approach (Lander 2011). It is one which universities are well placed to organise. Time to reflect, the opportunity for dialogue, and a supportive and reflective mentor are key elements of that learning space (Turner, 2012). All four teachers appeared to develop their thinking about what had happened to them in the course of their interviews. It may be that it was the discussion with someone outside the immediate school environment that supported them in drawing on the colour and power cognisant repertoire, despite the dominance of colour and power evasiveness in each of their schools. This supports the view that, 'teachers who have access to an external perspective... may have a better than usual chance of developing and sustaining practices outside current orthodoxies' (Ainscow et al 2007, 15).

It has been suggested that one reason mentoring programmes are supported by governments is that they separate teacher training from the critical gaze of universities (Hobson et al 2009). In fact, their focus on personal reflection, evidence based practice and wider social analysis could provide new teachers with the personal and intellectual support they need to reflect on complex and potentially threatening issues like racism. But in providing this support, academics will need to work closely with school based managers and mentors, and will 
therefore need to find accessible explanatory theories which will support both pre-service and perhaps mentor teachers in rethinking their attitudes. It may be that Frankenberg's model of discourses of race could be one element of that theory. It makes it possible to see a degree of agency and fluidity in the stance one takes on race, to see racism as a discourse which can be drawn upon by anyone, rather than a committed stance adopted by a few malevolent individuals. A shift from the colour and power evasive focus on intentions to the power cognisant focus on outcomes in defining racism can be allied to longer-serving teachers' acquaintance with the concept of institutional racism. Each of these conceptual tools may help to move teachers' thinking away from definitions of racism as individual prejudice to an understanding of how individuals are implicated in the social mechanisms through which structural racism is perpetuated. In the current context, such pragmatic approaches may be the best hope of keeping a proactive stance on racism on the agenda in English schools.

\section{References}

Ahmed S. (2007): 'You end up doing the document rather than doing the doing': diversity, race equality and the politics of documentation, Ethnic and Racial Studies 30, no.4: 590-609

Ainscow, M., Conteh, J., Dyson, A. and Gallanaugh, F. (2007) Children in Primary Education: demography, culture, diversity, inclusion (Primary Review Research Survey 5/1), Cambridge: University of Cambridge Faculty of Education

Aveling, N. (2006) 'Hacking at our very roots': rearticulating White racial identity within the context of teacher education, Race, Ethnicity and Education, vol. 9 no. 3: 261 - 274

Aveling, N. (2002) Student Teachers' Resistance to Exploring Racism: reflections on 'doing' border pedagogy, Asia-Pacific Journal of Teacher Education, Vol. 30, No. 2: 119-130

Ball, S. (2003) The teacher's soul and the terrors of perfomativity. Journal of Education Policy, 18, no.2: 215-228

Beattie, M. (1995) New Prospects for Teacher Education: Narrative Ways of Knowing, Teacher and Teacher Learning, Educational Research, 37 (1), 53-70 
Bell, Joyce M. and Hartmann, D.(2007) Diversity in Everyday Discourse: The cultural ambiguities and consequences of "Happy Talk”, American Sociological Review, 2007, vol. 72: $895-914$

Bourne, J. (2001) The Life and Times of Institutional Racism, Race and Class, vol. 43, 2: 722

BBC (2012) More than 87,000 racist incidents recorded in schools available at: http://www.bbc.co.uk/news/education-18155255 (accessed 22 August 2012)

Buehler, J. (2012) There's a problem, and we've got to face it': how staff members wrestled with race in an urban high school, Race Ethnicity and Education, iFirst article 1-24

Commission for Racial Equality (2002) The duty to promote race equality: a guide for schools. London: Commission for Racial Equality

Daily Mail (2012) 88,000 children branded racists: Pupils as young as three reported over name-calling available at: http://www.dailymail.co.uk/news/article-2148621/Britainsschools-record-115-racist-incidents-day-teachers-admit-seen-pupils-abused.html (accessed 22 August 2012)

Dickar, M. (2008) Hearing the silenced dialogue: an examination of the impact of teacher race on their experiences. Race, Ethnicity and Education, vol. 11 no. 2: 115-132

Erben, M. (1998) Biography and Research Method, in: M. Erben (ed.) Biography and Education- A Reader. London: Falmer

Equalities Office (2011) Equality Act 2010: public sector equality duty what do I need to know? A quick start guide for public sector organisations available at: http://www.homeoffice.gov.uk/publications/equalities/equality-act-publications/equality-actguidance/equality-duty

Frankenberg, R. (1993) The social construction of whiteness-white women, race matters. Minneapolis: University of Minnesota Press

Gillborn, D. (2002) Education and institutional racism. London: Institute of Education 
Gillborn, D. (2009) The Stephen Lawrence Inquiry Ten Years On: a timeline. Race Equality Teaching, 27: 6-14

Glaser, B. and Strauss, A. (1967) The Discovery of Grounded Theory: strategies for qualitative research. Chicago: Aldine

Haberman, M. (1996) Selecting and Preparing culturally competent teachers for urban schools, in: W.R. Houston, J. Sikula, T.J. Buttery and E. Gruyton (Eds.) Handbook of Teacher Education. New York: Macmillan

Hick, P., Arshad, R., Mitchell, L., Watt, D. and Roberts, L. (2011) Promoting Cohesion, Challenging Expectations- educating the teachers of tomorrow for race equality and diversity in $21^{\text {st }}$ century schools available at:

http://www.esri.mmu.ac.uk/resstaff/ promoting\%20Cohesion\%20Challenging\%20Expectations.pdf

Hobson, A., Ashby, P., Malderez, A., Tomlinson, P. (2009) Mentoring beginning teachers: What we know and what we don't. Teaching and Teacher Education, 25: 1

hooks, b. (1994) Teaching to Transgress: education as the practice of freedom. New York: Routledge

Houser, Neil O. (2008) Cultural plunge: a critical approach for multicultural development in teacher education Race, Ethnicity and Education, vol. 11, no. 4: 465-482

Lander, V. (2011): Race, culture and all that: an exploration of the perspectives of White secondary student teachers about race equality issues in their initial teacher education, Race Ethnicity and Education 14, no.3: 351-364

Levine-Rasky, C. (2001). Identifying the Prospective Multicultural Educator: three signposts, three portraits. The Urban Review 33, no.4: 291-318.

Macpherson, W. (1999) The Stephen Lawrence Inquiry. London: HMSO 
Omi, M. and Winant, H. (1986) Racial formation in the United States: from the 1960s to the 1980s. New York; London: Routledge \& Kegan Paul

Parsons, C. (2009) Explaining sustained inequalities in ethnic minority school exclusions in England- passive racism in a neoliberal grip Oxford Review of Education 35, 2: 249-265

Parsons, C. and Hepburn, S. (2007) What should schools and local authorities being doing about institutional racism? Race Equality Teaching, no. 25: 16-21

Pearce, S. (2005) You Wouldn't Understand: white teachers in multi-ethnic classrooms. Stoke on Trent: Trentham

Pearce, S. (2012). Confronting dominant whiteness in the primary classroom: progressive student teachers' dilemmas and constraints. Oxford Review of Education 38, no.4: 455-472

Picower, B. (2009) The unexamined Whiteness of teaching: how White teachers maintain and enact dominant racial ideologies, Race Ethnicity and Education, 12, 2: 197-215

Pollock, M. (2004) Colormute: Race Talk Dilemmas in an American School. Princeton: Princeton University Press

Rich, M.D. and Castelan Cargile, A. (2004) Beyond the breach: transforming white identities in the classroom Race Ethnicity and Education, Vol. 7, No. 4: 351-365

Schneider-Ross (2003) Towards Racial Equality: an evaluation of the public duty to promote racial equality and good race relations in England and Wales (2002) London: CRE

Schön, D.A. (1991) The reflective practitioner : how professionals think in action. Farnham: Ashgate

Solomon, Patrick R., Portelli, John P., Daniel, Beverly-Jean and Campbell, Arlene (2005) 'The discourse of denial: how white teacher candidates construct race, racism and 'white privilege", Race Ethnicity and Education, 8:2, 147 - 169

Turner, M. (2012) Beyond the 'good teacher': guiding pre-service teacher reflections on culturally diverse students, Teachers and Teaching: Theory and Practice 19, 1: 1-15 
Ullucci, K. (2011) Learning to see: the development of race and class consciousness in white Teachers, Race Ethnicity and Education, vol. 14, no. 4: 561-577

Warren, S. (2007) Migration, Race and Education: evidence based policy or institutional racism? Race, Ethnicity and Education 10, no. 4: 367-385

7. The militarisation of English schools: Troops to Teaching and the implications for Initial Teacher Education and race equality

Charlotte Chadderton, Cass School of Education and Communities, University of East London, c.chadderton@uel.ac.uk

\section{Abstract}

In this article I consider the implications of the Troops to Teaching (TtT) programme, due to be introduced in England in autumn 2013, for Initial Teacher Education (ITE) and race equality. TtT would fast-track ex-armed service members to teach in schools, without necessarily the requirement of a university degree to do so. Employing the notions of white supremacy, and Althusser's (1971) concept of Ideological and Repressive State Apparatus, I argue that this initiative both stems from, and contributes to, a system of social privilege and oppression in education. Despite appearing to be aimed at all young people, the planned TtT initiative is actually aimed at poor and racially subordinated youth. Rather than a critical education, for those subordinated along lines of class and race, a military education is to be provided. This is likely to further entrench the increasing polarisation in an education system which already provides two tier educational provision: $\mathrm{TtT}$ will be a programme only for the inner-city disadvantaged, whilst wealthier, whiter schools will mostly continue to get highly qualified teachers. Moreover, TtT contributes to a wider devaluing of current ITE; ITE itself is rendered virtually irrelevant, as it seems TtT teachers will not be subject specialists, rather will be expected to provide military-style discipline, the skills for which they will be expected to bring with them. More sinister, I argue that the TtT programme is part of the wider militarisation of education. This military-industrial-education complex seeks to contain and police young 
people who are marginalised along lines of race and class, and contributes to a wider move to increase ideological support for foreign wars - both these aims ultimately in the service of neoliberal objectives which will feed social inequalities.

\section{Keywords}

Militarisation of education; surveillance in schooling; ITE; social inequality; white supremacy

\section{Introduction}

The questions asked when exploring issues of race and ITE in the UK seem to have remained similar over many years: Why does racism persist in the education system? How do teachers continue to end up complicit in racist structures of white supremacy? Is it possible for individual teachers to affect even small changes? How much impact can ITE have on teachers' attitudes? The UK's Coalition government, in power since May 2010, has introduced a range of radical reforms to the education system, which raises questions for the implications for race equality. In this article I consider the implications of the Troops to Teaching (TtT) programme, due to be introduced in England in autumn 2013, in order to reconsider these questions for the present social and political context. TtT would fast-track ex armed-service members to teach in schools, without necessarily the requirement of a university degree to do so (DfE 2012). I argue firstly that this initiative both stems from, and contributes to, a system of social privilege and oppression in education, and contributes to wider policies which devalue current teacher education. Secondly, and possibly somewhat controversially, I argue that the initiative is part of a wider trend to securitise and militarise society in general and education specifically, and should be seen as part of a wider move to remove issues of equality, including racial equality, from the educational agenda.

A consideration of the $\mathrm{TtT}$ initiative and the purpose and implications of its introduction offers us fresh insights into the (re)production of structures of white supremacy in the education system. White supremacy in this sense does not solely refer to the actions of extreme right-wing groups such as Neo-Nazis or Apartheid, nor only to overt racist systems such as slavery, although it does understand these as extreme forms of structures of discrimination. Rather it refers to social and political structures, which privilege those categorised as white, and disadvantage those categorised as $\mathrm{BME}^{\mathrm{i}}$ (Gillborn 2005; Preston 2007). In an education context, white supremacy is understood as a process which denies 
BME students and staff the same opportunities as whites, and elevates the position of whites (Diangelo 2006). The term white supremacy, therefore, does not necessarily refer to skin colour, rather to structures of domination and oppression which shape values, attitudes, interpretations, roles, identities, interaction and policy, which are often invisible to those privileged by them, although those they disadvantage tend to be more aware of these structures. This challenges dominant understandings of racism simply as racial discrimination - white supremacy reveals the system of privilege for whites as well as discrimination for BME individuals. It also challenges understandings of racism only as deliberate, individual and overt actions, by showing that racism can also be unwitting. However, scholars who employ notions of white supremacy often urge a caveat, pointing out that

"although race inequity may not be a planned and deliberate goal of education policy neither is it accidental. The patterning of racial advantage and inequity is structured in domination and its continuation represents a form of tacit intentionality on the part of white powerholders and policy-makers." (Gillborn 2005, 485)

This notion of 'tacit intentionality' is particularly important when analysing policy implications, as it helps us understand that even when a policy is not intended to be racist, it can have racist consequences, which policy-makers might have been able to predict had they studied the outcomes of previous policies.

Like all social structures, structures of white supremacy have to be continually reinforced in order to be effective (Preston 2007). We therefore see it as socially produced and reproduced in social, economic, political and discursive spaces. Racial structures do not function in isolation, but intersect with other categories such as class and gender - however, the intersection with other forms of discrimination should not detract from the importance of white supremacy as a key way of thinking which shapes education policy (Bhopal and Preston 2012).

As a researcher categorised as white myself, I am aware of my contradictory position as a white person writing about white supremacy. As we are all complicit in racial structures, I also receive privileges by virtue of being white (for a fuller discussion of the positioning and complicity of the white researcher, see Chadderton 2012a). I aim to avoid both a fetishistic gaze upon the racial other, and attempting the naive and ultimately futile aim of speaking from beyond whiteness. Rather I employ the framework as an analytical tool and 
from my unavoidable position within whiteness, I hope my efforts to critically problematise and reveal the structures of white supremacy in education go some small way towards dismantling and abolishing whiteness (Levine-Rasky 2002; Ignatiev 1997).

When considering the military and schooling, one might fruitfully refer to the work of Marxist theorist Althusser (1971). Althusser argued that in order to maintain capitalist relations of production, a range of tools are necessary to ensure the compliance of the population. He identifies what he calls Repressive State Apparatuses (RSAs), which include the government, the church, the courts, the army and prisons; and Ideological State Apparatuses (ISAs), which include religious, educational, family, legal, political and communications control. Although represented as neutral, the RSAs provide more overt social control, and the ISAs work at a more subconscious level to ensure that the population internalizes the dominant social values and remains compliant. The two types of State Apparatuses are however, not separate, rather they feed into and sustain each other. The TtT initiative combines the RSA the army, and the ISA education. Throughout most of the $20^{\text {th }}$ century, the dominant form of governance was governmentality (Foucault 1991), which relied more on ISAs than RSAs and was characterized by the de-centring of power and promotion of self-regulation. More recently, social theorists (e.g. Butler 2004; Brown 2011) have argued that we are currently undergoing a shift in governance from governmentality towards sovereignty, characterized by more repressive forms of social control and the more overt exercise of state power, exemplified by a growing culture of militarisation. It is in this light that I consider the implications of TtT.

\section{Troops to Teaching: the policy}

Armed Service leavers are to be encouraged to become teachers and mentors in schools in the TtT programme. The initiative is supported both by the current Coalition government of Conservative (politically right of centre) and Liberal Democrat (centre), and the previous Labour (traditionally left of centre) government. Initial details and reasoning are outlined in the Schools White Paper, The Importance of Teaching (DfE 2010), which gives the main purposes for the introduction of this initiative as twofold: firstly, poor standards of achievement in comparison with other industrialised nations, and secondly, a need for increased discipline in schools. One of the main solutions to these issues, the introduction to the White Paper claims, is to 'raise the status of teaching' by improving the quality of teachers by making changes in the way they are trained (Cameron and Clegg 2010,3). The government therefore firmly places their agenda for improvement in the field of teacher 
training. In 2008 the Centre for Policy Studies, a centre-right think tank, produced a policy paper initially advocating the introduction of the programme in the UK, based on the success of a similar programme in the US (Burkard 2008). As reported by the BBC, a Department for Children, Schools and Families (DCSF) spokesman said at the time: 'We know that professionals with industry experience can make really inspirational teachers and we are always looking to recruit teachers who have skills in other fields' (BBC 2008).

The Department for Education (DfE) emphasises that there will be opportunities for both non-graduate and graduate Armed Service leavers to enter teaching (DfE 2012). This is in contradiction to the government's own stated commitment to increase the academic requirements for teachers (DfE 2010), highlighting the academic suitability and subject expertise of new teachers as being of particular importance. The White Paper also states a commitment from the government to pay the tuition fees of service leavers (DfE 2010,22), at a time when tuition fees in England have been raised to up to $£ 9,000$ p.a. for other home students, a rise of $300 \%$ on the previous year.

The UK is not alone in introducing such programmes of collaboration between the military and schooling, there are other countries which have them too. The Troops to Teachers (T3) programme in the US, for example, retrains ex-soldiers with a minimum of 10 years' experience, and a degree (BBC 2008). The programme has been in place since 1994 and is administered by the US Department of Defense.

The T3 programme in the US has three main explicit purposes. First, it is one of a range of initiatives to help relieve teacher shortages, particularly in high need subject areas such as Maths, Sciences, Special Education and Vocational Education; it aims to provide employment for veterans; and thirdly it aims to recruit teachers in 'high need', low-income, ethnically diverse, urban areas (DANTES 2011; Broe 2008). Financial support and reduced entry requirements are provided in some states to persuade more troops to join the teaching profession (Broe 2008), and as stipulated on the T3 website, '[p]articipants who accept the Stipend or Bonus must agree to teach for three years in schools that serve students from lowincome families' (DANTES 2011).

The programme has been referred to as having been an 'outstanding success', with $88 \%$ remaining in the profession three years after they qualified, compared to the usual retention rate for teachers in the US of 50\% after five years (BBC 2008). 2008 figures suggest that approximately 16,000 ex-service personnel have qualified as teachers since T3 was set up in 1994 (ibid). The programme has also been beneficial in bringing in more men and ethnic minorities to the teaching profession (Marnie 2001). T3 teachers have been 
reported as being more prepared to teach in inner city schools, and teach shortage subjects such as Maths and Science and in areas such as Special Education and Vocational Education (Feistritzer et al. 1998; Marnie 2001; Owings et al. 2005), and more likely to move where demand for teachers is greatest (Feistritzer 2005). Evaluations have suggested the programme provides 'effective teachers' and 'excellent role models', 'who bring unique and valuable life experiences to the classroom' (Feistritzer et al. 1998, 8). It has been reported that over $90 \%$ of school principals have claimed that $\mathrm{T} 3$ teachers keep better discipline than traditional teachers (Owings et al. 2005).

In Germany, there is a tradition of so-called 'Jugendoffiziere' holding project days at secondary schools, and many German local education authorities have official agreements to work more closely with the military, including the military having input on modules in some teacher training programmes (Schulze von Glasser 2012). Since 2010, there has been an increase in military activity in German schools, both in order to attract more support among the population for Germany's foreign wars (ibid.) (generally unpopular in a country whose population is aware of the controversial nature of its military involvement overseas due to its Nazi legacy), but also as a recruitment drive, since compulsory national service was abolished in 2011 (ibid.).

\section{The social context of the TtT programme}

For all the advances we have made, and are making in education, we still, every year allow thousands more children to join an educational underclass $[\ldots]$ It is from that underclass that gangs draw their recruits, young offenders institutions find their inmates and prisons replenish their cells. These are young people who, whatever the material circumstances which surround them, grow up in the direst poverty - with a poverty of ambition, a poverty of discipline, a poverty of soul. [...] There is an ironclad link between illiteracy, disruption, truancy, exclusion and crime which we need to break. [...] Over the years there has been a slow, and sustained, erosion of legitimate adult authority in this country. It has been subverted by a culture of dutiless rights which empowers the violent young to ignore civilised boundaries which exist to protect the weak and vulnerable. [...]We need more male teachers [...] to provide children who often lack male role models at home - with male authority figures who can display both strength and sensitivity. [...] And specifically in order to ensure that there are many more male role models entering teaching we will be launching our troops to teachers 
programme later this autumn, so that we can draft gifted individuals from the armed services into the classroom.

(Michael Gove, Secretary of State for Education 2011)

Some might argue that the introduction of the TtT programme is simply a way of getting service-leavers into employment (e.g. BBC 2008). Whilst this is no doubt one of the aims of the initiative, a consideration of communications about $\mathrm{TtT}$ suggest there are much wider aims as well. The quote above suggests that the $\mathrm{TtT}$ programme is not a neutral intervention aimed at supporting all young people, despite being presented as such. In his speech, Michael Gove claims to identify 'an educational underclass [...] with a poverty of ambition, a poverty of discipline, a poverty of soul', a group which allegedly includes violent gang members, and is often brought up by women without male support. This group, he argues, is a threat to those he refers to as 'the weak and vulnerable', and destined for a life of crime. The solution he sees as 'adult authority', and possible physical intervention, which he views as best provided by 'male role models' and military-style discipline. Thus TtT is aimed at specific social groups in response to a specific social situation, which will be dealt with in a specific way.

Despite Gove's apparent disclaimer, 'whatever the material circumstances which surround them', TtT seems to be aimed at the economically disadvantaged. Indeed, use of terms such as 'underclass', 'poverty' in Gove's speech make explicit reference to disadvantaged groups, as does Burkhard's (2008) report, which refers to '...children from more deprived neighbourhoods' (p.8). As Dermott (2011) writes, many of the characteristics which those advocating the programme identify provide 'authorial shorthand for a collection of socio-economic markers. It does the same work as "class", but without invoking this contentious idea; thereby giving the impression of objective description rather than valueladen categorization' (pp.6-7). The term 'inner-city', for example, whilst not employed by Gove in this speech, is used throughout Burkard's (2008) paper and also by the BBC, to identify the sorts of young people at which the initiative is aimed, as in, 'to bring military style discipline to tough inner city schools' (BBC 2008).

However, the references to economic and social disadvantage are equally not neutral. The literature on TtT refers not just to disadvantaged young people, but to problematic young people. Schools in urban areas tend to be regarded as problematic due to a widespread belief that many of their pupils are both failing academically, and engaged in anti-social behaviour. Equally, the reference to young people being in 'gangs' - both in Gove's speech above, and 
on the Gemini Forces website (2011), an ex-military recruitment agency - can be seen as a reference to their class background. There is a wide perception that large numbers of young people, particularly young men in disadvantaged urban areas, are members of organised and violent gangs engaged in 'turf wars' and criminal activity, predatory groups which dominate the streets, intimidate other residents and dictate behaviour and interaction in entire neighbourhoods. Indeed, Gove's reference to 'the weak and vulnerable' suggests he is aiming to give the impression that he differentiates between the violent and criminal poor, and the genuinely needy who are threatened by the latter - similar to traditional discourses which differentiate between the perceived deserving and undeserving poor. However, the speech has the effect of equating disadvantage with criminality and violence. Moreover, other literature shows that whilst organised gangs do exist in the UK, they are not as widespread as often perceived, and relations are much more complicated than the good versus evil binary set up by Gove, including functioning as protection for the more vulnerable (e.g. Joseph et al. 2011).

Explicit links are also made with the protests in summer 2011, a week of rioting and protest on the streets of several English cities sparked off by the shooting by police of a young, working class man of dual heritage in London, and their subsequent refusal to provide any explanation for his death to his family members. These references appear particularly on the Gemini Forces website, which states that the TtT programme has been introduced, '[i]n response to the recent riots in England' (Gemini Forces 2011). The protesters were widely viewed as lower class youths, feckless and taking advantage of a situation for their own gain by looting, not because they are poor, but because they are, as Gove would argue, poor 'of discipline and soul'.

Seen from an Althusserian point of view, this link between the TtT and the discipline of the lower classes makes perfect sense. The dominant ISA is the school, which teaches young people their role in the capitalist social hierarchy. The disadvantaged need to be taught to accept their position as the lowliest workers,

the reproduction of labour power requires not only a reproduction of its skills, but also, at the same time, a reproduction of its submission to the rules of the established order, i.e. a reproduction of submission to the ruling ideology for the workers (Althusser, 1971). 
The combination of an RSA with an ISA is likely to make this learning process even more effective.

Secondly, the literature on TtT implicitly targets boys. Although Gove does not explicitly mention which gender the proposal is aimed at, in the policy paper by the Centre for Policy Studies, at one point there is a mention of boys, and girls are mentioned in brackets. As Dermott (2011) points out in her analysis of gender in the programme, the context to the initiative includes hysteria around the educational under-achievement of boys and bad behaviour in the classroom, seen as an issue of masculinity. As exemplified in Gove's speech above, there are indeed many assumptions made about gender in the literature: that low-achieving children lack male role models in their lives; that there is a causal link between the lack of male role models and young people's under-achievement and anti-social behaviour; that a male teacher improves educational attainment; that men themselves provide a masculine authority which allow them to keep better discipline; that ex-service-leavers (of either gender?) will have access to this masculinity. There is, however, little evidence that any of these assumptions are accurate (e.g. Read 2008).

Commentaries on the TtT programme in the UK are virtually silent on the issue of race. Yet race, like social class, is present implicitly in the language employed. Just as terminology such as 'inner-city' and the assumption that youths are members of organised gangs is classed, it is also raced. England's larger cities are racially diverse, and the notion of violent gangs is associated in popular imagination with African-Caribbean youth (Joseph et al. 2011). There is more generally a perceived connection between BME groups, particularly black and Asian, and crime, violence (e.g. Blair 2000), and more recently, terrorism. Equally, the problematising of young people from families with absent fathers can be seen as racially coded. This is because particularly families where the male partner is of African-Caribbean heritage are perceived to be likely to be headed by lone mothers, black males often stigmatised as sexual predators, unable to remain in a relationship and take responsibility for children (Roopnarine 2004). Moreover, the educational context is also raced as there has been much media attention around the under-achievement of certain BME groups (Gillborn 2005) who have also traditionally been considered badly-behaved and challenging (Blair 2000).

In a documentary programme made by the BBC (2011) which reported on what was hailed as the success of the T3 initiative in the US, and a school in Birmingham in the UK which is already employing ex-army as teachers, virtually every young person on screen is of BME heritage. Whilst this passes without explicit mention, the viewer is left with the 
impression that the initiative does, indeed, target young BME people rather than white young people.

The literature and the film thus implicitly portray the TtT initiative as aimed at young, disadvantaged, BME (often male) young people, who are positioned as being in need of discipline and authority. This therefore reinforces the alleged, essential links between disadvantaged young BME people, and crime, violence, lack of responsibility and underachievement. The introduction of TtT then, seems to be both informed by, and feed, discourses of white supremacy.

\section{The implications for ITE}

There are two main implications of the TtT programme for ITE. Firstly, it devalues current ITE in several ways. The focus on discipline and authority to tackle (perceived) bad behaviour, youth violence and crime seems to imply that current teachers are unable to cope and the behaviour problems can only be dealt with by sending in the troops. Burkhard's (2008) report seems to suggest that it is the macho and violent image of the military which will inspire respect: '[w]hether we like it or not, children from more deprived neighbourhoods often respond to raw physical power' (p.8).

Further, commentators have also noted that although the initiative is touted as encouraging a move away from violence, crime and exclusion, rather than aiming to downplay aggression and violence, what $\mathrm{TtT}$ paradoxically seems to aim to do is embrace aggression (e.g. Dermott 2011). There is no mention of notions of democratic and collaborative values, solidarity, social justice, social transformation, active citizenship and emancipation (Gilbert 2011). This equally seems to imply that current ITE is too 'liberal'. The TtT proposal comes in the context of a wider move in England to 'restore adult authority' in schools, in the form of discipline and unquestioning obedience. The government has also recently announced the scrapping of the requirement for teachers to record instances when they use physical force (Gove 2011). As Giroux (1986) argues, speaking for the US, 'the new conservatives have [...] argued that the current crisis in public education is due to the loss of authority' (p. 22). Although Giroux wrote this a quarter of a century ago, its relevance has only increased, in both the US and UK. Far from being educated to become 'transformative intellectuals' (Giroux 1986, 28), preparing young people for life in a participatory democracy and stimulating critical thought and debate, or technical competence and subject knowledge, $\mathrm{TtT}$ teachers will be expected to provide additional discipline for young people who are already marginalised. 
Moreover, the introduction of TtT comes in the context of ongoing calls for more male teachers. The argument goes that men will be able to provide the discipline needed to contain disruptive and under-achieving young (mostly) males (Read 2008). However, as mentioned above, there seems to be some confusion between men and masculinity, as some ex-army will, of course, be women. Also, there is no evidence to suggest that male teachers do provide 'better' discipline. However, important here is that the call for (male? masculine?) service-leavers devalues the work being done by a predominantly female teaching staff currently in UK schools.

The second key implication is that TtT seems to render ITE in general virtually irrelevant. There is an assumption that ex-armed forces will somehow automatically maintain discipline in the classroom (Dermott 2011,9), assumed to be an inevitable consequence of them having been in the army. The Centre for Policy Studies Report generalises, arguably somewhat naively, '[e]x-servicemen are sure of their own moral authority and are not intimidated' (Burkard 2008,5). There is a lack of acknowledgement that, unlike schools with their diverse cohorts of young people and compulsory attendance, '[the Army] is a community with shared values, which respects its leader as an embodiment of those values. The reason Army officers are respected is because everyone they command is - voluntarily a member of the military community with a very strong shared identity and purpose' (Wright 2011) - there is therefore every reason to believe that some young people will resist and cause discipline problems, as with every other teacher. Equally, there is no acknowledgement of the different type of discipline required in schools from that required in the army. As Gilbert (2009) argues,

The army is very different from school; soldiers have to be trained to deal with life or death situations. Disobedience has to be stamped upon immediately with the most severe punishments. Discussion or questioning of orders is largely forbidden because it has to be; no soldier in the context of battle can start ruminating about the validity of a superior's orders.

There is also no acknowledgement at all of the harassment, bullying, abuse and racism reported as being systemic in the British army (e.g. Channel 4 2012), suggesting that ex-army can certainly not be viewed as somehow belonging to a transcendental realm of moral authority or discipline. 
Moreover, TtT teachers will not be expected to be subject specialists, further rendering ITE irrelevant for this cohort. Despite one of the main aims of the TtT programme explicitly being improving educational achievement, there is little mention of teaching and learning in the literature (Dermott 2011,9). The White Paper cites the most recent OECD PISA survey, carried out in 2006, in which England 'fell from 4th in the world in the 2000 survey to 14 th in science, 7 th to 17 th in literacy, and 8th to 24th in mathematics' (Cameron and Clegg 2010,3). However, the focus in the White Paper remains around behaviour and discipline. Although the British army places much emphasis on subject skill knowledge and technical competence, skills such as engineering, medicine and cookery are not mentioned in communications about the value of ex-service personnel to schools (Dermott 2011). This, along with the claim that $\mathrm{TtT}$ teachers will not necessarily be expected to have a degree, contrasts with the government's professed determination to make teaching into an elite profession. Evidence suggests that very few ex-army members have a first degree in the UK, a much lower level than in the US (Dermott 2011).

It merits attention that these moves all come in the wider context of the devaluing of teacher education in general. The same White Paper (2010) calls for more training to take place in teaching schools, rather than in universities, despite student teachers already spending large chunks of the $\mathrm{PGCE}^{2}$ in schools. TtT is one of many new routes into teaching, including widening of school based routes, Teach First, Teach Next (for those wanting a change of career), which take teacher education out of universities, decreasing the opportunities for student teachers to engage with different theoretical and critical approaches. As Maguire (2011) argues, such constructions position teaching as a skill which can simply be acquired, with a focus on prescribed methods, suggesting "the teacher is reconstructed as a state technician" (p32).

\section{The military-industrial-education complex}

There is, I argue, a wider and more sinister political context to the TtT initiative. Western societies, particularly urban areas, are becoming ever-more militarized and securitized spaces. This can be observed in developments such as militarized policing at demonstrations and public events, the extent of surveillance cameras in both private and public spaces, military-style borders around areas such as financial districts, embassies and airports, the introduction of biometric surveillance, the explosion of gated communities. As Giroux (2011) argues, '[h]igh-intensity policing is no longer merely a tactic or policy, it has become a mode of governance' (p. viii). These are techniques of security and surveillance commonly 
associated with war-torn regions such as Baghdad and Gaza, and the massive cities of the global south (Graham 2011). However, they are now widely employed in western cities.

The process of militarisation is commonly associated with the so-called 'war on terror' which has formed the response to the attacks of $11^{\text {th }}$ September 2001 on the US. However, it began before 2001, and set the stage for the militarised response to those attacks. Now it has been argued that the ensuing 'war on terror' is perpetual and all-pervasive (Butler 2004; Graham 2011), impacting on populations in the US and Europe as well as Afghanistan and Iraq.

This militarisation should be understood in relation to the global expansion of markets (Graham 2011; Saltman 2011). This involves both the marketisation of all aspects of life in the West, as well as globally. In order to ensure the global triumph of capitalism and marketisation, populations have to be forced to accept the values and policies of neoliberalism. This involves the removal of constraints on business and the imposition of constraints on the population. As I argue elsewhere (Chadderton 2013) this combination of market liberalisation and security, summarised by Gamble (1994) as the politics of 'the free economy and the strong state', has been a key element of 'New Right' thinking in the US and UK since the 1970s, and exemplified by the Reagan and Thatcher governments in the 1980s. The focus of state spending is shifting away from care and towards control (Harvey 2003), that is, away from social welfare, and towards the surveillance and control of populations. The public sphere is redefined as a profit opportunity and citizens redefined as consumers. One of the main implications of this redefinition of the public sphere and citizenship is the criminalization of disadvantage. Those who are economically inactive are positioned as threatening to the neoliberal project, referred to as 'flawed consumers' (Bauman 1998). Large groups of people are being created for whom neither much work nor social support is available, referred to as 'disposable' (Giroux 2009). These disadvantaged groups are therefore positioned as requiring discipline and containment.

As the government withdraws its support for the welfare of the population and turns increasingly to profit and away from democratic practice, it makes sense that it will need ever more repressive apparatuses to ensure the compliance of the population and prevent revolt. Those most likely to revolt are the disadvantaged or 'disposable' youth, as seen in the UK's 2011 riots, and frequent protests in the French banlieues. It should come as no surprise that those in power combine traditional RSAs and ISAs: schools and the army, to help achieve this. 


\section{'The Home Front': Securitisation, children and schools}

[C]ontemporary war takes place in supermarkets, tower blocks, subway tunnels, and industrial districts rather than open fields, jungles or deserts (Graham 2011, xiv)

The culture of securitization and war is shaping everyday life, including school and educational cultures and discourses. One of the main functions of incipient militarisation is to increase acceptance among the population for permanent war (Graham 2011). As Althusser (1971) would argue, there is a need to ensure that the population is conditioned to accept the ideology of the ruling class, which, in this case, involves imposing neo-liberal values on the world through violence and war. Schulze von Glasser (2012) has referred to military engagement in German schools as 'The Home Front'. The impact of the militarisation culture on education and children's lives is vast. Schools in the US have been compared to maximum security prisons (Hope 2009), with features including on-site police officers, mandatory drug testing, CCTV cameras even in toilets, metal detectors and biometric testing (Giroux 2011; Monahan and Torres 2010). Schools in the UK, whilst not (yet) so securitized as those in the US, have also already introduced many of these measures (see Chadderton 2012b). Schools in both the US and UK are criminalizing the young for relatively minor infractions which would previously have been dealt with by the headteacher, parents and governors (Giroux 2011).

The boundaries are blurring between children's toys and real weapons. As Graham (2011) argues, toys have always mimicked weapons, but now weapons are starting to mimic toys, e.g. some military weapons mimic PlayStation controls. Whilst I do not argue that young people cannot tell the difference between simulation and reality on the one hand, on the other, these are 'hyperreal constructions [...] through which war and violence are constructed, legitimized and performed' (Graham 2011,22).

$\mathrm{TtT}$ can be seen, to some extent, as contributing to this militarisation and the conditioning of the population to accept a culture of permanent war. The incipient militarisation makes war seem natural, and normalizes and glorifies violence. German evidence suggests that military programmes in schools teach young people to regard war as something positive, a legitimate and logical response to which there is no alternative (Schulze von Glasser 2012). Children and adults are educated 'to identify with militaristic, authoritarian and anti-democratic practices' (Saltman and Gabbard 2011, 19). Education joins the cultural pedagogies of mass media which support identification with the military, 
violence, social inequality and consumerism (Saltman and Gabbard 2011, 22), rendering such values common sense. Saltman (2011) argues that programmes such as TtT turn 'hierarchical organization, competition, group cohesion, and weaponry into fun and games' (p.1), thus rendering these values more acceptable to the population. There has been criticism of the German army's project days in schools, which focus disproportionately on the role of the army as 'peacekeepers' and 'conflict resolution' in order to attract ideological support for Germany's wars, and silence discussion of alternatives to military conflict, Germany's geopolitical interests, and the realities of violent conflict for both victims and soldiers (Schulze von Glasser 2012).

A further function of the militarisation of schools is potentially military recruitment. In the US, there is evidence that the TtT programme is linked to military recruitment (Saltman and Gabbard 2011). Whilst there are no precise figures available for military recruitment linked to TtT, a similar programme, Junior Reserve Officers Training Corps (JROTC), which also sends ex-military service-people into schools, is seen as a recruitment programme (Brown 2011). This programme also targets poor, inner city areas, mostly African American and Latino communities, with high rates of joblessness, marketed as “ "a way out" for poor youth of color' (p. 138). As Eugene J. Carroll, deputy director for the Center for Defense Information stated, '[i]t is appalling that the Pentagon is selling a military training programme as a remedy for intractable social and economic problems in inner cities. Surely, its real motive is to inculcate a positive attitude towards military service at a very early age, thus creating a storehouse of potential recruits' (Carroll, cited in Brown 2011, 140). In Germany, there is a direct connection with recruitment, engagement between the military and secondary schools having increased greatly since the abolition of compulsory military service (Schulze von Glasser 2012). Although it could be argued that the military is actually currently being downsized in the West, and such conditioning of the population is therefore not necessary, one could also assert that the West is fighting wars on many fronts, and even where war has not officially been declared, there is military activity, such as the operation of drones in Pakistan. In order to continue to spread neo-liberal values, the West needs the ideological support of the population for military action.

It is not the first time that education has been tied to militarisation, it was for example during the Cold War, but the connection between militarisation and the marketisation of education is new (Saltman 2011) and thus the direct connection with the current increase in social inequalities caused by neoliberal policies. The more recent securitisation of schools, then, needs to be viewed in the neoliberal context of high-stakes testing, league tables which 
rank schools according to narrow markers of pupil success in exams, the introduction of market values in schooling e.g. Free Schools in the UK. All these changes in education have been sold to the population by employing a rhetoric of increased choice and improved standards, but all have been shown to increase social inequalities (Ball 2007). It is this connection with increased social inequalities to which I move next.

\section{Race, militarisation and schools}

The militarisation of society is a racial issue. Firstly, as many theorists have argued, the wars of the West are imperial, racist wars (Graham 2011; Harvey 2003; Saltman 2011). Imperial discourses dominate as the West seeks to justify the ongoing 'war on terror' with populations at home. Such discourses depend on the dehumanisation of the racial 'other'- the dehumanisation is not new, but is reinforced by the 'war on terror' (Graham 2011; Butler 2004). Equally, military nationalism tends to have white supremacist overtones, to be linked to notions of racial homogeneity and cultural superiority (Hall 2011; Preston 2007). Military programmes in schools, then, provide preparation for racial domination abroad (Brown 2011), in terms of both soldier recruitment, and on an ideological level. An example of lesson material recently used by the military in German schools included a page entitled 'Threats of the $21^{\text {st }}$ century', with pictures of Iranian president Mahmoud Ahmadinejad and a full boat of North African refugees off the coast of Spain (Schulze von Glasser 2012, 75). It could be argued that the implication of such pictures is to locate the perceived threat beyond the borders of German/European whiteness, both physically and racially, and to feed white supremacist nationalism. As I argue above, this may well be in the form of tacit intentionality (Gillborn 2005).

Secondly, such white supremacist wars also shape racial realities at home. Critical Race Theorists (Ladson-Billings 2003; Oztas 2011) have examined the role of the current 'war on terror' in shaping racial discourses, arguing that identities have become polarised into those who are with the US and the UK, and those who are against. The population is perceived as divided: one group which is to be protected from threat - those categorised as white -, and a group which is threatening - the racial other. In this case the alleged terrorists are Muslims, pre-defined as belonging to an uncivilised culture, incompatible with the values of the West. This is of course not new, but builds on longstanding orientalist discourses of Islam as an under developed culture which condones, even encourages violence. 
the way in which urban life in colonised zones is imagined reverberates powerfully in the cities of the colonisers. Indeed, the projection of colonial tropes and security exemplars into postcolonial metropoles in capitalist heartlands is fuelled by a new 'inner city Orientalism' (Graham 2011, xix)

Such discourses shape racial reality in western cities. In the UK, the right wing have long portrayed multi-ethnic urban areas as unBritish, external to the nation, and threatening to a white, monocultural suburban or rural nation with (partially imagined) traditional values (Chadderton 2009). Similarly in France, immigrant districts are portrayed as backward and threatening to the cities, a discourse employed to justify the aggressive policing of the riots in 2005. Graham (2011) argues that this process is shaped by the memory of the anti-colonial wars in north Africa. A similar situation prevails in the US, where the discourse dominates that urban areas are dominated by minority ethnic communities who allegedly do not share white values. It has been argued that the portrayal of African American youth in mainstream US media is very similar to the portrayal of the terrorists who threaten America (Graham $2011,45)$. The racial 'other' is thus positioned as a threat, requiring containment and pacification, this portrayal justifying increased surveillance and policing.

Very much linked to this point, the culture of securitization is also resulting in changing notions of citizenship: rather than being regarded as civilians with universal citizenship, citizens are separated into two distinct groups: potential citizens and potential targets. As Graham (2011) argues, they are separated based on the profiling of individuals, groups, communities, places, behaviours, and perceived association with factors such as violence, crime, resistance to dominant neoliberal capitalism, places. This profiling tends to be racial, those who tend to be understood as non-citizens are racial others (Butler 2004), which strengthens white privilege.

Thirdly, a culture of securitization 'legitimates a biopolitics of punishment and disposability' (Giroux 2011, viii). As I argue above, rather than providing employment or welfare support for young people from disadvantaged backgrounds, neoliberal governments invest in policing and surveillance of these groups perceived as 'disposable'. Those classified as 'disposable' tend to be already marginalized along lines of race and class. The militarisation of schools can be seen as part of a number of policies which criminalise youth, particularly minority ethnic and disadvantaged young people (Lipman 2011) and therefore feed white supremacy. In being classified as in need of the army for discipline, this in turn further confirms the racist stereotype that such groups are undisciplined, violent, tending to 
anti-social or criminal behaviour, and threatening to the social order, contributing to the essentialisation and fixing of such racial categories.

Indeed, it could be argued that high security, militarized schooling contributes to preparing disadvantaged young people, for whom there is little or no paid work once they leave school, for a life in jail by conditioning them to accept such an environment. The US has the highest prison population in the world, with one in 100 Americans incarcerated (Alexander 2010). At present, the UK incarcerates more young people than any other EU country (BBC 2009), and the number of children held in prison on remand has risen by $41 \%$ since 2000-01 (Pemberton 2010).

\begin{abstract}
Although state repression of children is not new, what is unique about the current historical moment is that the forces of domestic militarisation are expanding, making it easier to put young people in jail rather than to provide them with the education, services, and care they need to face the growing problems characteristic of a democracy under siege (Giroux 2011, xiv)
\end{abstract}

Young people of colour are disproportionately affected by the incarceration programme, to the extent that US commentators have identified what is referred to as the 'School-to-prison pipeline' for young people of colour in the US. It has recently been argued that the criminal justice system in the US can be considered 'the new Jim Crow' (Alexander 2010), 'a new process of racialised social control' (Lipman 2011, 84) through which people of colour are denied many basic rights. Black children make up 15\% of young people in the US, but $46 \%$ of those incarcerated (Giroux 2011, xiv). Equally in the UK, BME people are disproportionately imprisoned: $26 \%$ of the prison population come from minority ethnic groups (Justice 2011), although only 14\% of the population is of BME heritage (Khan 2012). Like all security industries, prisons and juvenile detention centres are rapidly growing industries both in the US (Saltman and Gabbard 2011) and UK (Behindbars 2012). There is money to be made out of mass incarceration. The privatization of prisons and related facilities, referred to as the prison-industrial complex, is led by desire for higher profits (Schlosser 1998). The State Apparatus, school and the military, already function in connection with each other and contribute to the maintenance of capitalist relations of production. It is likely that $\mathrm{TtT}$ in the $\mathrm{UK}$ will feed into existing programmes of social control which disproportionately affect BME groups, contributing to racial disadvantage and processes of white supremacy. 
Some may argue that military education programmes cannot possibly disadvantage young people of colour, because, for example, the US military is currently the largest employer of African-Americans. However, as Brown (2011) argues, despite this, 'urban military exercises predominantly target African-American urban neighbourhoods' (p.62). Viewing this through a critical race theoretical lens, I would argue, in a white supremacist culture, people of colour are also recruited to protect white privilege.

\section{Conclusion}

To return to some of the questions about race and ITE from the beginning of this paper, why does racism persist in the education system, how do structures of white supremacy function, and what does this mean for ITE? In this article I have argued that the planned TtT initiative in the UK, despite appearing to target all young people, is actually aimed at poor and racially subordinated youth. Rather than a critical education, for those subordinated along lines of class and race, a military education is to be provided - patriarchal, hierarchical and authoritarian. This is likely to further entrench the increasing polarisation in an education system which already provides two tier educational provision: $\mathrm{TtT}$ will be a programme only for the inner-city disadvantaged, whilst wealthier, whiter schools will mostly continue to get highly qualified teachers (Brown 2011). Indeed, ITE, already in the process of being devalued by wider Coalition policies, is itself further brought into question, as it seems TtT teachers will not be subject specialists, and will be expected to provide military-style discipline, the skills for which they will be expected to bring with them. By situating my consideration of $\mathrm{TtT}$ in the wider context of the militarisation of the population through education, I have argued that $\mathrm{TtT}$ could be part of a wider move to increase ideological support for foreign wars, and keep disadvantaged 'disposable' youth under surveillance both these aims ultimately in the service of neoliberal objectives. Indeed I have argued that the cooperation of an RSA and an ISA is entirely logical in order to ensure the compliance of the population in the massive social inequalities brought about the relations of capitalist production. The introduction of $\mathrm{TtT}$ therefore, both feeds, and is fed by white supremacy '...the processes through which whites acquire and deploy social dominance' (Levine-Rasky 2002,2), and BME young people are further disenfranchised. TtT is just one example of the ways in which white supremacy is continually upheld, and racial identities are likely to be further polarised. This is neither wholly deliberate nor wholly accidental, rather it is example of tacit intentionality. 
Although schools have always been undemocratic spaces, there have equally always been moves (both by individual teachers, schools, and Local Education Authorities) to encourage more democratic participation. These recent political shifts from a system of governance towards a system of sovereignty (Butler 2004) show how the possibilities for democratic resistance and the promotion of social justice are shrinking. Racism continues to persist in the education system because the system continues to be informed by white supremacist discourses and white supremacist policies which ensure the continued dominance of white people. As I have suggested in this paper, racism should be understood less as individual acts of discrimination against BME people, rather as a system of white supremacy which ensures on every level the continued privilege of those classified as white.

What opportunities are there for resistance to the militarisation of schools? In Germany, where there is a higher level of public awareness around the issue than in the UK, there have been activities at schools involving teachers, students, parents and members of the community, including a small number of demonstrations outside schools, which have had varying levels of success but have always raised public awareness. At a party political level Die Linken (The Left Party) have actually petitioned parliament to prevent military involvement in schools, although their petition was rejected by all other German parties, including the Social Democrats and the Greens (Schulze von Glasser 2012).

Equally, despite the reduced spaces for resistance, writing about education as 'a site of low-intensity warfare' (Giroux 2011, xv) contributes to the possibilities for discussing these issues and raising awareness of our complicity in maintaining structures of white supremacy. Without wanting to be naive about possibilities open to teachers under present neoliberal conditions, I repeat Giroux's (1986) call for teachers to strive to become transformative intellectuals which is already a quarter of a century old, but no less relevant then than now:

transformative intellectuals $[\ldots]$ are not merely concerned with forms of empowerment that promote individual achievement and traditional forms of academic success. Instead, they are also concerned in their teaching with linking empowerment - the ability to think and act critically - to the concept of social transformation. [...] Acting as a transformative intellectual means helping students acquire critical knowledge about basic societal structures, such as the economy, the state, the work place, and mass culture, so that such institutions can be open to potential transformation. (p.30) 
Transformative intellectuals view classrooms as spaces of dialogue, and support students to understand themselves as raced, gendered and classed subjects. Although TtT has yet to be introduced, the militarisation of education is already well underway and calls for both critical analysis of the implications for social justice and democracy, and active resistance.

\section{Acknowledgements}

This work was supported by the Economic and Social Research Council [grant reference ES/K000233/1: Mass population response to critical infrastructure collapse - a comparative approach].

Many thanks to John Preston, Rhiannon Firth and two anonymous reviewers for their comments on earlier versions of this paper.

\section{Bibliography}

Alexander, Michelle. 2010. The new Jim Crow. Mass incarceration in the age of colorblindness. New York, NY: The New Press.

Althusser, Louis. 1971. Ideology and Ideological State Apparatuses. In

Lenin and Philosophy and other Essays, ed. Louis Althusser, New York: Monthly Review Press. http://www.marxists.org/reference/archive/althusser/1970/ideology.htm [Accessed 10/09/12].

Ball, Stephen J. 2007. Education PLC. Understanding private sector participation in public sector education. London, New York: Routledge.

Bauman, Zygmunt. 1998. Work, consumerism and the new poor. Philadelphia: Open University Press

BBC 2008. Retrain ex-troops as teachers. http://news.bbc.co.uk/1/hi/education/7245122.stm [Accessed 15/06/12].

BBC 2009. 'Too many' young offenders jailed. http://news.bbc.co.uk/1/hi/uk/8198496.stm [Accessed 12/01/12].

BBC 2011 Classroom warriors. Panorama. http://www.bbc.co.uk/programmes/b00ysnt7

[Accessed 9/06/12].

Behindbars 2012. The prison-industrial complex- privatising prisons. Roehampton

University: Contemporary issues in Criminology. http://www.contemporary-issues-incriminology.com/blog/2012/03/the-prison-industrial-complex-privatising-prisons/ [Accessed 9/9/12]. 
Bhopal, Kalwant and John Preston. 2012. Conclusion: intersectional theories and 'race': from toolkit to 'mash-up'. In Intersectionality and 'race' in education, ed. K. Bhopal and J. Preston 213-220. New York, London: Routledge.

Blair, M. 2000. 'Race', school exclusions and human rights. In Citizenship and democracy in schools: diversity, identity, equality, ed. A. Osler. Stoke on Trent, UK and Sterling. USA: Trentham.

Broe, S. 2008. A phenomenological enquiry into the leadership experiences of troops to teachers. PhD thesis, University of Pheonix.

Brown, E. 2011. Freedom for some, discipline for 'others'. In Education as enforcement. The militarisation and corporatization of schools ( $2^{\text {nd }}$ ed.), ed. K. Saltman and D. Gabbard, 92-113. New York and London: Routledge.

Burkard, T. 2008. Troops to Teachers: A Successful Programme from America for our Inner City Schools. London: Centre for Policy Studies.

Butler, Judith. 2004. Precarious Life. The powers of mourning and violence. London and New York: Verso.

Cameron David and Nick Clegg. 2010. Foreword by the Prime Minister and Deputy Prime Minister. In Department for Education, The Importance of Teaching: The Schools White Paper 2010. London: The Stationery Office.

Chadderton, C. 2009. Discourses of Britishness, race and difference. Minority ethnic students' shifting perspectives of their school experience. $\mathrm{PhD}$ thesis, Manchester Metropolitan University.

Chadderton, C. 2012a. Problematising the role of the white researcher in social justice research. Ethnography and Education 7, no.3: 363-380.

Chadderton, C. 2012b. UK secondary schools under surveillance: the implications for race. A Critical Race and Butlerian analysis. Journal of Critical Education Policy Studies 10, no.1.

Chadderton, C. In press 2013. Secondary schools under surveillance: young people 'as' risk in the UK. An exploration of the neoliberal shift from compassion to repression. In. Technology, Society and Inequality: New Horizons and Contested Futures, ed. E. Cudworth, P. Senker and K. Walker. Peter Lang.

Channel 4. 2012. Sexual harassment and bullying rife in the army. http://www.channel4.com/news/sexual-harassment-and-bullying-rife-in-the-army. [Accessed 05/03/13]

Defense Activity for Non-Traditional Education Support (DANTES). 2011. Troops to teachers. Proud to serve again http://www.mpttt.org/Information.aspx. [Accessed 20/06/12].

Department for Education. 2010. The Importance of Teaching: The Schools White Paper 2010. London: The Stationery Office. 
Department for Education. 2012. Routes into teaching http://www.education.gov.uk/get-intoteaching/troops-to-teachers/routes-into-teaching.aspx [Accessed 20/06/12].

Dermott, E. 2011. Troops to teachers: solving the problem of working class masculinity in the classroom? Critical Social Policy XX, no.X: 1-19.

Diangelo, R. 2006. The production of whiteness in education: Asian international students in a college classroom. Teachers College Record 108, no. 10, 1983-2000.

Feistritzer, C. E., M. Hill and G. Willett. 1998. Profile of troops to teachers. Washington DC: National Center for Education Information.

Feistritzer, C. E. 2005. Profile of Troops to Teachers. Washington, DC: National Center for Education Information.

http://www.dantes.doded.mil/dantes_Web/library/docs/ttt/NCEI_TT_v3.pdf [Accessed 29/05/12].

Foucault, Michel. 1991. Discipline and punish: the birth of the prison. Trans A. Sheridan. London: Penguin.

Gamble, Andrew. 1994. The free economy and the strong state. The politics of Thatcherism, $2^{\text {nd }}$ edn. Palgrave Macmillan.

Gemini Forces 2011. Plans to bring soldiers to schools http://www.geminiforces.co.uk/News/September-2011/Plans-to-bring-Soldiers-toSchools.aspx [Accessed 25/06/12].

Gilbert, F. 2009. Soldiers in the classroom http://www.francisgilbert.co.uk/2009/06/soldiersin-the-classroom/ [Accessed 25/06/12].

Gilbert, F. 2011. The omens don't look good for Gove's Troops to Teachers programme http://www.francisgilbert.co.uk/2011/03/the-omens-don\%E2\%80\%99t-look-good-forgove $\%$ E2\%80\%99s-troops-to-teachers-programme/ [Accessed 25/06/12].

Gillborn, D. 2005. Education policy as an act of white supremacy: whiteness, critical race theory and education reform. Journal of Education Policy 20, no. 4: 485-505.

Giroux, H. 1986. Authority, intellectuals, and the politics of practical learning. Teachers College Record 88, no.1: 22-40.

Giroux, H. 2009. Youth in a suspect society. New York and Basingstoke: Palgrave Macmillan.

Giroux, H. 2011. Foreword: governing through crime and the pedagogy of punishment. In Education as enforcement. The militarisation and corporatization of schools ( $2^{\text {nd }} \mathrm{ed}$.), ed. K. Saltman and D. Gabbard, i-xvi. New York and London: Routledge.

Gove, M. 2011. Gove speech on 'the underclass' in full. http://www.politics.co.uk/commentanalysis/2011/09/01/gove-speech-on-the-underclass-in-full

Graham, Stephen. 2011. Cities under siege. The new military urbanism. London, New York: Verso. 
Hall, S. 2011. The Neoliberal revolution. Cultural Studies, 25, no.6: 705-728.

Harvey, David. 2003. The new Imperialism. Oxford: Oxford University Press.

Hope, A. 2009. CCTV, school surveillance and social control. British Educational Research Journal 35, no. 6: 891-907.

Ignatiev, N. 1997. How to be a race traitor: six ways to fight being white. In Critical white studies, ed. R. Delgado and J. Stefancic: 613. Philadelphia: Temple University Press.

Joseph, I., A. Gunter, S. Hallsworth, T. Young, F. Adenkunle. 2011. Gangs revisited: What's a gang and what's race got to do with it? London: Runnymede Trust.

Justice 2011. Race and the criminal justice system.

http://www.justice.gov.uk/publications/statistics-and-data/criminal-justice/race.htm [Accessed 7/2/12]

Khan, O. 2012. Who are we? Census 2011 reports on ethnicity in the UK. http://www.runnymedetrust.org/blog/188/359/Who-are-we-Census-2011-reports-onethnicity-in-the-UK.html [Accessed 20/02/13]

Ladson-Billings, G. 2003 It's your world, I'm just trying to explain it: understanding our epistemological and methodological challenges. Qualitative Inquiry, 9, no. 1: 5-12.

Levine-Rasky, C. 2002. Introduction. In Working through whiteness, ed. C. Levine-Rasky,125. Albany, NY: State University of New York Press.

Lipman, P. 2011. Cracking down. Chicago school policy and the regulation of black and Latino youth. In Education as enforcement. The militarisation and corporatization of schools ( $2^{\text {nd }}$ ed.), ed. K. Saltman and D. Gabbard, 73-91. New York and London: Routledge.

Maguire, M. 2011. Where next for teacher education? Research in Secondary Teacher Education 1, no. 1: 30-4.

Marnie, S. E. 2001. Troops to teachers. Program helped address teacher shortages. Report to congressional requesters. Washington DC: Report to general accounting office.

Monahan, Torin and Rodolfo D. Torres 2010. Schools under surveillance. Cultures of control in public education. New Brunswick, New Jersey, and London: Rutgers University Press

Owings, W., L. Kaplan, J. Nunnery, R. Marzano, S. Myran, D. Blackburn 2005. Supervisor Perceptions of the Quality of Troops to Teachers Program Completers and Program Completer Perceptions of their Preparation to Teach: A National Survey. Virginia Office of Troops to Teachers.

Oztas, C. 2011. The march of the Mehteran. Rethinking the human rights critiques of counter-terrorism. Utrecht Law Review 7, no. 2: 180- 191.

Pemberton, C. 2010. Youth crime down but number of children in prison too high. http://www.communitycare.co.uk/Articles/2010/05/28/114608/youth-crime-downbut-number-of-children-in-prison-too-high.htm. [Accessed 14/01/12]. 
Preston, John. 2007. Whiteness and Class in Education. Dordrecht: Springer.

Read, B. 2008. 'The world must stop when I'm talking': gender and power relations in primary teachers' classroom talk. British Journal of Sociology of Education 29, no. 6: 609-621.

Roopnarine, J. 2004. African American and African Caribbean fathers. In The role of the father in child development, ed. M. E. Lamb, 58-88. Hoboken, NJ: Wiley.

Saltman, K. 2011. Introduction to the first edition. In Education as enforcement. The militarisation and corporatization of schools $\left(2^{\text {nd }}\right.$ ed.), ed. K. Saltman and D. Gabbard, 1-18. New York and London: Routledge.

Saltman, K. and D. Gabbard. 2011. Introduction to the second edition. In Education as enforcement. The militarisation and corporatization of schools $\left(2^{\text {nd }} \mathrm{ed}.\right)$, ed. K. Saltman and D. Gabbard, 19-25. New York and London: Routledge.

Schlosser, E. 1998 The prison-industrial complex. The Atlantic. http://www.theatlantic.com/magazine/archive/1998/12/the-prison-industrialcomplex/304669/ [Accessed 10/09/12].

Schulze von Glasser, Michael. 2012. Soldaten Im Klassenzimmer. Die Bundeswehr an Schulen. Cologne: PapyRossa Verlag.

Wright, M. 2011. Michael Gove, and the false allure of shiny buttons http://www.huffingtonpost.co.uk/matthew-wright/michael-gove-and-thefals_b_956229.html. [Accessed 15/06/12].

\footnotetext{
' Fully aware of the risks of essentialisation involved in naming, in order to offer an insight into the way these diverse groups are positioned in UK society, I use the tern BME, Black and Minority Ethnic, because this is the way in which people of colour (US terminology) are currently referred to in the UK.

ii The Postgraduate Certificate in Education is the qualification taken by those training to teach in the UK.
}

\title{
8. "If I'm going to teach about the world, I need to know the world": Developing
} Australian preservice teachers' intercultural competence through international trips.

\author{
Ninetta Santoro \\ University of Strathclyde, Scotland
}

\begin{abstract}
:
Increasingly, there is an imperative to prepare teachers who can address the needs of ethnically and racially diverse learners. One way to do so is to make available to preservice teachers opportunities for an international experience so that they might learn about the world and
\end{abstract}


develop better understandings of cultural diversity and difference. In this article, I draw on the findings of a qualitative study that aimed to investigate preservice teachers' perceptions of the value of an international experience to their development as teachers. I present excerpts of interview data that highlight how fourteen Australian preservice teachers who went to India to live and teach for a month, made sense of their experiences. Findings raise concerns about how they saw the trip primarily as an opportunity for tourism and how it became a vehicle through which postcolonial and neocolonial views were developed and maintained. I conclude by making recommendations for teacher education as well as for the organisation of the trip.

\section{Introduction}

"If I'm going to teach about the world, I need to know the world" (Kelly).

Increasingly, teacher education is concerned with the preparation of professionals who can address the education needs of linguistically and culturally diverse communities. Unprecedented levels of migration, both forced and voluntary have changed the demographic profile of classrooms in many places in the world (Banks 2008; Goodwin 2010). Teachers must have the skills and pedagogical strategies to address the needs of students whose cultural beliefs, values and practices are different from the dominant cultural majority. The development of culturally responsive pedagogies is no longer a choice, but a professional imperative embedded in teacher standards (eg. Australian Institute of Teaching and School Leadership 2011). Culturally responsive practitioners must have nuanced and deep understandings of difference and diversity and have considered how their own encultured positioning shapes their interactions with their students, and their expectations of them. They must know their students, understand how to build on their prior experiences and cultural knowledge, know how to design curriculum and assessment strategies that enable students to maintain connections to their home language and culture as well as build the necessary cultural capital to integrate into the new community (Siwatu 2007). Culturally responsive teachers also teach against racism and teach for social justice as well as teaching all students respect for cultural difference. Increasingly, teachers must develop what Goodwin calls contextual knowledge and to be able to "examine learners' needs as nested within multiple socio-culturaleconomic-political locations" (2010, 24).

There is a significant body of research concerned with how best to prepare teachers for this complex work. Some scholars (eg. Cushner and Brennan 2007; Walters, Garii, and Walters 
2009) suggest that direct experience and interaction with culturally diverse 'Others' is one way to extend preservice teachers' understandings of difference and diversity. Such experiences can challenge preservice teachers "to read and interpret their experiences with diversity and understanding of self, and the interconnectedness with their own students' lives and school opportunities" (Dantas 2007, 76). Brown suggests that "exposure to a new culture has transformative potential" $(2009,504)$ because it "evolves from a confrontation with a new culture into an encounter with the self" (505).

One way to broaden preservice teachers' perspectives and ensure direct contact with different cultures is to make available to them opportunities for overseas experiences ${ }^{\mathrm{i}}$. In Australia, as in Europe and North America, international experiences are increasingly being incorporated into teaching degrees in order to deepen preservice teachers' understandings of cultures different from their own (Rapoport 2008; Dooly and Villanueve 2006; Hill and Thomas 2005; Dantas 2007). Kelly, whose words appeared at the beginning of this article is studying to become a teacher. As part of her Australian teacher education course, she and 14 other preservice teachers went on a short term study trip to India to begin to learn about the world, to learn about different cultural perspectives, different schooling systems and different ways of teaching and learning. In this article I draw on data obtained from interviews with Kelly and her preservice teacher colleagues. In what follows, I provide details about the study, outline the theoretical frames that have informed the data analysis and the discussion. I then present excerpts of data that highlight how the preservice teachers understood the world they had come to see and experience. Findings raise concerns about how they regarded the trip as an opportunity for tourism that had transformative potential, how they viewed Indian culture as either exotic or deficit and how they took up identities embedded within discourses of charity and benevolence. I conclude by making recommendations about the organisation of the programme as well as the need for teacher education that promotes reflective and reflexive learning.

\footnotetext{
i These can take a variety of forms such as exchange programmes for up to one year, short-term study programmes, credit-bearing and non-credit bearing units of work, programmes with varying levels of supervision, programmes involving teaching practice in schools overseas.
} 


\section{The Study}

This article reports on a qualitative case study that investigated what preservice teachers perceived to be the benefits of an international experience for their development as teachers. The key research question was; 'How does an international experience assist students gain knowledge that will enhance their readiness to teach in culturally diverse contexts?' After obtaining university ethics approval, volunteer participants were sought from a cohort of 9 students who had gone to Korea on a three week study tour and a cohort of 15 students who had gone to India on a four week study tour. The organisation of both trips was out-sourced to a third party with whom the students' university negotiated the provision of activities and schedules. In the case of Korea, it was a university in a major Korean city and in India, a nongovernment organisation. The cost of the trip was subsidised by the preservice teachers' home university and the remaining costs were met by the individuals. They were also required to keep journals in which they regularly recorded their reflections about what they were learning in relation to their development as teachers. Seven students from the Korea programme volunteered to participate in the research and 8 from the India trip. Each group had a mix of students who were at various points in either a primary teaching degree or a secondary teaching degree.

Data were collected via semi-structured interviews with the students as well as the two group leaders who provided a different perspective on the students' experiences. The interviews were conducted approximately two months after the preservice teachers had arrived back in Australia. The questions aimed to elicit information from the preservice teachers about: their backgrounds and ethnicity; their reasons for going on an international experience; what they expected to learn from the trip and whether their expectations were met, how the trip contributed to their development as a teacher; what they found challenging and rewarding and their perceptions of the organisation of the trip. The interviews lasted on average 1.5 hours, were audio recorded, transcribed verbatim and returned to individual participants for checking and verification. In this article, I only present data obtained from the preservice teachers who went to India. 


\section{The Participants}

The preservice teachers ranged in age from 21 to 49 . Like most of the students studying at their university, they are from rural and regional Australian towns. They all describe themselves as Anglo-Australian and all but one, are monolingual. Three had never travelled overseas before and the others had travelled to holiday resorts in South-East Asia or had been to New Zealand, the United States or to Europe. One had previously backpacked in India. In this article I present interview data from the following participants:

- Tamsyn ${ }^{2}$ is in her early twenties and had travelled to New Zealand and Thailand before going to India. She grew up in a regional town $400 \mathrm{~km}$ from a capital city. She taught at a school for disabled students in India.

- Ellen is in her early thirties. She has travelled extensively in South-East Asia and Europe and speaks a little Spanish. She taught in an orphanage school in India.

- Tanya is the oldest preservice teacher in the group and is in her late 40s. She had never been overseas prior to going to India. She taught in an orphanage school in India.

- Bethany is 21 years of age. She grew up on a farm approximately 400 kilometres from a major city. She had never travelled overseas before. In India, she taught at a school for disabled children.

- Adeline is in her early twenties and grew up in a regional town. She spent a year living and working in England. She taught at a school for disabled children in India.

- Kelly is 20 years of age. She grew up on a farm near a small town. She had never been overseas prior to going to India. She taught at an orphanage school in India.

- Terry is in his early twenties. He had travelled to the USA and New Zealand prior to going to India. He grew up in a rural town. In India he taught in a school for disabled children.

\footnotetext{
${ }^{2}$ All names are pseudonyms.
} 
The preservice teachers were not closely supervised and travelled independently each day from their accommodation in a village in central India to schools, including an orphanage school and a special needs school where they taught English to primary school children. They were under the supervision of the teaching staff in the school. They also went on some trips to tourist sites on the weekends. The students were accompanied by a non-academic member of staff from the students' university who had lived in India and was very familiar with many Indian cultural practices. The preservice teachers relied on the teachers with whom they came in contact, the group leader and the trip organisers for cultural information and assistance. While they had participated in briefing sessions to prepare them for their trip, their exposure to academic course content related to diversity and difference was limited and occurred at various points in their programmes of study with no specific subject devoted solely to this topic.

\section{Data Analysis and Theoretical Frames.}

A thematic approach to the data analysis was adopted (Shank 2006). This involved reading and re-reading each semi-structured interview transcript and using a process of open coding to identify patterns in the interviewees' experiences and attitudes. The patterns that emerged in the data were in regards to what the preservice teachers learned about India and Indian education, their motivation for going to India, what they found challenging about the trip, what they found rewarding about the trip, how the trip contributed (or not) to their development as a teacher and what they learned about themselves. The patterns of data were then compared, contrasted and cross checked across the sets of interview data with the researcher looking for differences and similarities, tensions, contradictions and complexities. I also attended to the silences, to what was not said and how discursive practices shaped preservice teachers' experiences and expectations in implied, but not explicit ways. The data were then sorted and categorised under themes and subthemes. In this article, I am concerned with the broad and interrelated themes of: a) 'motivation for going to India'; b) 'what the preservice teachers learned about India'; c) 'what the preservice teachers learned about Indian education'; d) 'what the preservice teachers learned about themselves'. Further refinement of these themes resulted in the presentation of the data under the following sub-headings and headings: 'Opportunities for Transformation and Self Realization'; The Exotic Other, and the Deficit Other; 'Discourses of Charity and Benevolence'. 
It was not intended that the trip to India was for tourism. However, the data analysis revealed that the preservice teachers' expectations of what they would see and experience in India and their understanding of the purpose of the trip were embedded within, and shaped by discourses of tourism. Therefore, accompanying, and interwoven throughout the thematic data presentation in this article is literature drawn from the field of tourism studies. This literature serves to validate, support and at the same time, shape the analysis in a dialogic kind of relationship.

Much research in the area of critical tourism studies draws on postcolonial theory in order to understand the impact of 'Western' tourism on the 'developing world'. Postcolonial theory is concerned with identifying the effects and the legacies of colonising practices on the contemporary social institutions and practices of previously colonised societies (eg. Bhabha 1994; Said 1993; Spivak 1988). The subjectivities of those who have been colonised and those who have been colonisers are shaped by discourses of power and dominance, with the legacies of these asymmetrical power relations having long lasting effects. Some tourism studies literature and research suggests the 'developed West' and the 'undeveloped rest' are binary opposites with "....non-Western people and cultures [...] as "exotic Others": primitive, backwards, superstitious, irrational, despotic, hypersexual, childlike —in short, everything that supposedly rational, civilized, democratic, enlightened Westerners are not" (Caton 2011, 2). Some tourists are drawn to non-Western countries because they regard the hardships and difficulties they encounter, albeit in the short term, as offering opportunities for self development, fulfilment and opportunities to help those in need. Travel to these places can satisfy their deep curiosity about the exotic Other and provide a chance to see firsthand, places and people they are likely to have seen in promotional material and in the media.

Connected to, and shaping tourism experiences embedded within postcolonial frames is the concept of whiteness, an area of study that has been taken up and developed by a variety of scholars over more than 20 years (eg. Morrison 1992; Frankenberg 1993; Schick 2010; Matias 2012). Whiteness can be defined as a process of being and acting in the world, the subscription of ideologies that lead to, and maintain the domination of white people. Whiteness is "socially, historically, and culturally constructed in social structure, ideology, and individual actions" (Yoon 2012, 3). Yoon talks about 'whiteness-at-work' as a "socially constructed, dynamic set of strategies in speech and action" $(2012,10)$. The practices of tourism in 'developing' countries can be seen as examples of whiteness-in-action. Tourists who are most likely white, engage in practices that reinforce to varying degrees, the dominant and powerful 
position of whites. Tourism is an expression of privilege, both financial and social. It is the tourist who travels to observe the non-white and exotic 'other' and who chooses what cultures are worthy of their attention (and money). The tourist not only assumes the right to enter communities for the purpose of satisfying their curiosity but also assumes the right to pass judgement on what it is he/she has come to see. "Since the earliest imperialist expeditions Western Europeans and their descendants have become accustomed to being the viewer and the judge of all they encountered. Whiteness is something that defines the 'other' but is not itself subject to others' definitions" (Bonnett in Pearce 2003, 274). Whiteness and white privilege, are largely invisible, especially to those who are white (Dyer 1997; Frankenberg 1993) and who benefit from white dominance.

I do not seek to generalise from the findings of this research. The experiences of these preservice teachers are not the experience of all preservice teachers. These findings however, may 'speak' to, and resonate with others in similar contexts. I am also acutely aware of the ways in which 'naming' is a discursive practice that serves to produce the subject rather than simply reflect it. According to Butler (1997, 43), "What does it mean for a word not only to name, but also in some sense to perform and, in particular, to perform what it names?" In an attempt to categorise and describe, researchers can produce the identities of those whose identities they seek to understand. Therefore, my use of terms such as 'developing countries' and 'Western countries' is cautious.

While there is a growing body of literature from North America, Britain and Europe that focuses on the internationalisation of teacher education (e.g. Dantas, 2007; Devlin-Foltz, 2010; Dooly and Villanueva, 2006; Kissock and Richardson, 2010; Scoffham and Barnes, 2009), there has been relatively little research in Australia that has examined the effectiveness of international experiences for preservice teachers. This article contributes to addressing that gap.

\section{Opportunities for Transformation and Self Realization}

Travel to foreign places has long held the promise of adventure, freedom and the potential for personal transformation. It "is often imagined in romantic terms as a direct visceral experience in which one leaves the comfortable surroundings of home to reach beyond, to engage the senses, to see the world for oneself and emerge somehow changed - seasoned from 
the journey" (Caton 2011, 1). In the case of the preservice teachers in the study reported here, one of the main reasons they gave for choosing to go to India was to have an experience that would be different from any other they'd ever had, or could imagine having. They expected India to test them, and transform them. With the exception of one student who had been to India before, all the preservice teachers' impressions and opinions of India were shaped by images, media representations, tourist information as well as the university promotional material for the trip. According to Caton,

Our existence in today's hypermediated world, in which we are constantly bombarded with visual information from every direction, impacts our consciousness, and it ensures that when we visit destinations - even those very remote from our ordinary life spaces — we are never really "seeing them for the first time" $(2011,1)$.

Kelly says she "was drawn to India because of photos she had seen" that portrayed it as beautiful and exotic but also poor and shocking. Adeline said, "I wanted to go just purely because it was different, like I'd already done Europe, already seen it and India was something that I'd never experienced or seen before". When Bethany was asked whether she would have been interested in going to a European country or to North America, she said, "No. I probably will go there at some stage in my life, but I wouldn't classify it as an experience. It would be like here" [Australia]. Although Bethany has not travelled overseas, she believes Europe and North America are not sufficiently different from Australia and wouldn't provide her with "an experience". It would seem that what constitutes "an experience" for her is something that is markedly 'foreign' and unfamiliar. Tamsyn says, "India fascinates me. So does Africa. So, yeah, because they are different, totally different cultures, away from the Westernised world as such".

A destination like India can be challenging for those who encounter it for the first time. It involves being confronted by extreme poverty as well as dealing with potential health risks. Travel to India usually means using public transport and other infrastructure that are often outdated and inefficient. However, despite this, and possibly because of it, India has long been a travel destination for those from the 'developed world' who seek adventure, risk and in some instances, spiritual enlightenment and authenticity (Korpela 2010). Lozanski refers to some 
types of travel as a "project of self realization" (2011, 466), an opportunity for personal development and growth.

The liberal norms of individual accomplishment [...] are played out through travelers' ability to embrace the hardships of travel, to succeed by surviving the difficult times, and to change as a person. This process of self-development is a further means by which travelers amass cultural capital (Lozanski 2011, 475).

A recurring theme in Bethany's interview data was how the trip helped her become a better person, a more tolerant and grateful person. She says,

I took strength just in knowing I'd chosen to do this. It was testing every part of me; physically, emotionally, bloody hard work. Yeah. I thought, I need to get the most out of it if I can. It's not for long. I've got a wonderful life waiting for me and very soon this will be over. [...] It's made me a better person, grateful for everything, little things, big things, things I'm given. I'm conscious of trying to be patient with my family and friends. It was a challenge for me to be living like that. But I'd say I benefitted out of it, even though it was a very long haul.

Bethany talks about the trip in ways that suggest she saw it as an endurance test, a test of her resilience and perseverance. Ultimately however, it enabled her to become a "better person". Fitzell talks about developing countries as providing an "opportunity to immerse ourselves in what we may perceive to be a somewhat dangerous, yet romantic way of life, in the hopes that through the overcoming of challenges we will gain a better sense of self" $(2012,25)$. Overcoming hardship, albeit temporary hardship, may provide opportunities to develop, "strength of character, adaptability, resourcefulness, sensitivity or even 'worldliness"” (Mowforth and Munt 2009, 121).

\section{The Exotic Other and the Deficit Other}

The preservice teachers were struck by the culturally different practices they encountered and used terms such "blown away" and "amazed" to describe their feelings. An analysis of how they talked about Indian people and Indian culture revealed a construction of Indians as either the deficit Other or the exotic Other. In understanding the Indians as exotic, 
the preservice teachers saw them as embodying and practising novel, striking, colourful and 'interesting' elements of culture. Their food, clothes, music, customs and folklore were seen as valuable for their potential to enrich the preservice teachers' lives. Kelly says, "I was so connected to the religion, the individuality of the country. The culture's so rich and I tried all sorts of different food".

The preservice teachers talked about some of the Indians with whom they had contact as 'beautiful' both in regards to their personalities and to their physical appearance. "The students were beautiful, very keen, very keen. And so was actually their teacher" (Tanya). "The lady who runs the place [the accommodation], I can't remember her name, she was beautiful so graceful" (Tamsyn). The colour and richness of Indian culture was highlighted and emphasised against what the preservice teachers regarded as bland Australian culture or even non-existent Australian culture. Ellen says:

Their culture is so old in comparison to Australia. We are so young, we are such a young country. They have more culture I think, I know it sounds weird, but they have more culture, and more traditions. We have nothing.

Kelly talked about Hinduism as "so interesting" because of its richness, colour and rituals. She goes on to describe herself as being "from a country where you are exposed to a lot of English culture and you don't really have your own culture".

It would seem that both Ellen and Kelly are drawing on narrow and common Euro-centric understandings of culture as constituted by old buildings, museums, long traditions of European folklore, art and music. With only a little over 200 years of European settlement in Australia, culture of this sort is limited. That Kelly understands Australian culture to be English culture, is to disregard the rich Indigenous cultures that predate European settlement in Australia by over 40,000 years, and to also ignore the impact of significant numbers of nonEnglish immigrants to Australia and the complexities of defining Australian cultural identity. The view of exotic cultures as valuable because of their potential to enrich and make interesting the lives of those from 'bland' cultures shapes their reasons for seeking out such enrichment through travel. Thus, such views can be seen to amount to the commodification of culture and the "commodification of people and places for the aesthetic consumption of self-indulgent tourists" (Gray and Campbell 2007, 466). According to Minnaard, “...exoticism can be 
considered as a form of epistemological imperialism. It produces knowledge that works to support and justify the imperialist project and that helps to legitimate the accompanying power relations" $(2010,76)$.

In exoticising Indian culture, the preservice teachers also inadvertently romanticize the material effects of poverty.

They were proud of their school, they were proud of what they had, they were very happy with it. It appeared to us Westerners that they had absolutely nothing, but they couldn't be happier.

Although the preservice teachers regarded the Indians as having "absolutely nothing", according to Bethany they were content, proud and even happy with the little they had. This view of them as 'poor but happy' is troubling for a number of reasons. It constructs the Indians as naïve (or stupid) because they don't know what it is they don't have (or should have). Alternatively, the suggestion that they are happy with the little they have may be shaped by a belief that materialism simply does not matter to them. It is popularly thought that the religions of 'The East' enable followers to rise above the materialistic concerns that dominate the lives of those from 'The West'. The mysterious and mystical cultural 'East' has long been a drawcard for those from the West seeking spiritual fulfillment and escape from materialism and consumerist lifestyle. This is particularly the case for India (Korpela 2010). The 'poor but happy' discourse to which Bethany subscribes not only ignores the material effects of poverty but it also ignores the gulf between the preservice teachers' and the Indians' access to material wealth. Thus, an interrogation and critique of the existing inequalities between the two groups, is made unnecessary.

At the same time as the Indians were seen as the exotic Other whose culture enriched the lives of the preservice teachers, they were also positioned via comparisons between Australia and India, as the 'deficit Other' and the 'needy Other'. In particular, a pattern that emerged in the data was how the Indian schooling system was inferior to that in Australia, how teachers were less skilled than Australian teachers and how Indian students lacked fundamental attributes such as imagination, self reliance and independence. Kelly says; 
One thing I struggled with, which they [the organisers] should have really, really told us, was the students' lack of imagination. You couldn't get them to draw a picture because they would get the book and they would just copy the picture.

Despite the Indian teachers having many more years of experience than any of the preservice teachers, only one of them, Terry, said he learned anything of value about pedagogy from the Indian teacher he was assigned to. All of the others said they either learned little of value or learned nothing from the Indian teachers. They portrayed Indian education as backward and decades behind Australia.

I don't know if we really learnt about [teaching] techniques from them. There wasn't really anything that I would use. Like it's very teacher-orientated so everything's about the teacher, whereas in Australia I'd say we're more studentorientated and everything's about the student. In India it's very much just like "I'm giving you a book, you read this, you copy off a board, like don't talk, you know"? (Adeline)

Education for girls is not valued at all. A lot of them leave primary school at age ten. They are encouraged over there to stay at home, raise the kids, like it was 50, 60 years ago for us (Kelly).

These comparisons of Indian education with Australian education construct the two education systems as binary opposites; backward/advanced, student centred/teacher centred. Such attitudes can be seen to be "embedded in the implicit hierarchies of colonialism that persist in a neo-colonial global setting" and "the vestiges of a distinctly imperial mindset, which establishes the West as the only right actor in the world" (Tester 2010, ix). That there was little the preservice teachers thought they could learn from the Indian teachers may well have led to them constructing themselves as experts in comparison and therefore, well positioned to improve the Indian children's experiences of education, a point I shall return to in the next section. 


\section{Discourse of Benevolence and Charity}

While the preservice teachers did not initially express a desire to go to India to 'do good', it seemed to gain great importance for many of them during the course of the trip. Their construction of the Indians as the 'deficit Other' and 'needy Other' in comparison to the forward thinking, modern, efficient and competent 'Western self' contributed to them taking up and positioning themselves within discourses of charity and benevolence. Caitlin speaks about taking teaching resources and gifts from Australia, a gesture she claims was not appreciated.

If someone came to my school and went out of their way to help or do something nice you would say, “Thank you so much." You know, go out of your way to show your gratitude, but nothing like that was happening at all. And it's not that we wanted them to fall at our feet at all, but there was nothing [...] I was so excited to bring this suitcase full of everything. It would just be amazing for them, and they [the teachers] just packed it up and took it off, and we never saw it again, we never heard about it again and I was like, I just carted that all the way around the world and for nothing! Not even "Thank you."

Maybe Caitlin's disappointment that the Indian teachers did not appear to share her enthusiasm is understandable. However, the construction of herself as generous and good and the Indians as unappreciative and lacking manners is reminiscent of postcolonial attitudes that construct the 'West' as charitable, moral and therefore civilised in comparison to the ill-mannered and ungrateful Other. Terry expresses similar sentiments when the Indians the preservice teachers met appeared to be cautious and uncertain about their motives for being in India. "There were times when you just wanted to say, "Well, I am over here trying to do a good thing”.

Bethany speaks about what she saw as the potential of the preservice teachers to make a difference to the lives of the students they taught.

[...] those kids have such a good opportunity to learn so much from us, and it's a waste if it's not done properly. It's a small window and we could change their lives ultimately. We can let them know that they can do, or be anything that they may not be aware of. 
Her suggestion that "they can do, or be anything" if only they realised it, is naïve and simplistic. Inequality of opportunity is a systemic problem embedded within complex and historical discourses of injustice, some of which are due to the exploitative relationships the West had, and still has, with some developing countries. Furthermore, that the Indian students' potential to be, and do anything, can be awakened by the efforts of a group of Australian preservice teachers over a four week period, is equally naïve. Bethany goes onto say;

I would love to eventually get some of them over here. When I'm out teaching and I'm on good money I'd love to get a few of those kids here because they were very, very special people, and they don't have opportunities. It would blow their minds, just the most simple things that we have would be the world to them, yeah.

The "helping imperative" in regards to "the imperative of moral "goodness" [that] suffuses white middleclass identity" (Heron 2007, 125) is reflected in the preservice teachers' views that they can identify what opportunities it is that the Indian students lack and can offer them such opportunities. These attitudes are similar to those of students who go on volunteer abroad trips to developing countries in that they too can develop a "bloated sense of self importance and ability to solve other people's problems" $(2008,82)$.

\section{Discussion and Conclusion}

This article has highlighted how the preservice teachers saw the trip as an opportunity for self realization, how they constructed the Indians as the exotic Other and the deficit Other and how their views about, and towards the Indians were embedded within discourses of benevolence and charity. These findings raise serious concerns that the trip facilitated the development and maintenance of postcolonial and neocolonial attitudes towards racial and cultural difference, rather than facilitating reflective and reflexive approaches to understanding self and others. In what follows I address specific concerns around: a) the preservice teachers' understandings of difference and the lack of opportunity for the preservice teachers to engage in reflective and reflexive practices; b) the organisation of the trip including the nature of the marketing of the trip and the choice of schools to which the preservice teachers were sent.

It is clear that the preservice teachers need to develop nuanced and sophisticated understandings of race, ethnicity and culture as well as interrogate the assumptions that 
underpin their beliefs and actions. This will, by necessity, require them to critique their own positioning as members of the white hegemonic 'mainstream' and engage with the concept of whiteness. However, whiteness and the privilege it accrues is taken for granted as 'normal' by those who are white, and thus it is invisible to them. Making it visible is challenging, but necessary teacher education work if the preservice teachers are to move beyond what Pearce names as 'unreflective standpoints' informed by whiteness $(2012,465)$. This is important academic work for all preservice teachers and needs to be incorporated into all teacher education curriculum. However, there is additional work needed to prepare preserivce teachers for an international experience that must occur before, during and after trips. While there were pre-departure briefings for the trip reported here, they focused on the logistics of the trip such as how to get to the accommodation, what the daily routine would be like, and so on. Some of the briefings advised the preservice teachers about how to cope with culture shock, what were acceptable ways to behave whilst overseas and the need for cultural sensitivity. The sessions were a couple of hours in length and the content presented was general in nature. There were no opportunities during the trip for the students to engage in guided reflection. While they completed journals, these took the form of a recount of events, rather than providing an opportunity for deep reflection. Similarly, the debriefing was primarily concerned the logistics of the trip and with getting feedback from the preservice teachers about the organization. These sessions could have, and should have provided opportunities for the preservice teachers to identify critical incidents from the trip, to reflect upon them and to interrogate their responses to the incidents. For example, that only one of the preservice teachers thought he had learned anything about teaching from the Indian teachers is troubling. Had they been encouraged to observe the classes with a 'trained eye' they may have been able to see the value of the teachers' particular approaches and to also look for elements of practice that could inform their own teaching. That the organisation of the trip was outsourced to a third party that does not have expertise in teacher education can also be seen as a contributing factor to the lack of academic rigour in the programme's activities.

The marketing and promotion of the trip is of significant concern. Flyers promoting the trip and recruiting prospective participants resembled tourism materials that exocticised India and Indians. They contained pictures of well known Indian tourist sites and landmarks, Indian food and Indian crafts as well as photographs of Indians in traditional dress. Photos of female preservice teachers from previous trips dressed in salwar kameez and surrounded by large groups of Indian children shoddily dressed and clearly poor, but happy and smiling, also 
reinforced the 'poor but happy' discourse to which some of the preservice teachers subscribed. While there was some attempt to direct the preservice teachers' attention to how the experience would help their development as a teacher, this was minimal. According to Caton and Santos, tourism materials and "media products tend to construct non-Western people and cultures as Other to the Western Self. Such constructions tend to recycle classic colonialist tropes that depict the Other as mysterious, backward, sensual, deviant, and peripheral" $(2009,192)$.

Furthermore, because the preservice teachers taught only at orphanages and schools for the disabled, they witnessed extreme deprivation, suffering and poverty and may have been overwhelmed by what they saw and experienced. In other work I have suggested that placing preservice teachers in contexts that are too far beyond their comfort zone can be counterproductive because their discomfort becomes a hindrance to what might otherwise be a productive learning experience (Santoro and Major 2012). Being in such a different education context might have meant it was difficult for the preservice teachers to make connections between what they were observing and their own practices, especially because they had not had the preparation to do so via adequate coursework and pre-departure briefings. Had the preservice teachers also gone to schools that were well resourced and contained a different student demographic, they would have had opportunities to develop a broader and more comprehensive view of contemporary India. Thus, there may have been less of a gulf between how they saw themselves and how they experienced India, and more of a chance that they might see the value of the experience to their development as teachers.

In conclusion, there is increasing pressure on all universities to increase their internationalisation efforts and make available to students international programmes as part of their teaching degrees. It is imperative that the sort of tourism experience promoted in this teacher education program, albeit unintentionally, is avoided. Without careful and sensitive marketing and recruitment, rigorous accompanying academic work and a careful selection of placement schools, there is the potential for trips to 'developing' countries to be seen by preservice teachers as primarily as an opportunity to travel to an exotic tourist destination. There is the risk that they will simply foster postcolonial and neocolonial racist attitudes, rather than facilitate the development of culturally aware and responsive practitioners. 


\section{References}

Australian Institute for Teaching and School Leadership 2011. National Professional Standards for Teachers.

http://www.aitsl.edu.au/verve/_resources/AITSL_National_Professional_Standards_for_Teac hers.pdf

Banks, J. 2008. Diversity, group identity, and citizenship education in a global age. Educational researcher 37: 129- 139.

Bhabha, H. 1994. The location of culture. London: Routledge.

Brown, L. 2009. The transformative power of the international sojourn: An ethnographic study of the international student experience. Annals of Tourism Research 36, no. 3: 502521.

Butler, J. 1997. Excitable speech: A politics of the performative. New York: Routledge.

Caton, K. 2011. Pedagogy and the Other: Discursive production in study abroad. The Journal of Tourism and Peace Research 2, no. 2: 1-15.

Caton, K. and C. A. Santos. 2009. Images of the Other : Selling study abroad in a postcolonial world. Journal of Travel Research 48: 191- 204.

Cushner, K., and S. Brennan, eds. 2007. Intercultural student teaching: A bridge to global competence. Lanham, MD: Rowman and Littlefield Education.

Dantas, M. L. 2007. Building teacher competency to work with diverse learners in the context of international education. Teacher Education Quarterly 34, no. 1: 75-94.

Devlin-Foltz, B. (2010). Teachers for the global age: A call to action for funders. Teaching Education, 21 no. 1:113-117.

Dooly, M., and M. Villanueve. 2006. Internationalisation as a key dimension to teacher education. European Journal of Teacher Education 29, no 2: 223-240.

Fitzell, K. E. 2012. From the teacher's perspective: The complex nature of facilitating volunteer abroad programs in Ontario secondary schools. Master's Thesis, Queen's University, Kingston, Ontario, Canada.

Frankenberg, R. 1993. The social construction of whiteness: White women, race matters. Minneapolis, MN: University of Minnesota Press.

Goodwin, A. L. 2010. Globalization and the preparation of quality teachers: rethinking knowledge domains for teaching. Teaching Education 21: 19-32.

Gray, N. J. and L. M. Campbell. 2007. A decommodified experience? Exploring aesthetic, economic and ethical values for volunteer ecotourism in Costa Rica. Journal of Sustainable Tourism 15, no. 5: 463- 482. 
Hill, B., and N. Thomas. 2005. 'Making Sense of Bali: Unintended outcomes of study abroad. Intercultural Education 19, 67 -77.

Heron, B. 2007. Desire for development: Whiteness, gender, and the helping imperative. Waterloo, ON, CAN: Wilfrid Laurier University Press.

Kissock, C. and Richardson, P. 2010. Calling for action within the teaching profession: It is time to internationalize teacher education. Teaching Education, 21 no.1: 89-101.

Korpela, M. 2010. A postcolonial imagination? Westerners searching for authenticity in India. Journal of Ethnic and Migration Studies 36, no. 8: 1299-1315.

Lozanski, K. 2011. Independent travel: Colonialism, liberalism and the self. Critical Sociology 37: 465-482.

Matias, C. 2012. Who you callin' white?! A critical counter-story on colouring white identity, Race Ethnicity and Education, DOI:10.1080/13613324.2012.674027

Morrison, T. 1992. Playing in the dark: Whiteness and the literary imagination. New York: Vintage Books.

Mowforth, M. and I. Munt. 2009. Tourism and sustainability: Development, globalisation and new tourism in the Third World. New York: Routledge.

Minnaard, L. 2010. The spectacle of an intercultural love affair. Exoticism in Van Deyssel's Blank en geel. Journal of Dutch Literature 1, no. 1: 74-90.

Pearce, S. 2003. Compiling the White Inventory: the practice of whiteness in a British primary school. Cambridge Journal of Education, Vol. 33, no. 2: 273-288.

Rapoport, A. 2008. Exchange programs for educators: American and Russian perspectives. Intercultural Education 19: 67-77.

Said, E. 1993. Culture and imperialism. New York: Vintage Books.

Santoro, N. and Major, J. 2012. Learning to be a culturally responsive teacher through international study trips: transformation or tourism? Teaching Education 23, no. 3: 309-322

Schick, C. 2010. By virtue of being white: Resistance in anti-racist pedagogy. Race Ethnicity and Education 3, no. 1: 83-101.

Scoffham, S., and Barnes, J. (2009). Transformational experiences and deep learning: The impact of an intercultural study visit to India on UK initial teacher education students. Journal of Education for Teaching, 35 no.3: 257-270.

Shank, G. 2006. Qualitative research: A personal skills approach. 2nd ed. Upper Saddle River, NJ: Pearson.

Siwatu, K. O. 2007. Preservice teachers' culturally responsive teaching self-efficacy and outcome expectancy beliefs. Teaching and Teacher Education 23: 1086-1101. 
Spivak, G. 1988. Can the Subaltern Speak? In C. Nelson \& L. Grossberg (Eds.), Marxism and the interpretation of culture (pp. 271-313). Chicago: University of Illinois Press.

Tester, K. 2010. Humanitarianism and modern culture. University Park. PA: Penn State Press.

Tiessen, R. 2008. Educating global citizens? Canadian foreign policy and youth study/volunteer abroad programs. Canadian Foreign Policy Journal 14, no. 1.

Walters, L., B. Garii, and T. Walters. 2009. Learning globally, teaching locally: Incorporating international exchange and intercultural learning into pre-service teacher training. In M. Bennett, guest ed., Journal of Intercultural Education. International Association of Intercultural Education, 20, Supplement 1: January 2009.

Yoon, I. 2012. The paradoxical nature of whiteness-at-work in the daily life of schools and teacher communities, Race Ethnicity and Education, DOI:10.1080/13613324.2011.624506

\section{Acknowledgements}

I would like to acknowledge the preservice teachers who generously gave their time to be interviewed for the study, and the support of the other research team member, Dr. Jae Major.

Check

\section{Inspecting the inspectors: race equality and quality in initial teacher education}

\section{Chris Wilkins, University of Leicester caw11@ leicester.ac.uk}

\section{Abstract}

Equalities legislation in Britain has in recent years shifted towards requiring public bodies to proactively promote equality rather than simply prevent discrimination. This paper reports on a study of how this requirement, with specific reference to race equality, is enacted in the regulation and inspection of initial teacher education (ITE) in England. The study included a review of statutory guidance and inspection frameworks and quantitative analysis of how overall inspection outcomes reflect the quality of ITE providers' engagement with race equality issues. The study also included case studies of ITE programmes judged by their students to be either particularly good or particularly weak at preparing them to address race equality issues in their teaching. 
The study concludes that there is a significant gap between government rhetoric on race equality and the policy enactment of agencies involved in ITE. It argues that in the context of the high stakes accountability systems in place throughout all aspects of educational provision, this means that race equality issues are marginalised within institutional policies that focus on procedural compliance rather than substantive challenge to practices that normalise and so perpetuate structural inequality.

Key words Race equality, ITE policy, accountability, ITE inspection framework

\section{Introduction}

The Race Relations (Amendment) Act (RRAA, 2000) introduced a requirement for public sector organisations in the UK to shift the emphasis of their approach to race equality issues from a passive 'anti-discriminatory' approach, to one which actively promotes race equality and works towards changing institutional cultures and practices. This 'proactive principle' was also embedded in the wider Equality Act of 2010, and has been widely credited with bringing about a fundamental cultural and attitudinal shift, not just in UK public sector institutions but in wider society (EHRC 2009). This attitudinal shift has in turn contributed to a discourse in which Britain is constructed as a socially progressive, 'post-racial' society (Sayyid et al. 2010). This post-racial discourse has been widely critiqued (Kapoor 2011, Lentin 2012), in particular for the way in which it contributes to an underplaying of the significance of institutional racism (Gillborn 2005; Solomon et al. 2006). Given the centrality of schooling in shaping social values and practices, the RRAA, and subsequent Equality Act, were intended to have a particularly significant impact on UK educational institutions. This paper explores the extent to which this intention is realised within a specific aspect of education policy and practice in England; ; namely Initial Teacher Education (ITE).

The legislative framework, underpinned by the RRAA, suggests the race equality issues have greater prominence in educational policy and regulatory frameworks. However, the political discourse of all aspects of education policy and practice (including ITE) has been dominated by the priorities of the neo-liberal performative agenda that has characterised public sector management in England for the past two decades. Central to this agenda has been the focus on 'standards' and 'accountability', and this focus can be seen to marginalise issues of equality and social justice (Ahmed 2007; Morrison 2007; George \& Clay 2008). For this reason, this 
paper examines the way race equality issues are addressed within the inspection of Initial Teacher Education (ITE) in England, drawing upon a range of evidence:

- Policy frameworks Office for Standards in Education (Ofsted) Frameworks for the Inspection of ITE (and guidance for inspectors), Standards for Qualified Teacher Status (QTS) and statutory Initial Teacher Training (ITT) Requirements ${ }^{\mathrm{i}}$;

- ITE Inspection reports 203 inspection reports of university-based ITE programmes over a 5 year period are analysed to identify the extent to which race equality-related issues are 'headlined' by inspectors and the ways in which providers' 'performance' in this respect impacts on overall inspection grades;

- Newly-Qualified Teacher (NQT) Survey outcomes Case studies of particular institutions explore the extent to which inspections are influenced by the perceptions of student teachers of how well prepared they feel for embedding equality and diversity issues into their teaching. The data comes from the national NQT Survey, issued to all newlyqualified teachers mid-year through their first year of teaching.

\section{The performative backdrop}

In the performative system, inspection provides the key disciplinary mechanism by which state priorities are imposed upon public sector providers (Ball 2003, Apple 2005), and so for teacher educators as much as schools, the strategic priorities evident in the relevant inspection framework inevitably influences their own strategic priorities. However, whilst Ofsted school inspection is indirectly shaped by political priorities (through the prescribed framework), ITE inspection is under more direct political control, by means of the inspection process being mediated through the government's delivery agency, the National College for Teaching and Leadership (NCTL)

The introduction in 2008 of an annual Self-Evaluation Document (SED) for ITE providers was superficially merely an extension of the model of self-evaluation already in place in schools. However, in the case of schools, judgement on the self-evaluation (SEF) is solely the responsibility of Ofsted, whereas ITE providers are expected to submit their SED to the NCTL. The judgement they make about the SED (not shared with providers and therefore 'unchallengeable') is then used to shape the timing, scale and the 'lines of enquiry' of each individual inspection. This additional tier of scrutiny has significant implications for the independence of the inspectorate, and the change of status of the NCTL in 2012, from an 'arms- 
length' body to an executive body within the Department of Education (DfE), meaning that the extent of the political control of Ofsted has increased still further. The use of the SED has effectively allowed the government to directly influence the inspection outcomes of individual providers by determining the 'risk ratio' of each inspection (Troman 2007, Wilkins \& Wood, 2009).

The use of self-evaluation as the basis for inspection in schools has itself been widely studied, with many critics arguing that it creates a Foucauldian environment of disciplinary selfsurveillance, in which institutional managers act to ensure the strategic priorities of the State (Ball, 2003; Perryman, 2006; Bubb et al, 2007). Its deployment in the ITE sector forms a key policy backdrop to this study.

\section{Race Equality legislation and its impact on ITE}

There is a substantial body of evidence to suggest that issues of race and diversity have for long periods occupied at best a marginal place in Initial Teacher Education in England. The underrepresentation of Black and minority ethnic (BME) groups in the teaching profession has been long recognised (Rampton 1981; Swann 1985; CRE 1986), as has the persistent disparity in rates of career progression between BME and white teachers (Ross 2001, McNamara et al. 2009; Shah \& Shaikh 2010). These and other studies have highlighted the degree to which BME teachers experience social isolation and marginalization (Ghuman 1995; Osler 1997; McNamara et al. 2009).

A number of government initiatives have attempted to address these imbalances and inequalities in the profession by increasing recruitment and retention of BME student teachers. However, any claims for success of these initiatives have been persistently undermined by evidence of poor retention rates (Carrington \& Tomlin 2000; Basit et al 2006), and of institutional racism and discriminatory treatment from tutors, schools and white peers (Cohen 1989; Siraj-Blatchford 1991; Wilkins \& Lall 2010). This evidence continues to emerge even following the introduction of the RRAA, which was envisaged as a turning point in public sector institutional cultures, by shifting the emphasis from a passive 'anti-discriminatory' ethos to one in which public bodies had a duty to positively promote race equality. In particular, although wider social attitudinal surveys suggest British society has become incrementally more 'progressive' and 'tolerant' in its views of race and ethnicity issues (Ford 2008), there is 
evidence that significant numbers of white student teachers persist in holding views that present their BME peers (and pupils) in a discourse of 'otherness' (Cole \& Stuart 2005; Wilkins \& Lall 2010, Lander 2011).

When considering the impact of the RRAA, Gillborn notes that although the RRAA envisioned a shift to a focus on practice and outcomes, this has not been realised at an institutional level, where the emphasis too often remains on instances of individual 'intentional' racism rather than tackling the underpinning racist inequalities built into institutional practices and cultures (Gillborn 2005). This superficial approach can negate any understanding of racism as a structural phenomenon, and in an institutional context, can create barriers to institutional change. Challenging inequality is seen as a matter of 'procedural compliance' rather that a genuine attempt to change culture and practices (O'Cinneide 2003; Ahmed 2007; Morrison 2007). From this perspective, education (and teacher education) policy should be judged primarily by its practice and outcomes, rather than its intention. As Gillborn and others have consistently argued, despite a decade of shifting the UK legislative framework pertaining to equality towards a proactive, practice-focused approach, the outcomes of marketized, standards-driven, performative policies have had little or no impact on the 'under attainment' for some groups of BME pupils (Gillborn 2005; Strand 2007).

This study therefore attempts to examine both the practice and outcomes of Ofsted's inspection of ITE in respect of race equality issues, and reflects on the possible impact of this on providers' engagement with these issues.

\section{Focus of enquiry}

This study explores how Ofsted teacher education inspection reports evaluate and form judgements about aspects of provision relating to race equality and diversity. It does this by drawing upon a range of publically accessible 'performance profile' data about provision to explore the relationship between the use of this data and inspection outcomes, as well as the policy framework that informs the inspection process. Table 1 details the documentation and data examined. ITE policy documents (including the statutory Standards framework for assessing teacher quality and Requirements for ITE providers) were analysed at a textual level; initially through a primarily quantitative approach of word counts of references either directly or indirectly related to issues of race equality. This was interpreted broadly, so included not 
only terms such as 'race', 'racism' and 'discrimination', but more oblique references to 'equal opportunities', 'diversity', 'inclusion' and even more widely, references to language issues (references to 'English as an Additional Language (EAL)' were also noted). Whilst this simple quantitative approach is sufficient to give some indication of the strategic priorities of the policies analysed, the particular language choices are examined; textual-analytical approaches to documentary research note that policy documents such as these do not simply report reality, they construct it (Atkinson \& Coffey 2011: 85). This paper particularly critiques these documents in the light of the extensive literature which argues that UK educational policy, at a structural level, perpetuates and reinforces racial inequity through a socially constructed discourse in which whiteness is normalised and discussion of racist practices and outcomes is diffused or obscured through the use of vague terms as 'diversity' and 'inclusion' (Leonardo 2000; Gillborn 2005).

Table 1: Documentation and data sources

(a) Policy document/legislative framework

\begin{tabular}{|c|c|}
\hline Legislation & Statutory policy \\
\hline Equality A & $\begin{array}{l}\text { Professional } \begin{array}{l}\text { Standards } \\
\text { Teachers/Teachers' }\end{array} \\
\text { (TDA/TA) } \quad(2007-2011 \text { and } 2012 \\
\text { onwards) }\end{array}$ \\
\hline $\begin{array}{l}\text { Race Relations (Amendment) Act } \\
(2000)\end{array}$ & $\begin{array}{l}\text { Requirements for ITT Providers } \\
\text { (TDA/TA) covering two periods } \\
(2007-11 \text { and } 2012 \text { onwards) }\end{array}$ \\
\hline
\end{tabular}

(b) Government agency guidance for providers/inspectors \& policy reviews

\begin{tabular}{|l|l|}
\hline Guidance & Policy Reviews \\
\hline Frameworks for inspection of teacher & Annual Reports of Teaching Agency \\
education: guidance for inspectors & and Ofsted \\
covering 3 inspection frameworks & \\
$\left(\begin{array}{l}2005-2008, \quad 2008-2011 \text { and 2012 } \\
\text { onwards) }\end{array}\right.$ & \\
\hline
\end{tabular}




\begin{tabular}{|l|l|l|}
\hline $\begin{array}{l}\text { Best Practice guidance on } \\
\text { equality/diversity (Ofsted) }\end{array}$ & $\begin{array}{l}\text { Policy Reviews on equality/diversity } \\
\text { (Ofsted)An }\end{array}$ \\
\hline $\begin{array}{l}\text { Guidance for ITT providers on } \\
\text { Standards \& Requirements (TDA/TA) }\end{array}$ & \\
\hline
\end{tabular}

(c) Performance data

\begin{tabular}{|c|}
\hline Performance Profile (TDA) \\
\hline $\begin{array}{l}\text { Ofsted inspection reports on ITE } \\
\text { provision }(2007-2012)\end{array}$ \\
\hline $\mathrm{NQ}^{\prime}$ \\
\hline
\end{tabular}

\section{Statutory guidance for Teachers' Standards/Professional Standards}

The NCTL (under its previous incarnations as the Teaching Agency (TA) and the Training and Development Agency (TDA))determines the assessment framework by which teachers are judged to be competent and suitable for teaching. During the period of this survey (20072012), the Professional Standards for Teachers (TDA 2007) sets out 33 'Q' Standards that must be met by student teachers in order to be recommended for Qualified Teacher Status (QTS) ${ }^{\mathrm{i}}$. These are accompanied by extensive guidance (running to 62 pages in its print form) covering the rationale, scope and nature of likely evidence for each Standard, as well as key questions to support providers in making assessment decisions.

Despite the extensive nature of the Standards guidance, the attention given to matters of race equality and diversity is almost non-existent, with just a handful of references to wider equality issues, and to working with pupils with English as an additional language (p21), but the entire document contains just a single explicit reference to racism. However, even this emphasises awareness over action, since it refers to students' awareness of 'the range of policies that support school practice, for example those that relate to equality, behaviour - including bullying, racial harassment and abuse - and special educational needs?” (p11). 
One section of the Standards (Q18-20: 'Achievement and Diversity') would appear to be the obvious site for a deeper engagement with race equality issues, but although the rationale refers to "learners from minority ethnic groups including those for whom English is an additional language” (p34), 'race' and racism are conspicuous by their absence.

In the area of the Standards concerned with Professional Skills, the area most directly addressing the way student teachers actually perform in the classroom, equality and diversity falls within scope for Standard Q25(a); this contains perhaps the closest acknowledgement of the existence of racism by posing the following 'key questions' for providers:

- Does the trainee encourage and draw on the contribution of diverse groups to enhance the learning and progress of all children and young people?

- Does the trainee promote equality and inclusion of all learners in their teaching strategies and choice of resources?

- Does the trainee avoid and, where necessary, challenge stereotyping?

- Does the trainee know how to deal with sensitive and/or controversial issues that might arise through children and young people's perception of difference? ( $p 46)$

These questions however seem crafted to deliberately reduce racism to its surface phenomenon of individual prejudice, overlaid by notions of 'difference' and 'diversity', rather than as a structural phenomenon. This in turn limits schools to simply addressing the outward manifestations of racism (harassment, abuse) rather than challenging it as a structural matter, as a fundamental social justice issue.

Professional Standards were superseded from September 2012 by Teachers' Standards (DfE 2012). Although race equality (and equality more widely) is demonstrably marginalised in the Professional Standards, its place in the future is considerably worse. The Teachers' Standards appear to avoid even a token acknowledgement of these issues. Guidance is extremely limited, and not only is there no explicit reference to race equality or racism, even the terms 'diversity' and 'inclusion' have been removed. 'Equal opportunities' only appears in the preamble, in an explanatory note giving this as an example of the "statutory frameworks" that cover the work of teachers. Even English as an Additional Language (EAL) is only mentioned in one Standard area, where it is bracketed alongside Special Educational Needs (SEN) and "those with disabilities" (DfE 2012). The closest the Teachers' Standards come to acknowledging any 
notion of diversity and equality comes in references to "pupils of all backgrounds", and to "tolerance of those with different faiths and beliefs" (DfE 2012). This reference to tolerance is made as an example in a significant addition to this model of Standards, the requirement that teachers must "uphold public trust...[by]...not undermining fundamental British values" (DfE 2012).

The use of the notion of 'British values' in this context is, of course, worthy of a more detailed analysis than can be given here. However, in the context of post-Equalities Act developments in education policy, its use appears to signal that the current Coalition Government is keen to re-establish a 'traditional British 'cultural hegemony by consciously retreating from the already minimalist acknowledgement of systemic race injustice in UK education institutions.

\section{TA/TDA guidance for ITT Requirements}

Whilst Professional Standards sets out the level that student teachers need to demonstrate achievement to be awarded QTS, the Requirements for ITT (TDA 2008) set out the statutory requirements on providers of teacher education in respect of their design, delivery and management of courses ${ }^{\mathrm{i}}$. As with Professional Standards, however, guidance on Requirements is extensive (53 pages); it is also conspicuously lacking in explicit acknowledgement of racism.

The guidance includes several references to 'promoting equality of opportunity' and 'avoiding discrimination' in those requirements relating to recruitment and selection criteria ( $\mathrm{p} 4, \mathrm{p} 8$, p17), with a further reference occurring in 'Training' requirements (p21).

Requirement 2.5 specifically addresses 'Equality of access', and the guidance provided here is revealing. The key questions providers are advised to ask themselves are as follows:

- Do our procedures and practices for selection, training and assessment promote equality of access?

- How effective is our monitoring of equality of access?

- Do we have appropriate support systems for trainees?

- Do we need to provide further training for staff in relation to the needs of trainees from underrepresented groups of all diversity strands? 
- How would we know if trainees experience discrimination during training? How do we prepare trainees, mentors and initial teacher training (ITT) staff for dealing with such incidents if they arise?

- Are all trainees confident that we are meeting our commitment to ensure equality of access to training? (p29)

These questions suggest a preoccupation with policy, procedures and tutor training needs; much of the guidance is taken up with listing the relevant legislation providers are obliged to respond to.

Further references to equality of opportunity occur in the guidance on 'Management and Quality Assurance', again focused on policy and procedures, monitoring rather than acting. Requirement 3.3 concerns 'Compliance and safeguarding'; the guidance here also reviews providers' duties in respect of key legislation (including equality legislation) (pp107-109).

\section{Ofsted and Race Equality}

As with all public bodies, Ofsted are bound by the requirement of the Equality Act and the RRAA to positively promote race equality, and has responded with a regular series of review reports looking at, for instance, good practice in schools and local authorities with a focus on improving; BME pupil outcomes and the quality of reporting and monitoring racist incidents (Ofsted 2005). Ofsted's 2007-10 Strategic Plan stated a commitment to "put equality and diversity at the heart of everything it does" (Ofsted 2009, p4). This Plan set out what it sees as more substantive responses to the RRAA has been a "strengthened focus on equality" in inspection frameworks, including (from 2008) a distinct 'equality and diversity judgement grade' that contributes to the overall inspection grading $(2009, \mathrm{p} 7)$.

This introduction of a quantifiable grading of providers' engagement with equality and diversity was clearly intended to send a signal about the importance of these issues; that providers would be expected to see them as core priorities rather than peripheral ones, and that Ofsted inspections would ensure there would be significant adverse consequences for those that did not. However, the impact of this commitment needs to be judged on the reality of inspection outcomes, and the ways in which inspectors actually engaged with the inspection 
framework. Ofsted's guidance for inspectors on the management and conduct of inspection provides the clearest insight into the way in which race equality practice is viewed. In order to interpret this, however, it is first necessary to outline the nature of ITE inspection, and in particular how it differs from the framework for inspecting the work of schools.

\section{ITE inspection: issues of independence and political 'steerage'}

As noted above, the relationship between the executive 'delivery agency' and Ofsted was made more complex by the introduction of a self-evaluation model of inspection in 2008. ITE providers are expected to submit an annual self-evaluation document (SED) to the Agency; the document follows a tightly prescribed format and the Agency issue annual 'strategic priorities' against which providers must demonstrate compliance. This SED is in turn used by Ofsted to determine 'lines of enquiry' during inspection, implying a potential risk to the independence of the inspectorate, who are effectively directed into making judgements on not only the quality of ITE programmes, but in the compliance of providers with the government's 'delivery agency' (Wilkins \& Wood 2009). In this context, the guidance for inspectors of ITE provision (Ofsted 2008) is particularly helpful in revealing the emphasis placed on race equality issues.

What is revealed is an almost total absence of acknowledgement of race equality. If the profile of race equality in Agency guidance is marginal at best, in Ofsted guidance it is virtually invisible. This is particularly worrying for an organisation that has been heavily criticised for its failure to adequately address race issues in schools inspections, in particular, for downplaying the centrality of race equality issues focusing on procedural compliance rather than outcomes (Osler \& Morrison 2002). Osler and Morrison's research was carried out just after the introduction of the RRAA, but despite the fact that the Act is over ten years old, there has been little or no research on its impact in ITE carried out since then. This study is intended to not only explore the extent to which Ofsted's engagement with race equality issues has developed since this critique, but to contribute to the wider debate about the impact of race equality legislation on institutional policy, practice and culture.

\section{How does Ofsted address race equality and diversity in inspection reports?}

This study began by examining Ofsted reports (publically available on the Ofsted website) on ITE providers over a 5 year period (2007-2012), focusing on the frequency of explicit 
references to race equality and diversity issues, and the extent to which particular aspects of equality and diversity were considered worthy of emphasis (either positively or negatively) by inspectors. To simplify the process, the study was restricted to HEI-based providers of Primary and/or Secondary ITE courses (comprising of approximately 80-85\% of the total ITE provision in England), leaving a sample of 67 providers to be examined. The study covers reports from two different inspection frameworks; the first in force from 2005-08, the second from 2008-11 (which actually continued to be used as the basis for inspections during 2011-12 whilst consultation was carried out in respect on the new framework, which eventually came into force for 2012-13). This means that this sample includes two inspections from many providers (and in a small number of cases, three inspections), giving a total of 203 reports (96 Primary, 107 Secondary).

Although the frameworks differ in many respects, the structure of the reports is similar, enabling this study to review their content in a consistent way. Each report begins with an 'executive summary'; a bullet point list indicating 'key strengths' and either 'points for action/consideration'(2005-08) or 'recommendations' (2008-12). These are followed by a narrative which sets out the findings of the inspection team in more detail. It is the 'executive summaries' that were the focus of the first level of analysis, as they provide an immediate insight into the issues thought to be significant by inspectors, and a clear insight into the rationale for the overall grade awarded to the provider.

What is immediately striking is the scarcity of direct reference to equality/diversity issues of any kind in report 'headlines'. The 203 reports contain around 1400-1400 'headlines' identified by inspectors; approximately 750 'key strengths' and 650 'points for action/consideration'. Of these, 48 'key strengths' and 19 'points for action/consideration' referred to issues of equality and diversity. Only 5 specific mentions of 'race' were found; these exclusively related to management/policy judgements, with reference made to "monitoring race equality policies" and to "procedures for recording and reporting racialist incidents".

Tables 3 and 4 below, summarising the frequency of references to equality/diversity, suggest at first sight roughly equal attention paid to practice/outcomes on the one hand, and policy/processes on the other. These are broken down by the overall inspection grade given to the provider (Grade 1 = 'outstanding', Grade 2 = 'good', Grade 3 = 'satisfactory'); it is perhaps 
worth noting that the vast majority of inspection reports in recent years have been Grade 1 or 2 (see table 2), and the likely funding consequences of a Grade 3 outcome means that this almost equates to a 'fail'. For simplicity, the handful of inspections with a Grade 4 outcome ('non-compliance') have not been included in this survey.

Table 2: Breakdown of overall grades of reports

\begin{tabular}{|l|c|c|c|c|}
\hline \multirow{2}{*}{ Sector } & Inspection reports & \multicolumn{3}{|c|}{ Grades } \\
\cline { 3 - 5 } & & $\mathbf{1}$ & $\mathbf{2}$ & $\mathbf{3}$ \\
\hline Primary & 96 & 31 & 56 & 9 \\
\hline Secondary & 107 & 41 & 57 & 9 \\
\hline Total & 203 & 72 & 113 & 18 \\
\hline
\end{tabular}

In order to examine more closely the ways in which inspectors formed their judgements, inspection 'headlines' were clustered around five aspects of equality and diversity suggested by the Ofsted framework and TDA Requirements: preparation for teaching in a diverse society; policy awareness; preparing students to teach pupils with EAL $L^{i}$ recruitment and selection; management and QA. Tables 3 and 4 show how headline references are distributed within these aspects.

Table 3: Summary of key equality/diversity issues rated positively in inspection reports

\begin{tabular}{|c|c|c|c|c|}
\hline \multirow{2}{*}{$\begin{array}{l}\text { Positive reference to } \\
\text { equality/diversity } \\
\text { issues in } \\
\text { inspection } \\
\text { 'headlines' }\end{array}$} & \multirow[t]{2}{*}{ Examples of specific issues noted } & \multicolumn{3}{|c|}{$\begin{array}{l}\text { Overall Inspection } \\
\text { outcome }\end{array}$} \\
\hline & & $\begin{array}{r}\text { Gra } \\
\text { de } 1\end{array}$ & $\begin{array}{r}\text { Gra } \\
\text { de } 2\end{array}$ & $\begin{array}{l}\text { Gra } \\
\text { de } 3\end{array}$ \\
\hline $\begin{array}{l}\text { Preparing students } \\
\text { for teaching in } \\
\text { diverse society }\end{array}$ & $\begin{array}{l}\text { - Students well prepared for teaching } \\
\text { pupils from 'diverse backgrounds' } \\
\text { - Students confident to 'teaching in } \\
\text { culturally and socially diverse } \\
\text { schools' }\end{array}$ & 3 & 10 & 3 \\
\hline
\end{tabular}




\begin{tabular}{|c|c|c|c|c|}
\hline $\begin{array}{l}\text { Preparing students to } \\
\text { teach pupils with } \\
\text { EAL }\end{array}$ & $\begin{array}{l}\text { - excellent attention to training for } \\
\text { diversity and equality and English } \\
\text { as an additional language (EAL) }\end{array}$ & $\mathbf{0}$ & 3 & $\mathbf{0}$ \\
\hline Policy awareness & $\begin{array}{l}\text { - Students aware of procedures, e.g. } \\
\text { equal opportunities and race } \\
\text { relations policies }\end{array}$ & 2 & 3 & $\mathbf{0}$ \\
\hline $\begin{array}{l}\text { Recruitment and } \\
\text { Selection }\end{array}$ & 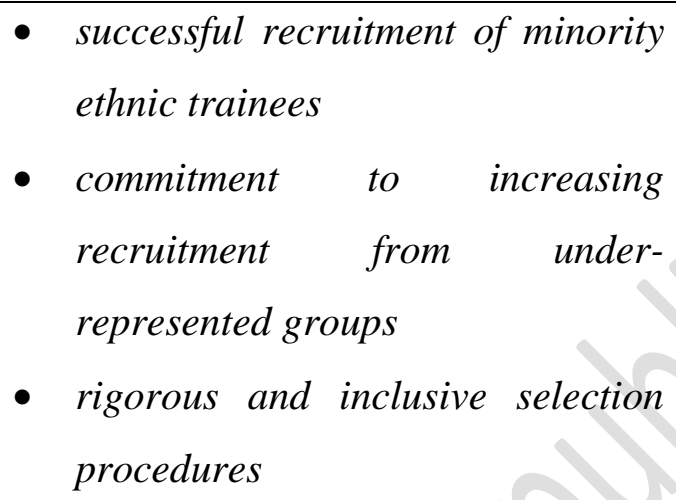 & 5 & 14 & \\
\hline $\begin{array}{l}\text { Management/Quality } \\
\text { Assurance and } \\
\text { monitoring }\end{array}$ & $\begin{array}{l}\text { - very effective procedures for } \\
\text { monitoring its policies on equality } \\
\text { of opportunity, } \\
\text { - strong policies on the promotion of } \\
\text { good race relations }\end{array}$ & $\mathbf{0}$ & 3 & $\mathbf{0}$ \\
\hline
\end{tabular}

Table 4: Summary of key equality/diversity issues rated negatively in inspection reports

\begin{tabular}{|l|c|c|c|c|}
\hline $\begin{array}{l}\text { Negative reference to } \\
\text { equality/diversity issues }\end{array}$ & Examples of specific issues noted & $\begin{array}{l}\text { Overall } \\
\text { outcome }\end{array}$ & & \\
in & & 1 & 2 & 3 \\
inspection 'headlines' & Grade & Grade & Grade \\
\hline $\begin{array}{l}\text { Preparing students for } \\
\text { teaching in diverse } \\
\text { society }\end{array}$ & $\begin{array}{l}\text { Develop further understanding } \\
\text { of teaching in a diverse society } \\
\text { Underdeveloped understanding } \\
\text { of some aspects of ethnic and } \\
\text { cultural diversity }\end{array}$ & $\mathbf{7}$ & $\mathbf{4}$ & $\mathbf{0}$ \\
\hline
\end{tabular}




\begin{tabular}{|l|l|c|c|c|}
\hline $\begin{array}{l}\text { Preparing students to } \\
\text { teach pupils with EAL }\end{array}$ & $\begin{array}{l}\text { Further development of } \\
\text { training to support pupils with } \\
\text { EAL }\end{array}$ & $\mathbf{1}$ & $\mathbf{0}$ \\
\hline Policy awareness & $\begin{array}{l}\text { Students aware of procedures, } \\
\text { e.g. equal opportunities and } \\
\text { race relations policies }\end{array}$ & $\mathbf{0}$ & $\mathbf{1}$ & $\mathbf{0}$ \\
$\begin{array}{l}\text { Secruitment } \\
\text { Selection }\end{array}$ & $\begin{array}{l}\text { Further development of } \\
\text { strategies to } \\
\text { increase recruitment from } \\
\text { under-represented groups }\end{array}$ & $\mathbf{3}$ & $\mathbf{0}$ \\
\hline $\begin{array}{l}\text { Mansurance } \\
\text { monitoring }\end{array}$ & $\begin{array}{l}\text { strengthening procedures for } \\
\text { monitoring the implementation } \\
\text { of equal opportunities policies }\end{array}$ & $\mathbf{1}$ & $\mathbf{1}$ & $\mathbf{0}$ \\
\hline
\end{tabular}

It is immediately apparent from this that the majority of references (both positive and negative) fall within 'preparation for teaching in a diverse society' and 'recruitment and selection'. This even more noticeable in the later period of this study, with virtually all references to equality issues in inspections carried out in 2008-11 being restricted to these aspects. Conversely, references to student teachers' awareness of equality policy contexts (including teachers' legal responsibilities), and to providers' management oversight of equality policy and practice (including the monitoring of outcomes) are almost invisible. Given that these aspects of institutional practice are directly addressed in the requirements of the RRAA, this raises a fundamental question about Ofsted's compliance with statutory obligations. The fact that these policy-related aspects do not get a single headline mention (either positive or negative) during the 72 inspection reports published since mid-2010 would suggest that Ofsted are falling well short of even a minimal engagement with their obligations.

Preparation for teaching in a diverse society features more heavily in 2008-11 inspections than those carried out under the earlier framework; this perhaps reflects a wider shift in the emphasis of inspection to focus on the observed practice of student teachers'. It also comes with an apparent downplaying of references to recruitment and selection issues in later inspections (the occurrences in this sample are predominantly in pre-2010 inspections). This raises an 
intriguing point about the relationship between inspection outcomes and the wider political context. Ofsted inspections are intended to be entirely driven by the methodology set out in the inspection framework, and so it should be able to see a reasonably consistent pattern of key foci throughout the lifespan of each framework. There is, however, a case for arguing that inspections taking place in 2010-11 and 2011-12 reveal a tendency to reflect not the priorities of the inspection framework, but the changing political context. The Conservative-Liberal Democrat coalition government's Schools White paper (DfE 2010) proposed that future inspection frameworks would focus more narrowly on attainment outcomes, and less on wider policy issues (including, of course, equalities legislation, policy and practice). This not only challenges the notion of an independent inspectorate, but suggests that the coalition government's positioning on equality has had a direct, and immediate, impact.

Although the inspection framework (and many inspection reports) refers to ITE providers' outcomes in terms of BME recruitment, there are no direct references to outcomes in terms of BME attainment. This is concerning, given the weight of evidence (including that of the TDA's own Performance Profile data), that BME students are significantly more likely to fail to complete teacher education than their white peers (TDA 2012). Moreover, this achievement gap has persisted over many years (Carrington \& Tomlin 2000; Basit et al 2006; Wilkins \& Lall 2010). One might have expected, therefore, especially given that supporting BME recruitment and retention is claimed as a key strategic priority by the TDA, that Ofsted would be examining carefully the performance data of providers and highlighting this issue in their reports. The relatively 'relaxed' view of how inspectors report findings relating to race equality runs counter to the broader thrust of TDA/Ofsted strategy, which is almost entirely driven by measurable outcomes. This is transparent in the way inspection reports address other issues (e.g. support for developing subject knowledge, partnership arrangements, providers' improvement planning), where the focus of inspectors on 'outcomes' is relentless - little or no attention is paid to anything else.

It is also interesting to compare the different ways in which positive and negative references are used in relation to the overall outcome of inspections, particularly comparing Grade 1 reports against Grade 3s. Given that Grade 1 reports, unsurprisingly, contain more positive references overall than Grade $3 \mathrm{~s}$, it might be expected that they would also contain proportionately more positive references to equality/diversity practice. In fact, Grade 1 reports 
make up $35.4 \%$ of the total sample (72 out of 203) but account for only $20.8 \%$ (10 out of 48 ) of positive references to equality/diversity. Grade 3 reports, conversely, make up 8.8\% (18 out of 203 ) of the sample, and provide $10.4 \%$ (5 out of 48 ) positive references.

Perhaps even more notable is the distribution of negative references. Grade 3 providers, being judged as the weakest provision by inspectors, inevitably have more "points for action/recommendation', yet not a single one of these relate to equality/diversity. Given that these are apparently the weakest courses, it would be very surprising if they do not have any weaknesses in equality/diversity provision. It would appear, then, that the only explanation for this is that inspectors have decided that these weaknesses were not worthy of highlighting in reports. The frequency of negative references to equality/diversity in Grade 1 providers is also notable. There are 12 negative references in 72 reports (meaning that purportedly 'outstanding' provision produces more negative equality/diversity headlines than positive), compared to only 7 negative references in Grade 2 reports (a total of 113). This distribution appears even more anomalous when one considers that, unsurprisingly, reports on 'outstanding' provision contain fewer (if any) negative headlines; generally no more than 1, whereas Grade 2 reports typically contain up to 4 . From this distribution, it would therefore be reasonable to estimate that equality/diversity issues make up around 15-20\% of negative headlines in Grade 1 reports, as compared to $2-3 \%$ in Grade 2 reports.

The distribution of positive and negative references in Ofsted reports to equality/diversity provision provides a strong indication that Ofsted's claim that it treats equality and diversity as being 'at the heart of everything it does' (Ofsted 2009) is unfounded. The evidence from this review of 200+ reports carried out over a period of 5 years (encompassing 2 different inspection frameworks) is that that it is at best treated as a peripheral matter that has little or no impact on overall inspection outcomes. The data provided here suggests that the possibility for another dynamic operating in inspectors' consideration. A virtually ubiquitous feature of formal reporting on personal or institutional 'performance' is that those responsible for making judgements try to avoid being so 'one-sided' that they do not find something positive in even the weakest performers, or to find 'areas for development' in the strongest. It is extremely rare to find a Grade 1 report, therefore, that doesn't have at least one 'point for action/consideration', and equally rare to find a Grade 3 (or even Grade 4) report without at least one 'key strength'. 
One interpretation of this review of Ofsted reports is that 'equality/diversity' is no more than a convenient mechanism for providing meaningless 'balance' to inspection outcomes. When inspecting a provider judged as outstanding against fundamental criteria, inspectors feel comfortable in highlighting deficiencies in equality/diversity provision whilst not using it as a reason to reduce the overall grade. Similarly, faced with the challenge of finding something positive to highlight in weaker provision, inspectors seem quick to turn to equality/diversity issues, possibly for the same reason that it presents what looks like a 'balanced' report, but high quality work in this area is not considered sufficient to impact positively on the overall grade awarded.

In addition to the apparent lack of attention to outcomes relating to race equality, the language used in inspection reports reflects to a large extent the discourse of successive iterations of either Teachers' Standards or ITT Requirements. Race equality issues are rarely addressed directly, but filtered through notions of 'equal opportunities', 'diversity', 'culture', 'inclusion' and 'difference'. This suggests that despite the embedding of a proactive dimension within equalities legislation, Ofsted is no further forward than it was before the RRAA came into being, when race equality was seen as "one of a number of baubles on the Christmas tree" rather than "...a central part of the corporate culture" (Osler \& Morrison, cited in Klein 2000: p38).

This continuing marginalisation of race equality is made possible by the persistent discourse within educational policy which places 'standards' as its preeminent focus; by extension, this discourse places 'equality' in opposition to 'quality', hence the frequent populist accusation of 'dumbing down' made against proactive equalities policies. From a Critical Race Theory perspective, performative policies - and the outcomes of these policies - not only fail to address inequality, they reinforce it. In practice, the dominance of high stakes testing, data-driven inspection and the use of market levers to impose sanctions on underperformance suggests that education policy not only places race equity at the margins, but "retains race injustice at the centre" (Gillborn 2005: 499).

For teacher educators, under intense pressure to comply with TA/Ofsted priorities, this antitheoretical approach is a strong disincentive to exploring with students the structural underpinning of race issues and the ways in which institutional racism operates. 


\section{The Newly-Qualified Teacher Survey}

One of the key pieces of data used by the government in monitoring the performance of teacher education providers is the Newly-Qualified Teacher (NQT) Survey. This is an annual perception survey of NQTs carried out by the NCTL in February each year (so capturing the views of teachers at a halfway point in their first year of teaching). Whilst there is much debate about the quality of data produced by this survey, there is no doubt that it carries great weight. It provides a simple 'snapshot' of providers and has been used by the NCTL (often at the instigation of government ministers) to subject individual providers to intense scrutiny. In some cases this scrutiny has come on the basis of a 'negative' response on a single item in the survey. An example of this came following the 2008 Survey, when providers judged to have low scores on an item asking Primary NQTs about their confidence in teaching early reading through synthetic phonics were first threatened with early Ofsted inspections, reductions in recruitment allocations, and subjected to what was effectively a 'mini-inspection' of their provision (UCET 2011).

It was clear from this response that the Agency at the time were responding to an edict from the then Schools Minister Lord Adonis, and at the time of writing the message from the NCTL is that the new coalition government will give similar weight to the outcomes of the Survey. It would be reasonable to assume, therefore, that the NQT Survey is a key indicator of the political priorities of government and the agencies responsible for the management and regulation of teacher education.

The Survey asks NQTs to rate the quality of their training experience and how well they feel it prepared them for their first year of teaching, using a 4-point rating scale. For the purposes of this study, a three-year moving aggregate has been used in order to review data alongside Ofsted reports (different periods are covered in order to match with the data available to inspectors at the time of the most recent Ofsted report - these range from 2003-05 to 2007-09). Between 2003 and 2009, the number of items covered by the Survey increased from 15 to 25 (for Secondary NQTs) and from 15 to 27 (for Primary NQTs).

Whilst this is clearly an inexact instrument, two items in the Survey relate to issues of race equality and diversity. These items ask NQTs to rate the quality of their training in preparing 
them to teach learners from minority ethnic backgrounds (Item 2(f)), and in preparing them to work with learners with English as an additional language (Item 2(n)). In order to identify training programmes seen by students to be either particularly good or particularly weak at preparing them in these aspects of their teaching, responses by individual providers' were examined to select a sample where the three-year moving aggregate suggested this to be the case.

Ensuring statistical rigour was problematic, since this study only used data publicly available on the Agency's Performance Profile website (TDA 2012). Whereas this profile reports statistical significance by z-scores for single year results, it does not do this for the three-year moving aggregate. However, it can be assumed that the moving aggregate provides a more reliable picture of student perception than any single year; a further assumption is made that Ofsted inspectors would share this view and accordingly give greater weight to the aggregate. Therefore the sample was produced by firstly selecting providers where both items appeared at first sight to be 'outliers', then checking back against the separate yearly Survey results. The final sample of six (table 5) were selected because of a consistent pattern of significant $\mathrm{z}$-scores (positive or negative) across the three year period covered. Three consistently score above sector average, three below.

\section{Provider Case Studies}

Table 5: Provider case studies

\begin{tabular}{|l|l|}
\hline $\begin{array}{c}\text { Above sector average NQT Survey } \\
\text { (items 2f \& 2n) }\end{array}$ & $\begin{array}{c}\text { Below sector average NQT Survey } \\
\text { (items 2f \& 2n) }\end{array}$ \\
\hline University of Middletown & University of Somewhere \\
\hline University of Nowhere & University of Elsewhere \\
\hline Downtown University & Uptown University \\
\hline
\end{tabular}

\section{CASE 1 University of Middletown}

The University of Middletown is a large provider of both Primary and Secondary, including both 3 year undergraduate and postgraduate, based in a region with relatively high BME population. Performance profile data shows that this is broadly reflected in recruitment 
patterns (since 2005, national BME recruitment has ranged between 7-10\% (Primary) and 1518\% (Secondary) (TDA 2012).

For each of the three years 2003 to 2006, Middletown's Primary NQTs rated their experience in items 2(f) and 2(n) more positively than the national average (z-score significant at 95\%).

Middletown underwent inspections of both Primary and Secondary provision during 2007/8, and received overall Grade 1 'outstanding' in both inspections.

However, an examination of the full narrative of the two reports make no reference to any aspect of equality/diversity issues (apart from a passing comment about "initiatives leading to increased applications from under-represented groups"; other comments suggest that this probably relates to recruitment of men into Primary ITE, however). If the views of NQTs have any validity here, they did not appear to register with inspectors.

\section{CASE 2}

University of Nowhere is a large provider of both Primary and Secondary ITE, including both 3 year undergraduate and postgraduate, in a city with a high BME population. This is reflected in Performance profile recruitment patterns, with BME recruitment since 2005 ranging between 18-21\% (Primary) and 22-29\% (Secondary) (TDA 2012).

For each of the three years 2003 to 2006, both Primary and Secondary NQTs at Nowhere rated their experience in items $2(\mathrm{f})$ and $2(\mathrm{n})$ more positively than the national average ( $\mathrm{z}$-score significant at $95 \%$ ).

The University of Nowhere was inspected in both Primary and Secondary in 2006-07. The Secondary inspection resulted in an overall Grade 1, but the full narrative report makes with no reference to equality/diversity issues in report 'highlights', with just a single positive reference in the narrative to students' citizenship education work on homosexuality. Race equality does not feature at all.

The Primary inspection resulted in an overall Grade 2, and very unusually highlights two separate equality/diversity issues as 'key strengths'; "the successful recruitment of minority 
ethnic trainees" and "the very effective procedures for monitoring policies on equal opportunities and race relations". The narrative section includes relatively extensive references to equality/diversity issues, including particular referring to race relations and race equality, as well as preparation for teaching in bi-lingual settings.

CASE 3 Downtown University is a large provider of both Primary and Secondary, including both 3 year undergraduate and postgraduate, in a city with a high BME population. Downtown has been particularly successful in BME recruitment patterns, with BME recruitment since 2005 ranging between 26-30\% (Primary) and 50-52\% (Secondary).

For each of the three years 2003 to 2006, both Primary and Secondary NQTs at Downtown University rated their experience in items $2(\mathrm{f})$ and $2(\mathrm{n})$ more positively than the national average (z-score significant at 95\%).

Downtown University was inspected during 2009-10, one of only two in this sample to be inspected under the current (2008-11). It was awarded an overall Grade 2 in both Primary and Secondary inspections, and both reports highlighted equality/diversity issues in key strengths. Both specifically referred to the preparation of students for teaching in "a socially and culturally diverse society", and the Secondary report also noted "the inclusive ethos of the provider, its proactive promotion and support of equality and diversity".

\section{Below sector average}

CASE 4 The University of Somewhere is a predominately Primary provider, mostly 3 year undergraduate, based in a city with relatively high BME population. This is not, however, obviously reflected in its recruitment (since 2005 BME recruitment has been broadly stable at 5-6 \% for Primary and 8-9\% for Secondary)

For each of the three years 2003 to 2006, Somewhere's Primary NQTs rated their experience in items 2(f) and 2(n) less positively than the national average (z-score significant at $95 \%$ ).

When inspected in 2006/7, Somewhere was awarded an overall Grade 2 ('Good'). However, the perceptions of graduates (as would have been available at the time of inspection) appear to be contradicted in inspection outcomes. The narrative section of the report comments 
favourably on the "...focussed attention is given to developing trainees' skills and abilities in planning, teaching and assessing pupils for whom English is an additional language." Highlighted as a key strength of the course was the "very good selection procedures...[and]...the recruitment of good trainees...from under-represented groups.'

CASE 5 The University of Elsewhere is a large provider of both Primary and Secondary, including both 3 year undergraduate and postgraduate, based in a city with relatively high BME population, although this is not obviously reflected in its recruitment (since 2005 BME recruitment has been broadly stable at 3-4\% for Primary and 7-8\% for Secondary)

For each of the three years 2005 to 2008, Elsewhere's Primary NQTs rated their experience in items 2(f) and 2(n) less positively than the national average (z-score significant at 95\%).

Elsewhere was inspected under the current inspection framework, during 2008-09). It received an overall grade 2, and as with Somewhere, inspectors appeared to have a different view on the quality of equality/diversity provision. However, in this case, the highlighted 'key strengths' focused more on policy-related issues, noting in particular their "high quality policy documents on equal opportunities". The Primary report made no reference to equality/diversity, either in 'highlights' or in the full narrative.

CASE 6 The Uptown University is a Primary and Secondary provider, exclusively postgraduate, based in a city with relatively low BME population. This is reflected in its recruitment data, which shows that since 2005 BME recruitment has been broadly stable at between 3-5\% for both Primary and Secondary.

For each of the three years 2004 to 2007, Uptown's Secondary NQTs rated their experience in item 2(n) less positively than the national average (z-score significant at 95\%), with a similar outcome in 2 out of the 3 years for item 2(f).

When inspected in 2007/8, Uptown received Grade 1 outcomes in both inspections. The Primary report notes that "recruitment from under-represented groups remains an area for development", although this is not considered significant enough to specifically highlight as a point for development (nor, of course, does it prevent Nowhere being graded as 'outstanding' overall). Despite their NQT's less than enthusiastic response in the NQT Survey, inspectors 
appear to disagree, noting in the narrative that "Inclusion and equality of opportunity are high on the agenda".

In the Secondary report, inspectors note that "Sessions reflect the most recent subject developments and research and incorporate the wider professional aspects of the training, such as diversity and the promotion of race equality, with considerable imagination and ingenuity".

\section{Overview of case studies}

These case studies, when viewed alongside the data provided by the wider review of inspection report 'headlines', present a stark indictment of Ofsted's failure to use performative accountability levers to address race equality issues in even a minimalist way. The 'quality' of ITE providers' engagement with race equality has no bearing on the judgements made about their overall quality of provision, conversely, these studies can be read as inspectors actually creating a clear differentiation between race equality/wider social justice issues, and 'things that really matter'. For providers judged to be 'outstanding', it does not appear to make any difference how well they address race equality or diversity and inclusion issues; this point is reinforced by the extent to which they appear as 'weaknesses' in reports on outstanding programmes. The message is that these providers are successful in the core elements of their provision but simply have some minor weaknesses in peripheral areas such as race equality.

For provision that is weaker overall, the same tokenistic references to race equality issues are seen in mirror image. Provision is judged to be weak because of inadequacies in 'the fundamentals', whilst race equality practice seems to be primarily deployed as a 'consolation'; these reports frequently refer to good practice in this area yet it clearly does not impact on the overall grading of the inspection.

Finally, these inspection reports suggest that the student voice, on many issues, but particularly in respect of engagement with equality and social justice matters, is almost entirely disregarded. Fundamentally, race equality is seen as either a distraction or an irrelevance. This is particularly worrying, given the evidence over recent decades that it is not enough to rely on the 'good intentions' of teachers entering the profession; teachers need pre-service preparation that offers effective support and explicitly addresses the fundamental structural issues that perpetuate race inequity (Cole \& Stuart 2005; Wilkins 2005). 


\section{Conclusions}

Overall, the picture emerging from this study is of fundamental contradictions between the way in which government agencies regulate ITE, and successive governments' stated commitment to bringing about immediate, significant and sustainable social/cultural changes in public sector institutions, with respect to race equality and diversity issues. The complexity of the ways in which ITE is managed, with the TDA's delivery and funding allocation role intersecting with Ofsted's notionally independent inspection role, may contribute also to the contradictions.

This study was initially inspired by the perception of a focus on procedural compliance in TDA and Ofsted policy; a sense that government agencies were driven by a minimalist interpretation of the requirements of the RRAA that emphasised the importance of the establishment of policies in public sector provision rather than bringing about fundamental change in institutional practices and ethos. This feature of post-RRAA public sector policy has been widely commented upon (O’Cinneide 2003; Gillborn 2005, Morrison 2007), whilst Osler \& Morrison (2002) specifically identified this as a weakness of earlier Schools' inspection policy and practice.

The review of TDA and Ofsted documentation tends to confirm this view. Although policy publications and review reports signal a commitment to a proactive approach to addressing equality issues, these emphasise the establishment of policies, and the effectiveness of how providers raise student teachers' awareness of these policies. Race equality issues are rarely addressed directly, being more commonly subsumed into broader 'equality of opportunity' and 'diversity' issues, whilst racism as a phenomenon is virtually ignored. The Ofsted guidance for inspection is particularly deficient in this respect.

The changes in inspection framework (and in the way in which overall grades are calculated) create some difficulties in detecting consistent patterns, and it should be noted that the later reports did suggest that inspectors were looking more closely at practice, at how student teachers actually engaged with equality/diversity issues in their teaching. However, these are still clearly seen as 'peripheral' judgements, and the evidence largely fits with the overall tenor of the inspection framework, in that ITE inspectors are not placing race equality "at the heart of everything they do", contrary to the organisation's own stated strategic priority.

The marginalisation of race equality issues is transparent, and the fact that they are proportionately more likely to feature as 'key strengths' in Grade 2 inspection reports than in Grade 1 reports, whilst simultaneously being more likely to feature as negative 'points for 
action/consideration' in Grade 1 reports than Grade 2, seems almost perverse. The message this sends is one of a tokenistic recognition of equality and diversity in the external quality assurance assessment, that it does not carry the weight in inspection outcomes as other aspects of provision. Where the stakes of inspection are so closely linked to the funding allocation for ITE (this is determined for the most part by Ofsted outcomes), this presents a clear risk. The intensive pressure on providers to achieve the highest possible inspection outcome may (indeed, will almost inevitably) lead to a marginalisation of these issues in favour of those perceived to carry more weight with Ofsted.

The surprising outcome of this study is the lack of any clear links between the NQT Survey and inspection outcomes. Whilst many in government as well as the teacher education sector have rightly noted the limitations of this perception survey as a quality measure, the Teaching Agency demands that providers demonstrate how they take into account the findings of the survey in their self-evaluation, and as noted earlier, government ministers have been known to act quickly when the survey highlights patterns relating to issues seen as a political priority. If anything emerges from this study, it is that student teachers' perceptions of how their training addressed issues of equality and diversity are not a political priority. Not a single inspection report made explicit reference to NQT Survey outcomes in relation to race equality issues, nor did close analysis of the reports for the sample of 6 providers reveal any obvious attention paid to this. This is despite the fact that case study sample was chosen precisely because NQTs had consistently responded, over a 3 year period, in such a way as to suggest it was worthy of scrutiny.

What emerges from this study is a significant gap between government rhetoric on race equality and the policy enactment of government agencies involved in initial teacher education. Both the NCTL and Ofsted have consistently made strong claims to prioritise equality and diversity issues in the sector as part of their commitment to the intentions of the RRAA to challenge institutional racism and proactively promote race equality. However, the reality of their policy position reveals a more ambivalent, minimalist approach. Although outcomes are given attention, the emphasis is still largely on policy awareness and procedural compliance, where good intentions are seen as being as important, if not more so, than good practice.

Since this analysis of the outcomes of two inspection cycles was undertaken, the accountability framework for ITE has been substantially revised; from September 2012, new Teachers' Standards (replacing the Professional Standards), ITT Requirements and an ITE inspection framework came into force. In these frameworks, the ambivalent, minimalist approach to race 
equality appears to have become even more attenuated. The new inspection framework removes completely the requirement for inspectors to grade providers' performance in respect of "Promoting equalities and diversity" has been completely removed, with grades awarded in just three areas; outcomes for trainees, quality of training and quality of leadership and management (Ofsted 2012). The new Teachers' Standards and ITT Requirements (DfE 2012) similarly are completely devoid of any reference to race equality.

This gives a clear message about the political positioning of the coalition government in respect of how public sector institutions are accountable for their engagement with the full range of equalities legislation. Whilst the evidence of this study reveals the limitations of the accountability levers used to evaluate ITE provision over recent years, the future looks even more challenging, with the threat of providers forced to reduce still further their already minimal engagement with race equality issues by the new, even more narrow, inspection priorities.

The narrowing of institutional priorities is a common feature of performative systems; the punitive inspection framework (reinforced by the use of market levers) creates a culture of 'coercive compliance' throughout the institution (Wilkins \& Wood 2009). For beginning teachers, their entire educational experience (from their own schooling, higher education and ITE - through to working as a teacher) is increasingly likely to be a 'post-performative' one in which the ideological and strategic priorities of the performative system are seen as normative (Wilkins 2011).

Gillborn's analysis of race equality policy and practice (2005) notes how, despite the recognition of institutional racism in the RRAA, a wide range of education policies minimise its impact by focusing on intentionality (racism is not 'real' unless it is intentional). The RRAA was intended to refocus attention on the effects of institutional policies, practices and culture. However, whilst evidence about the under-achievement of some BME pupils continues to mount (Gillborn \& Mirza 2000; Youdell 2003; Strand 2011) with similarly persistent evidence of barriers to achievement and progression for BME teachers and student teachers (Osler 1997; Ross 2001; McNamara et al 2009; Shah \& Shaikh 2010), the inspection of ITE is making a little or no contribution to combating this. Apart from suggesting that the NCTL and Ofsted have been arguably non-compliant with equalities legislation, this indicates the persistence of a racialized discourse of public sector policy and practice. In the absence of overtly racist 
individualised practices, institutions are viewed as being 'colour-blind', as neutral arenas in which equality of opportunity can be achieved. In fact, this process simply normalises and so perpetuates structural inequality (Gillborn 2005). Whilst the RRAA and the subsequent Equality Act (2010) have provided a more positive culture in which the role race plays in interpersonal and 'micro-institutional' domains race can be explored, they still do not recognise, and therefore cannot challenge, the structural nature of race inequality.

\section{References}

Ahmed, S. 2007, 'You end up doing the document rather than doing the doing': Diversity, race equality and the politics of documentation, Ethnic and Racial Studies, 30:4, 590-609

Anderson, P. \& Coffey, A. 2011 'Analysing Documentary Realities', in Silverman, D (ed) Qualitative Research, (London, Sage)

Apple, M.W. 2005. Education, markets, and an audit culture Critical Quarterly 47, no.1-2: 11-29.

Ball, S.J. 2003. The teacher's soul and the terrors of performativity Journal of Education Policy 18, no. 2: $215-228$

Basit. T., L. Roberts, O. McNamara, B. Carrington, M. Maguire, and D. Woodrow. 2006. Did they jump or were they pushed? Reasons why minority ethnic trainees withdraw from initial teacher training courses, British Educational Research Journal, 32: 387-410.

Bubb, S., Earley, P., Ahtaridou, E., Jones, J., and Taylor, C. 2007. The self-evaluation form: is the SEF aiding school improvement? Management in Education 21, no.3: 32-37

Carrington, B., and R. Tomlin. 2000. Towards a More Inclusive Profession: teacher recruitment and ethnicity, European Journal Of Teacher Education 23(2): 2139-157.

Cohen, L. 1989. 'Ignorance not Hostility: Student Teachers, Perceptions of Ethnic Minorities in Britain', in Verma, G (ed) Education for All: a landmark in pluralism. Lewes: Falmer Press.

Cole, M. \& J, Stuart. 2005. 'Do you ride on elephants and 'never tell them you're German': the experiences of British Asian and Black, and overseas student teachers in South-east England, British Educational Research Journal, 31(3): 349-366.

Commission For Racial Equality (CRE). 1986 Black Teachers: The challenge of increasing the supply, London: CRE.

Department for Education 2012 Initial Teacher Training (ITT) criteria, downloaded at http://media.education.gov.uk/assets/files/pdf/i/itt\%20criteria\%202012.pdf

Department for Education 2012 Teachers'Standards, downloaded at https://www.education.gov.uk/publications/eOrderingDownload/teachers\%20standards.pdf 
Equality \& Human Rights Commission (EHRC) 2009 Strategic plan of the Equality \& Human Rights Commission 2009-2012, downloaded at http://www.equalityhumanrights.com/uploaded_files/strategicplan20092012parliamentary.pdf

Ford, R. 2008. Is Racial Prejudice Declining in Britain? The British Journal of Sociology 2008 59:4, 606-636.

George, R. \& Clay, J. 2008. Reforming Teachers and Uncompromising 'Standards': implications for social justice in schools, Forum, 50:1, 103-111.

Ghuman, P. 1995. Asian Teachers in British Schools: A Study of Two Generations. Clevendon, Avon: Multilingual Matters.

Gillborn, D. 2005. 'Education policy as an act of white supremacy: whiteness, critical race theory and education reform' Journal of Education Policy 20(4):485-505.

Gillborn, D. \& Mirza, H. 2000 Educational Inequality: Mapping Race, Class and Gender: a synthesis of research evidence. London: Ofsted.

Kapoor, N. 2011 The advancement of racial neoliberalism in Britain, Ethnic and Racial Studies, ifirst 30 November 2011 DOI:10.1080/01419870.2011.629002

Klein, G. 2000 Improving Inspection for Equality, Improving Schools, 3:2, 38-43

Lander, V. 2011 Race, culture and all that: an exploration of the perspectives of White secondary student teachers about race equality issues in their initial teacher education, Race, Ethnicity and Education, 14:3, 351-364

Lentin, A. 2012 Post-race, post politics: the paradoxical rise of culture after multiculturalism, Ethnic and Racial Studies, ifirst 22 March 2012 DOI:10.1080/01419870.2012.664278

Leonardo, Z. 2004 The color of supremacy: beyond the discourse of 'white privilege, Educational Philosophy and Theory, 36:2, 137-152

McNamara, O., Howson, J., Gunter, H. \& Fryers, A. 2009 The leadership aspirations and careers of black and minority ethnic teachers, Manchester: NASUWT/NCSLCS

Morrison, M. 2007. Equality audits in education: exercises in compliance or frameworks for inclusion? Ethnography and Education, 2:3, 327-347

O'Cinneide, C. 2003. Taking Equal Opportunities Seriously: The extension of positive duties to promote equality, London: Equality and Diversity Forum

Ofsted. 2005. Race equality in education: Good practice in schools and local education authorities, HMI 589, London: Ofsted.

Ofsted. 2008. The inspection of initial teacher education 2008-11: A guide for inspectors on the management and organisation of initial teacher education inspections, downloaded at http://www.ofsted.gov.uk/Ofsted-home/Forms-and-guidance/Browse-allby/Other/General/The-inspection-of-initial-teacher-education-2008-2011 
Ofsted. 2009. Equality and diversity on Ofsted: Employment report April 2008 to March 2009, 090323, London: Ofsted.

Ofsted. 2011. Ofsted Inspection Reports: Learning and Skills, downloaded at http://www.ofsted.gov.uk/Ofsted-home/Inspection-reports/Learning-and-skills

Ofsted. 2012. Initial Teacher Education Inspection (ITE) handbook, downloaded at http://www.ofsted.gov.uk/resources/initial-teacher-education-inspection-handbook

Osler, A. 1997. The Education and Careers of Black Teachers: Changing Identities, Changing Lives. Buckingham: Open University Press.

Osler, A., \& M. Morrison. 2002. Can Race Equality be Inspected?: Challenges for Policy and Practice Raised by the Ofsted School Inspection Framework. British Educational Research Journal 3: 327-38.

Perryman, J. 2006. Panoptic Performativity and School Inspection Regimes: Disciplinary Mechanisms and Life under Special Measures Journal of Education Policy 21, no. 2: 147161.

Race Relations (Amendment) Act 2000 London: HMSO.

Rampton, A. 1981 West Indian Children in Our Schools, 8273 London: HMSO.

Ross, A. 2001 Black and ethnic minority teachers in the teaching workforce, London: IPSE.

Siraj-Blatchford, I. 1991. A Study of Black Students' Perceptions of Racism in Initial Teacher Education, British Educational Research Journal, 17:1, 35-50.

Swann, L. (1985) Education For All, (London: HMSO)

Sayyid, S., Law, I. \& Sian, K. 2010 Analysis of Integration Policies and Public StateEndorsed Institutions at National/Regional Levels: Equality and Human Rights Commission $(E H R C)$ Centre for Ethnicity and Racism Studies downloaded at http://www.ces.uc.pt/projectos/tolerace/media/Working\%20Paper\%202/6\%20CERS\%20$\% 20$ Analysis $\% 20$ of $\% 20$ Integration $\% 20$ Policies $\% 20$ and $\% 20$ Public $\% 20$ State-

Endorsed\%20Institutions.pdf

Solomon, R., Portelli, J., Daniel, B-J. \& Campbell, A. 2006. The discourse of denial: how white teacher candidates construct race, racism and 'white privilege', Race, Ethnicity and Education, 8:2, 147-169.

Strand, S. 2007 Minority ethnic pupils in the Longitudinal Study of Young People on England RR851, (London: DfES)

Training and Development Agency for Schools (TDA). 2007. Professional Standards for Teachers. downloaded at http://www.tda.gov.uk/teachers/professionalstandards

Training and Development Agency for Schools (TDA). 2008. ITT Requirements Guidance. Downloaded at http://www.tda.gov.uk/partners/ittstandards/guidance_08 
Training and Development Agency for Schools (TDA). 2012. Provider Performance Profiles. Downloaded at http://dataprovision.tda.gov.uk

Troman, G. 1997 Self-Management and School Inspection: Complementary Forms of Surveillance and Control in the Primary School. Oxford Review of Education, 23:3, 345-364

Universities' Council for the Education of Teachers (UCET) 2011 Systematic Synthetic Phonics: briefing for UCET members. Downloaded at http://www.google.co.uk/url? sa=t\&rct=j\&q=\&esrc=s\&frm $=1 \&$ source=web\&cd=2\&ved=0C DgQFjAB\&url=http\%3A\%2F\%2Fwww.ucet.ac.uk\%2Fdownloads\%2F3388-UCET-adviceon-systematic-synthetic-phonics-andITT.pdf\&ei=ylo_UbLwHuTb7AbgsoGIAQ\&usg=AFQjCNH0ISDxDKU3oUEgoAXdKqq17 5VCSg\&bvm=bv.43287494,d.ZGU

Wilkins, C. 2005 'Teaching for Equality and Diversity: putting values into practice' in Osler, A (ed). Teachers, human rights and diversity: educating citizens in multicultural societies, (Stoke-on-Trent, Trentham)

Wilkins, C. 2011 Professionalism and the post-performative teacher: new teachers reflect on autonomy and accountability in the English school system, Professional Development in Education, 37:3, 389-409

Wilkins, C. \& Lall, R. 2010. 'Getting by' or getting on'?': Black student teachers' experiences of initial teacher education, Race Equality Teaching, 28:2, 19-26

Wilkins, C. \& Wood, P. 2009. Initial teacher education in the panopticon, Journal of Education for Teaching, 35:3, 283-297

Youdell, D. 2003. Identity Traps or How Black [1] Students Fail: The interactions between biographical, sub-cultural, and learner identities, British Journal of Sociology of Education, $24: 1,3-20$ 


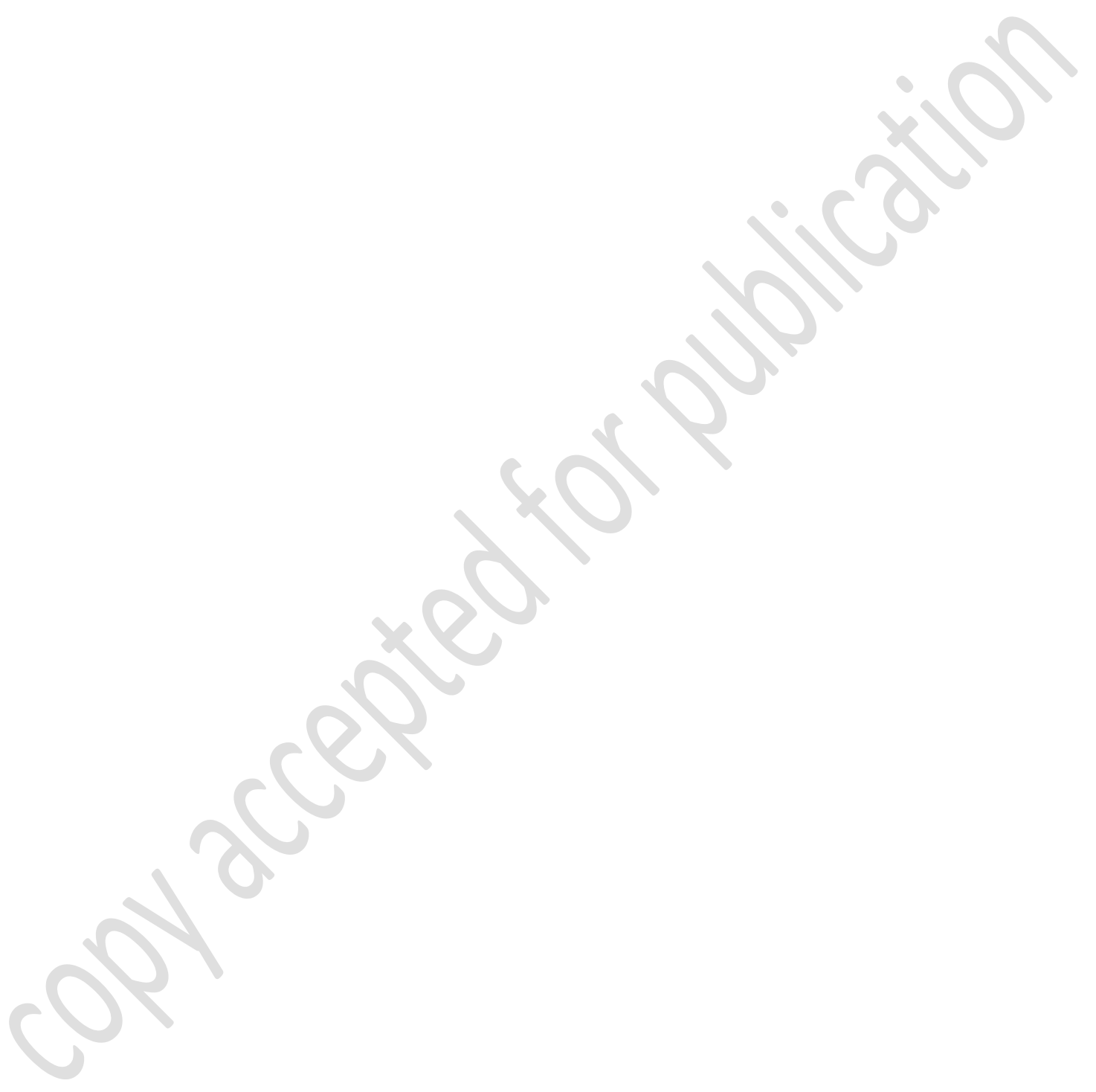

